Portland State University

PDXScholar

$6-2006$

\title{
Avian Affairs: A Study of the Occurrence and Benefits of Extra-pair Breeding Behavior in Eastern Kingbirds (Tyrannus Tyrannus)
}

Amy Catherine Dolan

Portland State University

Follow this and additional works at: https://pdxscholar.library.pdx.edu/open_access_etds

Part of the Biology Commons

Let us know how access to this document benefits you.

\section{Recommended Citation}

Dolan, Amy Catherine, "Avian Affairs: A Study of the Occurrence and Benefits of Extra-pair Breeding Behavior in Eastern Kingbirds (Tyrannus Tyrannus)" (2006). Dissertations and Theses. Paper 1654. https://doi.org/10.15760/etd.1653

This Dissertation is brought to you for free and open access. It has been accepted for inclusion in Dissertations and Theses by an authorized administrator of PDXScholar. Please contact us if we can make this document more accessible: pdxscholar@pdx.edu. 


\section{DISSERTATION APPROVAL}

The abstract and dissertation of Amy C. Dolan for the Doctor of Philosophy in Biology were presented June 24, 2006, and accepted by the dissertation committee and the doctoral program.

COMMITTEE APPROVALS:
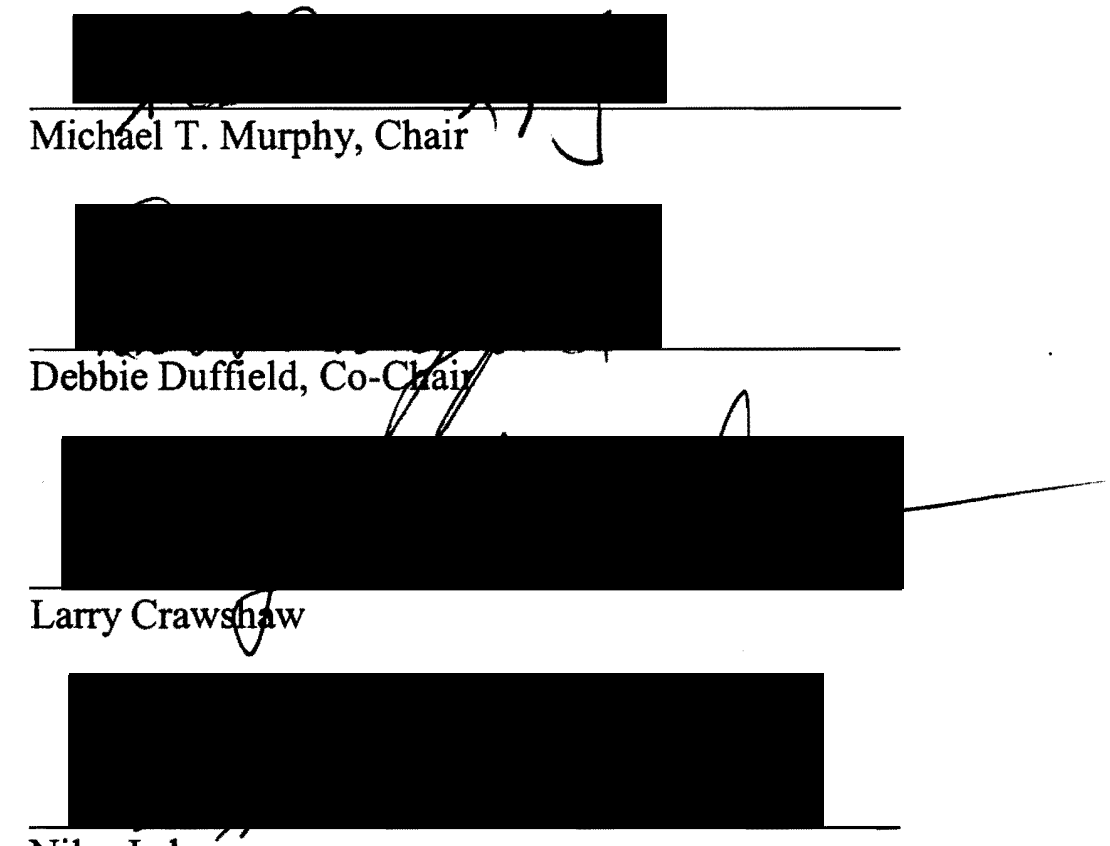

Niles Lehmán

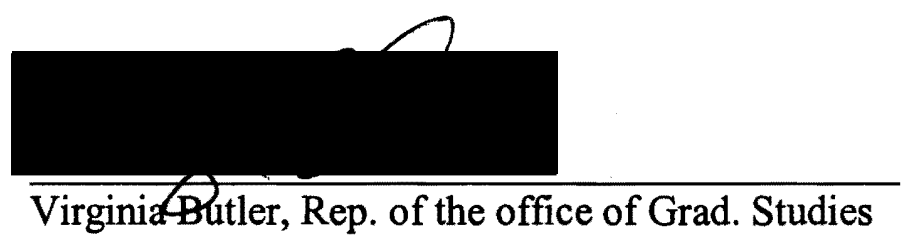

DOCTORAL PROGRAM APPROVAL:

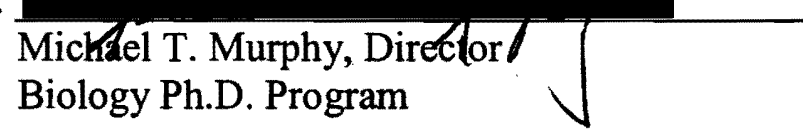




\begin{abstract}
An abstract of the dissertation of Amy Catherine Dolan for the Doctor of Philosophy in Biology presented June 24, 2006.
\end{abstract}

Title: Avian Affairs: A Study of the Occurrence and Benefits of Extra-pair Breeding Behavior in Eastern Kingbirds (Tyrannus tyrannus)

Over three consecutive breeding seasons I examined the breeding system of Eastern Kingbirds in Malheur National Wildlife Refuge in SE, Oregon. To assess genetic paternity, I optimized seven microsatellite markers and determined that extrapair paternity was common. Extra-pair young were present in approximately $60 \%$ of nests, representing $47 \%$ of young. I examined implications of extra-pair paternity from three perspectives.

First, I examined the impact of extra-pair paternity on the opportunity for sexual selection within a socially monogamous system and identified correlates of male reproductive success. Some males were successful at the expense of others, and $24 \%$ of males did not sire any young. Thus, variance in male reproductive success was more than nine times greater than female variance, indicating that sexual selection operates strongly in this system. Extra-pair success was positively related to tarsus length and inversely dependent upon dawn song start time. Within-pair success was positively related to nest defense intensity during the incubation period.

Second, I assessed the four genetic hypotheses proposed to explain female 
cooperation in extra-pair copulations. Extra-pair young were not distributed randomly among broods. Cuckolded within-pair males were not more closely related to females than were extra-pair sires. Pair wise comparisons indicated males with specific song and morphological traits were chosen as sires. Brood success (proportion of brood to fledge and recruit) was unrelated to the number of males who sired young in the brood. Extra-pair young were larger and heavier than their within-pair half-siblings. These results unambiguously support the 'good genes' hypothesis of female extra-pair mating.

Last, I examined the influence of breeding date and parental condition (mother, social father and genetic sire) on offspring sex ratio. Given that male variance in reproductive success is much greater than that of females, I predicted the characters of genetic sires would be the most important factor influencing offspring sex ratio. Contrary to my prediction, male traits did not influence offspring sex ratio. However, more males hatched early in the season and females in better condition produced more sons. I also found that male nestling survival to the next breeding season was inversely related to date. 
AVIAN AFFAIRS:

A STUDY OF THE OCCURRENCE AND BENEFITS OF EXTRA-PAIR BREEDING BEHAVIOR IN EASTERN KINGBIRDS (TYRANNUS TYRANNUS)

by

AMY CATHERINE DOLAN

A dissertation submitted in partial fulfillment of the requirements for the degree of

DOCTOR OF PHILOSOPHY

in

BIOLOGY

Portland State University

2006 


\section{DEDICATION}

I dedicate this dissertation to my friends and family especially my husband, Ryan

Moeckly and to the memory of my mother, Ruth Tauriainen. Without their love and support this work never would have been possible. 
LIST OF TABLES iv

LIST OF FIGURES vi vi v v v

GLOSSARY vii

CHAPTER 1-INTRODUCTION

INTERSPECIFIC BREEDING PATTERNS 1

INTRASPECIFIC BREEDING PATTERNS 4

COMPARISONS WITH OTHER PATERNITY STUDIES

EASTERN KINGBIRDS

CHAPTER 2- EXTRA-PAIR PATERNITY AND THE OPPORTUNITY FOR SEXUAL SELECTION IN A SOCIALLY MONOGAMOUS

PASSERINE

INTRODUCTION 11

$\begin{array}{ll}\text { METHODS } & 15\end{array}$

Study site and species $\quad 15$

Field methods $\quad 15$

$\begin{array}{ll}\text { Genetic analysis } & 16\end{array}$

$\begin{array}{ll}\text { Parental defense and song behavior } & 18\end{array}$

Statistical analyses $\quad 20$

RESULTS $\quad 22$

$\begin{array}{ll}\text { Paternity results } & 22\end{array}$

$\begin{array}{ll}\text { Opportunity for selection } & 24\end{array}$

Predictors of WP and EP success: breeding date, breeding

Synchrony and density 25

Predictors of WP and EP success: morphology and behavior $\quad 26$

$\begin{array}{ll}\text { Comparisons of cuckolder and cuckoldee } & 28\end{array}$

$\begin{array}{ll}\text { DISCUSSION } & 28\end{array}$

$\begin{array}{ll}\text { General characteristics } & 28\end{array}$

WP mating success $\quad 30$

EP mating success $\quad 32$

Is there an optimal male strategy? $\quad 34$

$\begin{array}{ll}\text { FIGURE LEGEND } & 37\end{array}$ 
CHAPTER 3-TESTING THE INDIRECT GENETIC BENEFITS

OF EXTRA-PAIR COPULATIONS FOR FEMALE EASTERN

KINGBIRDS

INTRODUCTION $\quad 47$

$\begin{array}{ll}\text { METHODS } & 51\end{array}$

Field methods $\quad 51$

Genetic analysis $\quad 52$

Statistical analysis $\quad 53$

RESULTS $\quad 54$

Distribution of EPY $\quad 54$

Variance in male reproductive success $\quad 55$

Male quality $\quad 55$

Brood performance $\quad 56$

Nestling comparisons $\quad 56$

$\begin{array}{ll}\text { DISCUSSION } & 57\end{array}$

FIGURE LEGEND $\quad 62$

CHAPTER 4-EASTERN KINGBIRD BROOD SEX RATIO

DEPENDENT UPON FEMALE CONDITION AND CLUTCH

INITIATION DATE, NOT MALE EXTRA PAIR SUCCESS

INTRODUCTION $\quad 72$

$\begin{array}{ll}\text { METHODS } & 77\end{array}$

General field methods $\quad 77$

Sex determination and paternity analysis $\quad 79$

$\begin{array}{lr}\text { Paternal characteristics } & 80\end{array}$

Territory quality $\quad 83$

Nestling characteristics $\quad 83$

Statistical analyses $\quad 84$

RESULTS $\quad 85$

$\begin{array}{ll}\text { Paternity results } & 85\end{array}$

General sex ratio patterns $\quad 86$

Food abundance, female condition, date and BSR 87

BSR and social and genetic pair characteristics $\quad 89$

Nestlings $\quad 90$

DISCUSSION $\quad 91$

$\begin{array}{ll}\text { FIGURE LEGEND } & 96\end{array}$

$\begin{array}{lr}\text { CHAPTER 5- CONCLUSIONS } & \mathbf{1 0 6}\end{array}$

$\begin{array}{ll}\text { REFERENCES } & 111\end{array}$

iii 


\section{List of Tables}

Table 2-1 Microsatellite primers used for Eastern Kingbird paternity analyses $\quad 38$

Table 2-2 Population level patterns of extra-pair paternity divided by year 39

Table 2-3 Reproductive success among male paternity groups $\quad 40$

Table 2-4 Apparent and realized male reproductive success

Table 2-5 Comparisons of nest defense and song behaviors among

$\begin{array}{ll}\text { paternity groups } & 42\end{array}$

Table 2-6 Pair wise comparisons between successful EP males and WP males who lost paternity $\quad 43$

Table 3-1 Predictions of the four "indirect genetic benefits" hypotheses of female EP behavior $\quad 63$

Table 3-2 Population level comparisons of EPP by year 64

Table 3-3 Logistic regression of male over-winter survival as predicted by morphology, song characters and number of offspring sired 65

Table 3-4 GLM of the proportion of a male's offspring that survive into the following breeding season as predicted by male characters $\quad 66$

Table 3-5 Comparisons of nestling relatedness, average heterozygosity, mass and tarsus length for all nestlings

Table 3-6 Comparisons of nestling relatedness, average heterozygosity, mass, tarsus length and differences from nest averages for nestlings in mixed 
parternity nests

Table 3-7 Stepwise logistic regression of nestling survival to fledging as predicted by hatch date, tarsus length, mass and average heterozygosity

Table 3-8 Stepwise logistic regression of nestling survival to following breeding season as predicted by mass and average heterozygosity

Table 4-1 Theoretical predictors of BSR adjustment by territory quality, date and parental characters

Table 4-2 Number of male and female nestlings produced among years

Table 4-3 Comparisons among sex ratio groups of date, condition, insect abundance, dawn song start time and NDI

Table 4-4 Comparison of reproductive success and PSR among male paternity groups

Table 4-5 Linear regression of PSR by male morphology and

behavioral characters

Table 4-6a Stepwise linear regression of BSR and male morphological and behavioral characters

Table 4-7 Comparisons of mass, tarsus and condition of nestlings 


\section{List of Figures}

Figure 2-1 'Histogram of expected and actual distribution of EPY within nests 44

Figure 2-2 Regression plot of EPY sired by tarsus length 45

Figure 2-3 Regression plot of EPY sired in by dawn song and incubation NDI 46

Figure 3-1 Histogram of expected and actual distribution of EPY within nests 71

Figure 4-1 Scatter plot of BSR by clutch initiation date 104

Figure 4-2 Scatter plot of BSR by female condition 105 


\section{GLOSSARY}

30MinRate - average song rate/min for 30 minutes

ActualRate - average song rate/min for the period of singing (omitting minutes of silence)

Apparent male reproductive success - the number of young in a male's nest that survived to day 7 for blood sampling

CPR - central patrol road at Malheur National Wildlife Refuge

EP - extra-pair

EPC - extra-pair copulation

EPF - extra-pair fertilization

EPP - extra-pair paternity

EPY - extra-pair young

Female quality - number of eggs produced

Genetic monogamy - copulating with only one individual

GLM - generalized linear model

MNWR - Malheur National Wildlife Refuge

$\mathrm{ND}$ - nest defense

NDI - nest defense index

PeakRate - was the average song rate/min for the 5 -min period of highest output

PIT - parental investment theory

Realized male reproductive success - the number of young sired 
Social monogamy - socially pairing with one individual to raise offspring

Tarsus - tarsometatarsus

VRS - variance in reproductive success

WP - within-pair

WPF - within-pair fertilizations

WPP - within-pair paternity

WPY - within-pair young 


\section{CHAPTER 1 - INTRODUCTION}

Frequent evidence of mixed reproductive strategies has profoundly altered our view of vertebrate mating systems. Behavioral ecologists have discarded the discrete mating system categories in favor of recognizing a nearly continuous range anchored on either extreme by genetic monogamy and promiscuity (Johnson and Burley, 1997). This paradigm shift is especially apparent in passerine bird species where the combination of genetic analyses with behavioral studies has made it clear that genetic monogamy is the exception (reviewed in (Griffith et al., 2002; Westneat and Sherman, 1997; Westneat and Stewart, 2003). Lack's (1968) characterization of over $90 \%$ of passerine species as monogamous is now more accurately discussed in terms of social monogamy (socially pairing with one individual to raise offspring; Johnson and Burley, 1997) and genetic monogamy (copulating with only one individual; Johnson and Burley, 1997).

\section{INTERSPECIFIC BREEDING PATTERNS}

Among passerine species, the percentage of young sired by extra-pair (EP) males averages just over 16\%, ranging from 0 to $60 \%$ (Spottiswoode and Moller, 2004). Phylogenetic effects appear to account for variation in the frequency of extrapair paternity (EPP). A recent meta-analysis found that phylogeny accounted for roughly $50 \%$ of the variation in levels of EPP (i.e. variation occurs at the level of family or order; Griffith et al., 2002). Large-scale variation has also been linked to life history traits such as social mating system, life span, and parental care (Birkhead 
and Moller, 1992; Forstmeier, 2003; Hasselquist and Sherman, 2001; Hoi-Leitner et al., 1999; Mauk et al., 1999; Stutchbury and Morton, 1995; Wink and Dyrcz, 1999). Extra-pair paternity is much less common in polygynous species presumably because females in these species are not constrained in their social mate choice to males who are not already paired (Hasselquist and Sherman, 2001). In a socially monogamous system, while only one female can form a pairbond with the top male, many females can obtain extra-pair fertilizations (EPFs) from him. Thus, among strictly pair-bonded, territorial species, extra pair copulations (EPCs) may allow for the separation of contradictory choices between the best social mate (considering factors such as territory quality, parental care etc.) and genetic mate. Extra-pair young (EPY) are also more frequently observed in short lived species presumably because these species tend to pair quickly and thus lack time to fully assess social mates. Females are therefore more likely to be socially paired to low-quality males (Mauk et al., 1999; Wink and Dyrcz, 1999) and within these species, it appears that males tolerate higher EPP levels without denying parental care to offspring because the probability of survival to subsequent breeding seasons is low and current reproductive effort likely represents their only reproductive opportunity. As a result, females risk fewer repercussions (reduction in male parental care) when engaging in extra-pair copulations (EPCs) in these species (Mauk et al., 1999; Wink and Dyrcz, 1999).

In general, the Constrained Female Hypothesis suggests that females risk losing parental care if they engage in EPCs and thus EPP is expected to be inversely related to the amount of male parental care and positively related to food availability 
and the capability of females to raise offspring alone (Forstmeier, 2003; Hoi-Leitner et al., 1999). Additionally, breeding synchrony has been invoked to explain interspecific differences in EPP, although results have been conflicting. Birkhead and Moller (1992) proposed that EPF frequency should be highest when populations breed asynchronously because males have greater opportunities to seek EPFs when they are not mate guarding during their mates' fertile periods. Alternately, Stutchbury and Morton (1995) found a significant positive relationship between breeding synchrony and EPF frequency. They argued that high breeding synchrony allowed females to simultaneously assess EP sire quality. Support and dissention has accumulated on both sides (Conrad et al., 1998; Strohbach et al., 1998; Stutchbury, 1998; Stutchbury et al., 1997). However, breeding synchrony is confounded by migration distances and the latitude at which species breed. Due to the brevity of long-distance migrant breeding seasons, individuals are forced to socially pair quickly and may choose actual sires after pair formation has occurred (Spottiswoode and Moller, 2004). While breeding density has also been proposed to influence EP behavior, presumably because high density affords increased opportunities to locate and assess potential mates (Moller and Birkhead, 1993; Westneat and Sherman, 1997). Breeding density and frequency of EPP are, not uncommonly, positively associated intraspecifically, but on the interspecific level, density accounts for essentially none of the variance in the frequency of EPP (Griffith et al., 2002). 


\section{INTRASPECIFIC BREEDING PATTERNS}

Females do not appear to choose extra-pair mates randomly in that a few males obtain a disproportionate number of EPFs (Thusius et al., 2001; Webster et al., 2001). This is underscored by studies demonstrating that males with high EP success also experienced high within-pair (WP) success (Kempenaers et al., 1997; Thusius et al., 2001; Webster et al., 2001). Assuming sufficient male availability, females presumably choose sires based on characters that provide an honest signal of male quality that reflects his condition and/or capacity to produce viable, quality young (e.g. Hasselquist et al., 1996; Moller, 1994; Moller and Birkhead, 1994; Zuk et al., 1995). Females may directly compare WP and EP males for size or plumage characters or quality, as these characters have all been correlated with WP and EP success. Alternately, females may assess males on the basis of behavioral traits such as arrival date (if migrants), or display characteristics. Successful EP sires may sing more elaborate songs (Forstmeier et al., 2002; Hasselquist et al., 1996), sing at the higher rates (Houtman, 1992; Poesel et al., 2001), sing particularly early in the morning (Otter et al., 1997), build particularly large nests or feed nestlings at high rates (Freeman-Gallant, 1997; Soler et al., 1998; Szentirmai et al., 2005). Interspecifically, sexual dimorphism has been correlated with EP rates on a species level (Moller, 2000). Thus, on an intraspecific level, this leads to the prediction that EPP levels should be high among dimorphic species. However, it is difficult to tease apart whether sexual dimorphism is a cause or consequence of EP mating behavior.

On an intraspecific level, most attention has been focused on correlates of male 
EP mating success, and in a socially monogamous system the benefits to males that acquire extra pair fertilizations are obvious as male fecundity increases directly with the number of extra-pair mates (Andersson, 1994). Conversely, females are constrained by the number of eggs they can lay, so their fecundity does not exhibit the same direct increase (Andersson, 1994). In addition, there are potential costs to EP mating behavior, such as withdrawal of male parental care (Xia, 1992) or the acquisition of sexually transmitted diseases (Poiani and Wilks, 2000). The widespread occurrence of EPFs despite the absence of an increase in fecundity and potential costs begs the question of why females seek EPFs (Moller and Alatalo, 1999). Females are generally thought to actively seek extra-pair fertilizations (Double and Cockburn, 2000; Kempenaers et al., 1992; Smith, 1988) as possible insurance against mate infertility, or for indirect genetic benefits that include the acquisition of good genes for young, production of a genetically diverse brood of young, or improvement of genetic compatibility between parents.

\section{COMPARISONS WITH OTHER PATERNITY STUDIES}

Molecular and behavioral studies documenting extra-pair paternity have become common, however four major shortcomings revolve around (1) identification of sires, (2) categorization of young, (3) alteration of natural nesting density by artificially adding nesting sites and (4) long-term tracking of offspring to document survival. As a result of incomplete sampling, many paternity studies determine EPFs occur by excluding social mates without identifying the actual EP sires (e.g. Cordero 
et al., 1999; McKitrick, 1990). Unfortunately, this makes it impossible to fully examine the distribution of EPY and consequences of within-pair (WP) and EP mate choice. Identifying EP sires makes it possible to examine specific fitness benefits gained as a result of individual mate choices.

Addressing the question of why females seek EPFs is based largely on the comparisons of WP and EP young. In general, it has been widely assumed that EPY are of inherently higher quality than WPY (Charmantier and Blondel, 2003; Schmoll et al., 2003), and the vast majority of studies group nestlings in this manner. However, this ignores the possibility that females paired socially to high quality males are unlikely to seek EPFs, and therefore these WPY will be sired by high quality males (Kempenaers et al., 1997). The solution is to examine the within-brood performance of maternal half sibs (WPY and EPY within the same nest), which rules out maternal and environmental effects (e.g. local food availability, parental proficiency). Furthermore, if the identity of EP sires is known, the performance of individual nestlings can be examined by the characteristics of their specific sires.

Because nesting cavities are usually rare, species that nest in secondary cavities will readily nest in artificial nest boxes (e.g. Charmantier and Perret, 2004; Lifjeld et al., 1993; Schmoll et al., 2003). Unfortunately, density has been shown to influence EPP, and nearest neighbors are often identified as EP sires in these species (Charmantier and Perret, 2004; Moller and Ninni, 1998). To eliminate the effects of density on breeding behavior it is thus important to examine the frequency of EPP in unmanipulated populations. 
Another general deficiency has been that juvenile recruitment in passerine species, (incorporation into the breeding population in subsequent breeding seasons) is generally very low (see Weatherhead and Forbes, 1994). This limits the ability to track long-term fitness benefits of WP and EP mate choice (i.e. survival and reproductive success of offspring). As described below, the eastern kingbird (Tyrannus tyrannus) represents an ideal opportunity avoid these shortfalls and comprehensively evaluate the function of EPP on both male and female reproductive success and to further examine traits associated reproductive success.

\section{EASTERN KINGBIRDS}

Eastern kingbirds (Tyrannus tyrannus) are socially monogamous, migratory passerines. After pair bonds are formed, mate switching is extremely rare (Rowe et al., 2001). Except in cases of nest failure, they lay one clutch of 2-5 eggs per season (Murphy, 1996). Eastern Kingbirds show high survival and site fidelity. They winter in South America and their breeding range extends over much of North America (Murphy, 1996). They are considered habitat generalists and tend to prefer open fields dotted with trees and shrubs or edge habitats in more forested regions. They show a strong preference toward nesting in trees overhanging water and are common in riparian and lakeside habitats (Murphy, 1996). At Malheur National Wildlife Refuge (MNWR) in Eastern Oregon, the population is located at the western border of their distribution within the Great Basin Desert. Here the habitat is very dry, with very few trees. The Donner Und Blitzen River cuts through the study site creating a very 
narrow riparian zone and it is in this area that the kingbirds nest.

Many aspects of eastern kingbird behavior indicate EPFs play an important role in their reproductive success. For example, males sing a dawn song, which has been implicated in social pair formation (Murphy, 1996; Smith, 1966). However, males continue to sing after they have a social mate, especially in areas of high population density (Smith, 1966). Thus, males advertise their availability even after pair formation, suggesting a possible role in advertisement to EP females. Eastern kingbird males also feed the young at only $50-55 \%$ the rate of females, a reduction that could be associated with regular losses of paternity (Moller and Cuervo, 2000; Woodard and Murphy, 1999). Indeed, two previous studies of eastern kingbirds in more typical habitats have demonstrated some of the highest levels of EPP reported among socially monogamous passerines (McKitrick, 1990; Rowe et al., 2001; reviewed in Griffith et al. 2002; Spottiswoode and Moller, 2004).

Over three consecutive breeding seasons, I assessed paternity in the Malheur population of eastern kingbirds to gain a full accounting of the reproductive success of males and females. With this information, I was able to assess the impact of EPP on the opportunity for sexual selection within a socially monogamous species, identify correlates of male reproductive success, test for benefits to females engaging in EPCs and the correlates of brood sex ratio variation. This study avoids the previously mentioned shortcomings of the intraspecific studies in the following ways:

1) I sampled the majority of the population. As a result, I was able to identify approximately $80 \%$ of sires, and to examine individual correlates of both WP 
and EP reproductive success, as well as directly compare successful EP sires and the WP males who lost paternity.

2) I directly examined nestlings in relation to parental characters and reproductive success in three ways. First, I grouped nestlings into six categories based on the WP and EP success of their genetic fathers. Second, when comparing EPY and WPY, I restricted the analyses to mixed paternity nests. This analysis removed differences in environmental quality (insect abundance, parental quality, etc.) and maternal genotype because these nestlings are maternal half siblings that were reared in the same nests. Third, I directly examined nestlings in relation to their parents' morphology, behaviors and genetics. These methods avoid the bias inherent in grouping nestlings into two categories (WPY and EPY), which erroneously separates the WPY and EPY of the most successful males.

3) I did not manipulate the nesting density of the study population at MNWR. Eastern kingbirds are open-cup nesters, and will not nest in nest boxes. This avoided the potential impact of density manipulation on EPP.

4) Due to extraordinarily high juvenile recruitment ( $20 \%$ of fledged nestlings return), I was able to track the influence of parental and nestling characters on nestling survival over a 3-year period.

This dissertation is organized into three main chapters, all formatted for publication. The first of these, Chapter 2, examines correlates of male reproductive success and whether EPP impacts the opportunity for sexual selection in this species. 
Chapter 3 examines female reproductive strategies, specifically the benefits to females that include EPY in their clutch despite potential costs and the absence of direct fecundity increases (such as larger clutches). Chapter 4 is an offshoot of the genetic and demographic data I collected and examines brood sex ratio variation and the potential impact on lifetime reproductive success in eastern kingbirds. Female birds are the heterogametic sex, and new evidence suggests sex ratio manipulation may be common in avian systems. Given the demographic, genetic and ecolocical data I collected, I was able to assess every major hypothesis proposed to influence offspring sex ratio and examine the fitness implications of such manipulation. These chapters are followed by conclusions and suggestions for future research. 


\section{CHAPTER 2- EXTRA-PAIR PATERNITY AND THE OPPORTUNITY FOR SEXUAL SELECTION IN A SOCIALLY MONOGAMOUS PASSERINE}

\section{INTRODUCTION}

Sexual selection may profoundly influence the evolutionary history of a species, resulting most notably in the striking size and plumage dimorphisms common among polygamous and lek breeding species (Andersson, 1994; Darwin, 1871). The strength of sexual selection is directly reflected by sexual difference in the variance of reproductive success (VRS), with large differentials resulting in strong selection (Andersson, 1994; Arnold and Wade, 1984). VRS arises from differences in (1) number of social mates, (2) fecundity of social mates, (3) success at obtaining extrapair fertilizations and (4) ability to guard within-pair paternity. (WPP; Webster et al., 1995).

Among polygamous species, extra-pair paternity (EPP) contributes little to reproductive success because VRS is dependent upon number of young sired which in turn is mostly dependent on number of mates acquired (Andersson, 1994; FreemanGallant et al., 2005; Webster et al., 1995; Whittingham and Dunn, 2005). Historically, therefore, the influence of sexual selection on socially monogamous species was thought to be minimal because VRS was perceived to be low. However, EPP is now known to be quite common among socially monogamous bird species (Griffith et al., 2002; Westneat and Sherman, 1997), and even low levels of EPP have been shown to strongly increase the opportunity for selection among socially monogamous species 
and to correlate with sexual size and plumage dimorphism (Dunn et al., 2001; Moller and Birkhead, 1994; Moller and Nini, 1998). This may be especially true if gains of extra-pair fertilizations (EPFs) do not come at the expense of within-pair fertilizations (WPFs; Byers et al.2004; Webster et al., 1995; Yezernac et al., 1995). Therefore, EPP potentially affects the VRS of socially monogamous species more than polygamous species because of the fixed number of social mates and high incidence of extra-pair paternity in many socially monogamous species (Andersson, 1994; Webster et al., 1995; Whittingham and Dunn, 2005). Ostensibly, sexual selection explains the paradoxical existence of sexually dimorphic traits among species with low apparent VRS.

However, recent studies suggest that, for three reasons, the impact of EPP on VRS of socially monogamous species has been overestimated (Freeman-Gallant et al., 2005; Webster et al., 2001; Whittingham and Dunn, 2005). First, reciprocal cuckoldry (i.e. gains $=$ losses) may not be identified when a large portion of the male population is not sampled. Incomplete sampling and subsequent failure to identify sires may overestimate the intensity of sexual selection because the denominator (mean reproductive success) in the equation to calculate standardized variance is artificially low. Accordingly, Freeman-Gallant et al. (2005) showed that there was a significant negative relationship between standardized VRS and the proportion of the male population sampled in 13 field studies. Second, recent studies of either facultatively polygynous and/or double-brooded species found that within pair (WP) components of reproductive success greatly overshadowed the extra pair (EP) components despite 
moderately high levels of EPP (Freeman-Gallant et al., 2005; Whittingham and Dunn, 2005 ) because variance in female reproductive success was much larger than in strictly single-brooded species. Thus, WP mate choice of males among doublebrooded species has much greater potential to affect total VRS than it does in singlebrooded species. Lastly, Whittingham and Dunn's (2005) comparison of EP frequency among socially monogamous species that were either sexually size dimorphic or monomorphic failed to detect the expected greater VRS among the dimorphic species.

However, behavior is also a potential target of selection. Passerine song is involved in intersexual communication (Part, 1991; Rodrigues, 1996), and song characters have been shown to affect both WP and EP mate choice of females (e.g. Ballentine et al., 2004; Forstmeier et al., 2002; Hasselquist et al., 1996; Vallet et al., 1998). Parental behaviors such as nest defense, nest building and parental feeding effort, while generally viewed as direct investment in current reproductive effort (Montgomerie and Weatherhead, 1988), may also represent sexually selected traits if females prefer to mate with aggressive males or males who invest more in behaviors that promote her reproductive success (e.g., Soler et al., 1998; Szentirmai et al., 2005). For instance, Freeman-Gallant $(1996,1997)$ showed that male parental effort in savannah sparrows (Passerculus sandwichensis) resulted in increased male reproductive success in subsequent breeding attempts because females appeared to prefer to mate with parental males. Parental behaviors thus represent an important class of sexually selected traits that Whittingham and Dunn (2005) did not consider. 
The eastern kingbird (Tyrannus tyrannus) is a socially monogamous species with no apparent sexual size or plumage dimorphism (Murphy, 1996). Kingbirds are also suboscine passerines with simple songs (Smith, 1966) and both sexes tend the single brood of 3-4 young that is raised annually (Woodard and Murphy, 1999). Few aspects of their biology suggest that sexual selection is operating within this system, but roughly $60 \%$ of nests from studies conducted in Michigan (McKitrick, 1990) and New York (Rowe et al., 2001) contained EPY. Kingbirds thus present an ideal opportunity to examine the potential influence of EPP on sexual selection because pairs are (1) strictly socially monogamous, (2) only one brood is raised annually, and (3) although nest failure and nest replacement are common, pairs virtually never divorce within a season. Male VRS is thus limited almost exclusively to his ability to secure WPP and success at gaining extra pair copulations (EPCs).

Previous kingbird studies did not determine the identity of EP sires or quantify VRS to test for an opportunity for sexual selection. We, therefore, in addition to quantifying the frequency of EPP, identified approximately $80 \%$ of EP sires in an eastern kingbird population over a three year period to test for the influence of EP mating success on the opportunity for sexual selection. I also measured male morphology, song and nest defense behavior to attempt to identify characters that potentially served as targets of female mate choice. Our results demonstrated that EP mating behavior created a very strong opportunity for sexual selection, and that female choice of EP sires appeared to be based primarily upon behavioral traits. 


\section{METHODS}

\section{Study site and species}

Work was conducted between May and August of 2002 through 2004 at the northern end of the Great Basin Desert at Malheur National Wildlife Refuge (MNWR), Harney County, Oregon $\left(43^{\circ} \mathrm{N}, 119^{\circ} \mathrm{W} ; 1400 \mathrm{~m}\right.$ asl). The Donner und Blitzen River runs through the refuge to create an island of riparian and marsh habitat surrounded by desert. The channelized river is narrow $(5-10 \mathrm{~m})$ and shallow $(<2 \mathrm{~m})$, and is paralleled closely by a gravel road (Center Patrol Road; CPR). Kingbirds are NearcticNeotropical migrants that arrive in MNWR in mid May. Females build their open-cup nests in late May in trees located along the river and egg-laying begins around the first week of June.

\section{Field methods}

Pairs and their nests were found by conducting daily censuses by vehicle and canoe along a $20 \mathrm{~km}$ length of the CPR and river. Nests are conspicuous and commonly overhang the river and simultaneous censuses by canoe and vehicle to locate nests . were often made. Areas with trees away from the river were censused on foot at least twice annually. Given the conspicuousness of kingbirds and their nests, I am confident that nearly all pairs were located. Nest locations were recorded with a Garmin GPS 72 (accuracy of 3-4 m). I uploaded the data points onto a PC using the program DNRGarmin (Minnesota DNR 2001), converted it to a shape file (ArcView 3.2a [ESRI 2000]), and measured distances between nests with ArcView extension 
nearest features v. 3.8 (Jenness, 2004).

Nests were visited at 2-3 day intervals to determine egg-laying dates, clutch size, hatching success, brood size and fledging success (number of young to fledge). Over $50 \%$ of nests failed every year, but most pairs renested, and identical data were collected for replacement nests. Adults were captured using mist nets placed near the nests during the nestling period and were banded with one aluminum US Fish and Wildlife service band and three colored plastic bands. Upon capture, mass was recorded to the nearest $0.1 \mathrm{~g}$ using a 50- or 100-g Pesola scale (Pesola AG, Baar, Switzerland), wing-chord was measured to the nearest $0.5 \mathrm{~mm}$ using a wing ruler, and tail, tarsometatarus (tarsus) and $9^{\text {th }}$ primary feather lengths were measured to the nearest $0.1 \mathrm{~mm}$ using dial calipers. A small blood sample (approximately $50 \mu \mathrm{l}$ ) was also taken from the brachial vein. Nestlings were measured (mass, tarsus and $9^{\text {th }}$ primary) on roughly day 13 (day $1=$ hatching date) and blood samples were taken between 5 and 13 days of age. Blood samples were immediately mixed with $1 \mathrm{ml}$ of Longmire's Buffer (Longmire et al., 1988) and stored at $4^{\circ} \mathrm{C}$. Eggs that failed to hatch and nestlings that died in the nest were also collected and assayed to avoid loss of paternity information.

\section{Genetic analysis}

Parentage of nestlings was determined by comparing nestling and adult genotypes at seven microsatellite loci. DNA was extracted from $100 \mu \mathrm{l}$ of buffered blood with a Qiagen DNeasy extraction kit (Qiagen, Valencia, CA 91355; \#69504) using the 
protocol for whole-nucleated blood. DNA was amplified in $25 \mu \mathrm{l}$ PCR reactions using GE Healthcare puReTaq Ready-to-Go PCR beads (GE Heatlthcare, Piscataway, NJ 08855; \# 27-9558-01) following conditions specified in Table 2-1. Primers were labeled with fluorescent tags and microsatellites were visualized and interpreted using fluorescent detection (ABI Genescan; Applied Biosystems, Foster City, CA 94404).

Maternity was confirmed by direct comparison of mother and offspring genotypes. Paternity was assessed by direct exclusionary analysis using the nestling's non-maternal genotype. Putative mothers matched their nestling at every locus, indicating that intraspecific brood parasitism did not occur and that mutation and nonamplyfying alleles did not influence paternity assignment. Nestlings with at least one mismatch with their social father were considered extra-pair, and their genotypes were compared to all the other sampled males in the population to identify the genetic father. To be assigned paternity, a nestling and a male had to match at all seven loci. I used CERVUS 2.0 to calculate average exclusion probabilities at each locus, and at all loci combined (Marshall et al., 1998; Slate et al., 2002). Because genetic mothers of the nestlings were known, this represents the probability that a randomly chosen male could be excluded as the genetic father of a nestling.

Annual return rates were high (65-70\% of adults; MT Murphy, unpublished data) and 19 males and 15 females contributed parentage data in more than one year. Repeatability (per Lessells and Boag, 1987) of EP, WP, and total reproductive success of males (ANOVA: $p=0.14, p=0.22$, and $p=0.07$, respectively) and females (ANOVA: $p=0.29, p=0.17$, and $p=0.22$, respectively) were all nonsignificant. 
Based on the absence of consistent tendencies for high or low reproductive success of particular individuals, I chose to include all nesting attempts in the analyses. Although I identified and monitored returning adults, I was not able to recapture and remeasure the morphology of all males for every year for which I had parentage data to test for relationships between morphology and reproductive success. Murphy (2004) showed, however, that wing chord, and tarsus and bill lengths were significantly repeatable across years. I therefore used tarsus and bill lengths from the previous breeding seasons in our analyses if parentage data existed for a male, but morphological data were only available for a previous year. Wing chord, although repeatable, may be subject to nutritional effects and therefore I did not use wing chord, body mass, nest defense or song data (see below) in our analyses unless they were collected in the same year for which parentage data were collected.

\section{Parental defense and song behavior}

In 2003 and 2004, I documented parental defense and song behavior to test for relationships between variation in each and WP losses and EP gains of paternity. Kingbirds are notoriously aggressive nest defenders (Davis, 1941) and males are more aggressive than females (Davis, 1941; Redmond, 2005). I used Blancher and Robertson's (1982) method for quantifying nest defense by measuring responses to the presentation of a taxidermic mount of an American crow (Corvus brachyrhynchos), a common nest predator in our study site, once during the incubation period and once when the nestlings were 6 to 8 days old (between 0900 and 1200 PDT). To measure 
nest defense response, the mounted crow was attached to a $3 \mathrm{~m}$ pole and held by one person within $\sim 1 \mathrm{~m}$ of the nest for a 5-min test period. Two observers, one for each parent, recorded responses on a scale of 1 to $5(1=$ call, $2=$ approach mount, $3=$ hover near mount, $4=$ dive at mount, $5=$ strike mount). All birds called and approached, so I used only the number of hovers, dives and strikes to derive a nest defense index (NDI) score for both the male and female:

$$
\mathrm{NDI}=\log ((\Sigma \text { hover }+1) *(\Sigma \text { dive }+1) *(\Sigma \text { strike }+1))
$$

( 1 was added to each score to account for zeros). Individual measures of NDI were repeatable both within and between years (Redmond, 2005).

Kingbirds vocalize throughout the day, but they sing a highly ritualized dawn song (Smith, 1966) nearly exclusively in the predawn darkness from a prominent perch located within $50 \mathrm{~m}$ of the nest. Copulations are virtually never seen and I assume that they occur during the dawn song period. Males continue to sing well into their social mate's nestling period (Sexton, 2006), and presumably, at least one function of dawn song is to advertise a male's availability to females. The narrow daily window of time in which dawn songs are delivered required a team of 3 to 5 people to document dawn song behavior nearly daily from mid-June to late July in 2003 and 2004. We arrived at the nest about two hours before dawn and recorded the time that the male began to sing (Start time), when he ended (End time), and total song length (Length; absolute value of difference between start and end time relative to 
civil dawn). Nearly all songs were produced within the first 30 min of singing (Sexton, 2006) and therefore the number of songs/min was recorded for the first halfhour of the bout. Not all males sang for the full $30 \mathrm{~min}$ and therefore I calculated three song rates: "30-MinRate" = average song rate/min for 30 minutes; "ActualRate" = average song rate/min for the period of singing; "Peak Rate" = average song rate/min for the 5-min period of highest output. Meteorological data (temperature at start and end, wind speed and dew point) were measured at the beginning and end of each sample period using a Kestrel 3000 mobile weather station (Niche Retail, LLC, Sylvan Lake, Michigan 48320), but song behavior was unrelated to weather (Sexton, 2006). Most males were observed several times throughout the breeding cycle, and start time and the three measures of song rate were highly repeatable for individuals both within and between breeding seasons (Sexton, 2006). I used the average values for each song behavior from multiple observations ( 2 to 5 ) for each male in the analyses.

\section{Statistical analyses}

The analyses were carried out separately for each of the three years and then for all three years combined. To determine whether EPY were randomly distributed among nests, I compared observed numbers of EPY to expected values using a Chi-square test. Expected numbers of EPY were computed based on a hypergeometric distribution based on population-level variation in clutch size, and number of extrapair and within-pair young using a SAS script (Neuhauser et al., 2001). All other 
analyses were performed using STATISTIX 8.0 and SPSS 11.5. Standardized variance in reproductive success (variance/mean ${ }^{2}$ ) was computed according to Arnold and Wade (1984). I used the following equations from Webster et al. (1995; Table 2-1) to calculate variance in WP and EP success and their covariance, where WP variance $=$

$$
\bar{N}_{w}^{2} \bar{P}_{w}^{2} \operatorname{Var}\left(M_{w}\right)+\bar{M}_{w}^{2} \bar{P}_{w}^{2} \operatorname{Var}\left(N_{w}\right)+\bar{M}_{w}^{2} \bar{N}_{w}^{2} \operatorname{Var}\left(P_{w}\right)+D_{w}
$$

EP variance $=$

$$
\overline{\mathrm{N}}_{\mathrm{e}}^{2} \overline{\mathrm{P}}_{\mathrm{e}}^{2} \operatorname{Var}\left(\mathrm{M}_{\mathrm{e}}\right)+\overline{\mathrm{M}}_{\mathrm{e}}^{2} \overline{\mathrm{P}}_{\mathrm{e}}^{2} \operatorname{Var}\left(\mathrm{N}_{\mathrm{e}}\right)+\overline{\mathrm{M}}_{\mathrm{e}}^{2} \overline{\mathrm{N}}_{\mathrm{e}}^{2} \operatorname{Var}\left(\mathrm{P}_{\mathrm{e}}\right)+\mathrm{D}_{\mathrm{e}}
$$

and Covariance $=$

$$
\begin{aligned}
& 2 \bar{M}_{w} \bar{N}_{w} \bar{P}_{w}^{2} \operatorname{Cov}\left(M_{w}, N_{w}\right)+2 \bar{M}_{w} \bar{N}_{w}^{2} \bar{P}_{w} \operatorname{Cov}\left(M_{w}, P_{w}\right) \\
& +2 \bar{M}_{w}^{2} \bar{N}_{w} \bar{P}_{w} \operatorname{Cov}\left(N_{w}, P_{w}\right)+2 \bar{M}_{e} \bar{N}_{e} \bar{P}_{e}^{2} \operatorname{Cov}\left(M_{e}, N_{e}\right) \\
& +2 \bar{M}_{e} \bar{N}_{e}^{2} \bar{P}_{e} \operatorname{Cov}\left(M_{e}, P_{e}\right)+2 \bar{M}_{e}^{2} \bar{N}_{e} \bar{P}_{e} \operatorname{Cov}\left(N_{e}, P_{e}\right)+D_{w e} .
\end{aligned}
$$

In these equations, $M=$ the number of mates, $N=$ the average number of young produced by a mate and $\mathrm{P}=$ the proportion of those young fertilized by the male. $\mathrm{D}$ represents the remainder terms that result from interactions between higher order terms' multivariate skewness. The subscripts " $w$ " and " $\mathrm{e}$ " indicate within-pair and extra-pair respectively.

I divided males into six groups based on whether they successfully sired EPY (yes or no) and gained paternity within their own nest (all, some or none), and used the groups to characterize variation in male and female genetic reproductive success and test for differences among the groups in male morphology and both song and nest 
defense behaviors (analysis of variance [ANOVA] or Kruskall-Wallis test). Least squares linear regression and stepwise multiple linear regression were also used to test for relationships between three measures of reproductive success (number of WP, EP and total young) and individual morphology (mass, tarsus, wing-chord, bill and tail lengths), behavior (NDI during incubation and nestling period, and song variables) and ecological circumstance (timing of breeding, breeding density, and breeding synchrony). Timing of breeding was defined as the date on which a female laid her first egg, while breeding density was measured as the distance to the nearest neighbor, and average distance to the three nearest neighbors. Stutchbury and Morton (1995) proposed that EPP would be more common among synchronously breeding species because females can more readily compare males when they are in the same breeding state. Consequently, I used Kempenaers' (1993) methods to calculate a breeding synchrony index for each female. Unless otherwise stated, all variables retained in the multiple regressions contributed significantly $(p \leq 0.05$, based on Type III sums of squares) and I report adjusted $R^{2}$. Pair-wise comparisons of morphological and behavioral characters between successful extra-pair males (i.e. cuckolders) and the within-pair males who lost paternity to them (i.e. cuckoldees) were made using paired $t$-tests. Sample sizes vary among tests because not all data were available for all males. 


\section{RESULTS}

\section{Paternity results}

Population size was 52, 59 and 52 pairs in 2002, 2003 and 2004, respectively. Initial nests were depredated frequently ( $57 \%$ of 193 initial nests), but most failed pairs renested successfully ( $40-85 \%$ depending on year). The 7 loci yielded 81 alleles (Table 2-1), resulting in a total exclusionary power of 0.998 . The predicted frequency of null alleles at the seven loci was low (CERVUS: Marshall, 1998) and none were observed. All loci were also in Hardy Weinberg equilibrium (CERVUS: Marshall, 1998), and every nestling matched the social female at every locus. Sires were identified for $73 \%, 76 \%$ and $85 \%$ of the offspring sampled in 2002,2003 and 2004 , respectively.

At least $59 \%$ of nests contained at least one EP young in all three years (Table $2-2)$, and no differences existed among years $(2 \times 3$ contingency table; $p=0.958 ; n=$ 89). Pooling across years, $61 \%$ of nests contained at least one EP nestling and $47 \%$ of all nestlings were sired by extra-pair males (Table 2-2). There was no difference in the frequency of EPY in first (25/60) and replacement nests (10/19; Fisher's exact test, $p=0.437)$. EPY were not randomly distributed among nests; more nests contained all or no EPY than expected by chance $\left(\chi^{2}=35.47, p<0.001, d f=14\right.$; Figure 2-1). The distance a female traveled for an EPF ranged between $67.2 \mathrm{~m}$ and $15,359 \mathrm{~m}(\bar{x}=$ $1779.8 \mathrm{~m}$, median $=404.1, s d=3246.7, n=39)$, and nearly half $(18 / 39)$ traveled across at least one territory to reach their EP mate. Five females traveled across 20 or more territories (range: $0-43$ ). 
Large differences in male reproductive success existed among the six paternity groups in all years (Table 2-3). Nearly a third of males gained EPFs (sum of paternity groups 2, 4 and 6), but over half of these males also lost paternity within their own nests (groups 2 and 4). Most males either sired no EPY (groups 1, 3 and 5: 70\%), and either failed to sire any WPY (group $1 ; 24 \%$ of males) or sired all of the young within their social mate's nest (group 5; 26\%). Among years, $16 \%$ to $36 \%$ (mean $=24 \%$ ) of the males sired no young at all (either WP or EP; group 1) and between $20 \%$ and $44 \%$ (mean $=31 \%$ ) of males sired no offspring within their nest (sum of groups 1 and 2 ).

The most successful males belonged to groups 4 (some WPY and some EPY; $10 \%$ of males) and 6 (all WPY and some EPY; 13\% of males). Males in the latter groups sired both EP and WP young, and averaged $91 \%$ higher genetic reproductive success than the next most successful group (group 5: all WPY and no EPY; $26 \%$ of males).

\section{Opportunity for selection}

Apparent male reproductive success (the number of young in a male's nest that survived until blood sampling) ranged between 1 and 5 nestlings (mean $=2.97$ ). The number sired (realized reproductive success) averaged just over 2 , but ranged from 0 to 9 (Table 2-4). EP success accounted for $46 \%$ of the standardized variation in reproductive success, while within-pair contributions accounted for $42 \%$.

Standardized covariance was moderate and positive and accounted for $12 \%$ of the total variance (Table 2-4). The variance in realized reproductive success was 9.4 times greater than for apparent reproductive success, a highly significant difference $\left(F_{M A X}\right.$ 
test, $p<0.001$ ) indicating that EPP contributed greatly to overall genetic reproductive success and the opportunity for sexual selection.

The largest contribution to the variance in genetic reproductive success of EP males was the proportion of the EP clutch sired by a male ( $30.6 \%$ of the variance of male success at siring EPY). There was a large, positive covariance between the number of EP mates a male obtained and the proportion of the EP brood that he sired, indicating that males who bred with several EP mates were also likely to sire a large proportion of each brood (Table 2-4). Nearly all the variance in male WP success was determined by the proportion of a male's clutch that he did not sire (Table 2-4). Female quality (defined as number of eggs produced) contributed virtually nothing to the variance in either WP or EP variance ( $1 \%$ for each; Table $2-4)$.

\section{Predictors of WP and EP success: breeding date, breeding synchrony and density}

Among first clutches, the social mate of males who sired EPY initiated their withinpair clutches approximately 5.5 days before males who failed to sire EPY $(F=7.31, p$ $=0.009, n=54)$. As a consequence, comparisons of the breeding synchrony index showed that successful EP males paired with females who bred outside the main laying period $(F=5.7, p=0.02, n=53)$. The occurrence of EPY was unrelated to nest density as the distance to the nearest nest did not differ between males that did ( $\bar{x}$ $=313.8, s d=374.7, n=53)$ or $\operatorname{did} \operatorname{not}(\bar{x}=275.7, s d=164.0, n=34 ; t=-0.56, p=$ $0.52)$ lose paternity. Similarly, nearest neighbor distance of males that did $(\bar{x}=$ 
261.0, $s d=158.8, n=28)$ or $\operatorname{did} \operatorname{not}(\bar{x}=361.9, s d=359.1, n=59)$ sire EPY did not differ $(t=1.01, p=0.32)$. Identical conclusions resulted for both of the latter comparisons when I used the average distance to the three nearest neighbors (results not shown).

\section{Predictors of WP and EP success: morphology and behavior}

Morphological comparisons failed to demonstrate any differences among males in the six paternity groups (ANOVA: greatest difference was for tarsus length, $F=1.70, \mathrm{df}=$ $5,81, p \geq 0.15$ ). Correlation analyses of WP success and morphological characters of individual males, without regard to group, also failed to detect any significant relationships (strongest correlation with wing chord: $r=0.154, n=87, p=0.154$ ). However, similar analyses of EP and total success showed significant and positive relationships with tarsus length (EP success: Figure 2-2, $r=0.374, n=87, p=0.0004$; total success: $r=0.220, n=87, p=0.040$; for all other correlations, $p \geq 0.16$ ).

The six paternity groups failed to show differences in NDI during either incubation or the nestling period (Table 2-5). Similarly, Start time for dawn song and Song Bout Length did not differ among groups (Table 2-5). The greatest differences tended to be associated with song rates. Although none of the differences were statistically significant (but for all, $0.05<p<0.10$ ), males that failed to sire any young consistently showed the lowest song rates. Interestingly, males that sired EPY but no WPY (group 2) were generally the strongest singers (Table 2-5), followed by the most successful males (group 6; Table 2-5). 
Correlation analyses without respect to paternity group revealed that WP success was positively associated with NDI during incubation $(r=0.292, n=83, p=$ $0.039)$, but not to NDI during the nestling period $(r=0.185, n=64, p=0.144)$ or to song behaviors (for all, $p \geq 0.11$ ). Number of EPY was unrelated to NDI score during either time period $(p \geq 0.29)$, but number of EPY correlated inversely with StartTime $(r=-0.470, n=55, p<0.001$; Figure 2-3) and positively with 30-MinRate $(r=0.307$, $n=55, p=0.023)$. Thus, males who began singing early relative to sunrise and males who sang rapidly sired more EPY. Among males who sired at least one extra-pair offspring, timing of dawn song accounted for $65.4 \%$ of the variation in EP success ( $p$ $<0.001, n=18$; Figure 2-3).

Timing of dawn song thus appeared to be particularly important to EP success, but timing of song was correlated with other song and morphological traits. Males who began singing early tended to sing at a higher rate $(r=0.569, p<0.001)$, for longer periods $(r=0.613, p<0.001)$, and had longer tarsi $(r=0.302, p<0.024 ; n=57$ for all). I therefore conducted a stepwise multiple regression to evaluate potential contributions of each variable. Our results showed that timing of the start of dawn song was the only predictor of number of EPY $(r=0.401, p=0.014, n=39)$ and total number of young (sum of WP and EP: $r=0.318, p=0.023, n=39$ ). A similar stepwise multiple regression of number of WPY sired by a male showed that WP success was related only to NDI during incubation ( $r=0.285, p=0.043, n=39$ ). 


\section{Comparisons of Cuckolder and Cuckoldee}

Pairwise comparisons of successful EP sires (cuckolders) to the males from whom they gained paternity (cuckoldees) suggested that song behavior differed greatly between groups. Morphological comparisons of the 40 pairs for which data for both males were available indicated that cuckolders had longer tarsi (and possibly longer tails; Table 2-6). Behavioral data were available for 21 of the 40 pairs (Table 2-6). Cuckolders started singing earlier and sang faster than cuckoldees, but nest defense behavior (NDI score), did not differ between the two groups of males during either reproductive phase (Table 2-6).

\section{DISCUSSION}

\section{General characteristics}

On average, EPY occur in $16 \%$ of nests of socially monogamous bird species breeding in north temperate regions (Griffith et al., 2002; Spottiswoode and Moller, 2004; Westneat and Sherman, 1997). EPP is most common among migratory passerines (Arnold and Owens, 2002), but even for this ecological group, eastern kingbirds are an extreme case; $61 \%$ of nests contained EPY and overall $47 \%$ of all offspring were the result of EP matings (Table 2-2). Virtually identical values have been reported for eastern kingbird populations from Michigan (McKitrick 1990) and New York (Rowe et al. 2000), indicating that eastern kingbirds consistently engage in cryptic polygamy.

EPFs of kingbirds were not evenly distributed among broods or among males, and reciprocal cuckoldry was not common. In addition, a positive covariance existed 
between the proportion of an EP brood sired by a male and the number of EP mates he obtained. This created big winners and big losers, and as a consequence, EPP accounted for nearly half of the variance in male reproductive success. The extreme skew in reproductive success is best exemplified by the fact that $31 \%$ of males provisioned broods in which they had no genetic investment. The major contribution of EPP to variance in male reproductive success underscores the point that extra-pair mating behavior is not merely an alternative mating strategy involving a minority of males, but is instead a primary selective force that defines the eastern kingbird mating system.

Although Whittingham and Dunn (2005) and Freeman-Gallant et al. (2005) concluded that the effects of EPP on the opportunity for sexual selection among passerine birds have been generally overstated, our data suggest otherwise. The combination of relatively small population size and spatially restricted habitat allowed us to sample most of the population, and as a result, each year I identified sires for most young (73-85\%). Our estimate of the opportunity for selection is therefore not methodologically inflated (see Freeman-Gallant et al. 2005). The two largest differences between our study and those of Whittingham and Dunn (2005) and Freeman-Gallant (2005) are that, unlike most of the species included in their samples, eastern kingbirds are strictly socially monogamous and single brooded. Reproductive variance is sensitive to total number of young produced, not just the proportion of a brood sired (Andersson, 1994; Webster et al., 1995). Therefore, if some females are double brooded or some males acquire two or more mates, a male's WP mate choice 
would contribute more to the variance in reproductive success than in a population where females are strictly single brooded and males are limited to a single partner. Thus, among strictly single brooded, socially monogamous species, EPP can represent a significant source of variance in reproductive success and create opportunities for sexual selection.

Whittingham and Dunn (2005) also found no difference in the opportunity for sexual selection between sexually dimorphic and monomorphic species, where dimorphism was defined as overt intersexual size or plumage differences. However, behavior (e.g. parental care, nest building, and song characters) have also evolved under the influence of sexual selection. While eastern kingbirds lack the overt size or plumage dimorphism typically associated with sexual selection (but see Murphy, in press), our results suggest substantial opportunity for sexual selection to operate and influence other sexually selected traits, most notably behavior.

\section{Within-pair mating success}

WP mating success of males was completely independent of morphology and song behavior, but $\sim 10 \%$ of WP success was associated with nest defense behavior: males that defended nests vigorously tended to sire more WPY. Male nest defense behavior is repeatable both within and across seasons (Redmond 2005), suggesting nest defense has a strong individual component that females may use when making mate choice decisions. Why then do males that vigorously defend nests tend to have greater WP success? 
At least three possible explanations exist. First, intensity of nest defense may be used by females as a proxy to assess potential costs of infidelity, and females paired to aggressive males may engage in fewer EPCs to avoid male retribution. Retribution for infidelity is a theoretical cost of EPCs (Gowaty and Buschhaus, 2000; Petrie and Kempanaers, 1998) and experiments have shown that males of some species sometimes physically assault unfaithful females (Barash, 1976; Valera et al., 2003; Zenone et al., 1979). While vigorous response to an intruding crow is perhaps indicative of a male's likely response to actual or perceived cuckoldry, I have never observed intra-pair agonistic behaviors consistent with this scenario and thus find it unlikely.

Second, WP success may vary positively with vigorous nest defense because the latter correlates positively with a male's ability to repel cuckolders. Although aggressive males may theoretically be more effective at mate guarding, for a number of reasons I also find this explanation unlikely. Copulations occur in the predawn darkness (Murphy, 1996; Smith, 1966) when visibility is very low and mate guarding is probably ineffective. Moreover, males are sedentary and remain on territory to sing (88.2\% of males were present and singing near their nest during 195 recorded singing sessions). Females must therefore move to seek EPCs, and territories of extra-pair partners were commonly more than a kilometer apart (up to $15 \mathrm{~km}$ ). Given these observations, I suspect that males do not even attempt to guard paternity.

The third possibility is that nest defense behavior is an inter-sexually selected trait that females find attractive. Nest defense is often considered a parental rather 
than an agonistic behavior (e.g. Dale et al., 1996; Knight and Temple, 1988;

Montgomerie and Weatherhead, 1988; Rytkonen, 2002), and other parental behaviors such as nest building (Soler et al.,1998; Szentirmai et al., 2005) and feeding rates (Freeman-Gallant 1996, 1997) have been shown to influence female mate choice and function as sexually selected characters (Freeman-Gallant, 1996, 1997). Predators are responsible for most kingbird nest losses (Blancher and Robertson, 1985; Murphy, 2000) and females may be attracted to aggressive males for utilitarian purposes if vigorous nest defense translates to reduced probability of nest predation. Intensity of nest defense and nest success have been shown to correlate positively in some (Blancher and Robertson, 1982), but not all (Redmond, 2005; Siderius 1993), kingbird populations. That females profit from pairings with aggressive males in at least some years lends credence to the possibility that aggressive behavior may be a trait used by females during mate choice. However, as shown here, pairing and mating are different phenomena and it would seem necessary that vigorous nest defense provide additional information regarding male quality for her to share parentage with him. For instance, vigorous behavioral display was correlated with immune response and presumably good genes in black wheatears (Oenanthe leucura; Soler et al. 1999), and potentially, vigorous male kingbird nest defense likewise functions to advertise male quality to females.

\section{Extra-pair success}

EP mating success was correlated with breeding date, song performance, and male 
morphology, but was independent of the vigor of nest defense. Timing seemed to be an especially important factor in this system because the most successful EP males were paired to females that bred nearly a week before males that did not sire EP young, and EP success was highest among males who were the earliest to begin daily dawn song. Breeding date and timing of the initiation of dawn song were positively correlated (i.e. late breeders began singing late relative to dawn; Sexton, 2006). In other species, early spring arrival date has been related to high male quality, expression of secondary sexual characters and mating success (Lozano et al., 1996; Moller, 2003). Although I have no information on arrival and breeding date for the years of this study, data from subsequent years confirm that early arriving male kingbirds are the first to form pair bonds and breed (Murphy, unpubl. data). Hence, males that began to sing earliest in the predawn period were very likely high quality individuals. Indeed, early and rapidly singing males had long tarsi, long wings and tails (Sexton, 2006) and therefore song seemed to provide reliable information regarding male size and presumably quality. Our multivariate analyses showed that start time of dawn song was the single most important predictor of EP success, and thus song behavior appeared to be the primary cue used during female choice of EP sires. Similarly, a recent study of song behavior in blue tits (Parus caeruleus) also found that males who sired EPY initiated dawn songs earlier than their unsuccessful counterparts, a trait which indicated a male's age (Poesel et al., 2006).

Estimates of the metabolic cost of singing vary, but they may be very high in some species (up to 9 times the basal metabolic rate in the Bewick's wren 
[Thryomanes bewickii], Eberhardt, 1994; but see Oberweger and Goller, 2001). Performance of dawn song is likely to be costly for kingbirds, and therefore is a reliable signal of male condition or quality, because it occurs at a time of day when energy demands from thermal stresses are high but when reserves are at their lowest point of the day (Mace, 1987). Few studies of suboscine song behavior exist, but song performance in kingbirds is individually repeatable both within and between seasons, and appears to be sufficiently variable to convey details specific to the singer (Sexton, 2006). At the population level, EP success was inversely related to start time (early singers sired more EP young) and was positively related to song rate. Pair-wise comparisons of cuckolder and cuckoldee provided even stronger evidence of the importance of song for selecting EP sires: cuckolders outperformed cuckoldees in 4 of 5 song behaviors (Table 2-5). The fact that suboscine song is innate and free of the confounding effects of differences in social environment on song development (Kroodsma 1984, Kroodsma and Konishi 1991), and that it varies mainly in measures of performance (timing and rates), suggest that suboscine song may be used commonly in mate choice because it may reflect a male's condition and overall quality.

\section{Is there an optimal male strategy?}

Dawn song seemed to be the primary means by which females assessed the quality or condition of males as EP sires (see also Forstmeier et al., 2002; Turner and Barber, 2004). Song may serve intrapair functions as well (Amhrein et al., 2003; Forstmeier 
and Balsby, 2002; Rodrigues, 1996; Slagsvold et al., 1994), but given that male kingbirds continued to sing dawn songs well after their social mate was no longer fertile (Smith, 1966; Sexton, 2006), dawn song appears to serve primarily to advertise a male's availability as an EP mate.

WP and EP success were related to different sets of traits, and only a minority of males (23\%) was successful at both. At first glance, the uncoupling of characters that relate to male WP and EP success, and the nearly equal contribution of WP and EP success to variance in male reproductive success, suggest the possibility of alternate behavioral routes to equivalent reproductive successes. Conceivably, high parental commitment might secure sufficient paternity to raise WP success to a level equal to that of less parental males who direct more resources towards EP mating attraction. However, the behaviors associated with WP (nest defense) and EP success (dawn song behavior) occur at different times of day and therefore performance of one is not in conflict with the other. Instead, our evidence suggests that a strategy of attempting to secure all WP paternity, while ignoring EP options, resulted in poor reproductive performance compared to males that obtained some EP reproductive success, even when some losses of WPP occurred (Table 2-3). Assuming that dawn song is associated solely with EP mate attraction and that all effective copulations occur in the predawn period, it would seem that males who did not participate in dawn song and instead attempted to mate guard would ultimately fledge fewer young than males who "chose" to not mate guard and advertise their availability to all females. I propose, therefore, that selection has favored males that dispensed with what are 
probably futile attempts to guard paternity, and instead, directed their efforts towards EP mate attraction primarily through strong performances during the dawn song period. Ultimately, our proposal can be tested by long-term tracking of the recruitment and success of offspring, and given the high natal return rates of our population ( $\sim 28 \%$ of banded young; MT Murphy unpubl. data) I hope to be able to answer this question with our continuing research. 


\section{FIGURE LEGEND}

\section{Figure 2-1}

Comparison of observed and expected number of nests with different levels of extra-pair paternity. The expected number was calculated using a hypergeometric distribution with statistics describing population-level variation in clutch size, and number of extra-pair and within-pair young.

\section{Figure 2-2}

The relationship between number of extra-pair young sired by a male and his tarsus length (number of EPY $=-0.984+0.517$ (tarsus length).

\section{Figure 2-3}

Bivariate plot of the relationship between number of extra-pair young sired by a male and the average time that he began dawn song. Lower line represents the least squares linear regression between number of young and start time for all males (including males that had no extra-pair mating success), while the upper line represents the same relationship, but only for the subset of males that sired extra-pair young. 
Table 2-1 Microsatellite primers used for eastern kingbird paternity analyses.

Characterization includes sequence, primer concentrations $[\mathrm{P}]$ (in $\mu \mathrm{M})$, annealing temperatures $\left(T_{a}\right)$ and numbers of alleles.

\begin{tabular}{|c|c|c|c|c|}
\hline Primer & Sequence & {$[\mathrm{P}]$} & $\mathrm{T}_{\mathrm{a}}$ & Alleles \\
\hline \multirow[t]{2}{*}{$\mathrm{EMIC}^{2} 3^{\mathrm{a}}$} & ACTTGCTGTTCTGCAAGGGTTG(F) & 0.2 & $61^{\circ} \mathrm{C}$ & 9 \\
\hline & ATACCCTAAGGCAAGCCACAGC(R) & & & \\
\hline \multirow[t]{2}{*}{$\mathrm{EMIZ2}^{\mathrm{a}}$} & CGTGTCAGAGCAAGGCAGTG(F) & 0.2 & $61^{\circ} \mathrm{C}$ & 2 \\
\hline & ACTGATCTGCACGTGAGCACC(R) & & & \\
\hline \multirow[t]{2}{*}{$\mathrm{SAP} 2^{\mathrm{b}}$} & TGCTTTTCCAACTGCAACAG(F) & 0.2 & $61^{\circ} \mathrm{C}$ & 24 \\
\hline & GGACCCAATGTCTCTTAAGGG(R) & & & \\
\hline \multirow[t]{2}{*}{ ASE9 $^{c}$} & GACTGAAGTCCTTTCTGGCTTC(F) & 0.4 & $61^{\circ} \mathrm{C}$ & 13 \\
\hline & CACCAGGAATACAAGTCCATTG(R) & & & \\
\hline \multirow[t]{2}{*}{$\mathrm{MJG}^{\mathrm{d}}$} & CCCGGGAAAGGCTTCGTCTTC(F) & 0.2 & $61^{\circ} \mathrm{C}$ & 8 \\
\hline & GGAGATTTTATATCGGTGGC(R) & & & \\
\hline \multirow[t]{2}{*}{ GATA5 $^{\circ}$} & AGGCTTATTTTCAAGACAAGCAAATGGAAACAT(F) & 0.1 & $65^{\circ} \mathrm{C}$ & 18 \\
\hline & GAAGGATTCCTTTGGTCTTCAATTATTCACCTATCTT(R) & & & \\
\hline \multirow[t]{2}{*}{$\mathrm{ACG}^{\mathrm{e}}$} & TGGCGATGGGAAGCACCAGAGC(F) & 1.0 & $65^{\circ} \mathrm{C}$ & 7 \\
\hline & GTCCGTGAGCAGAAGCCCTAAAACACAGAGT(R) & & & \\
\hline
\end{tabular}

${ }^{a}$ Tarof et al., 2001; ${ }^{b}$ Watson et al., 2002; ${ }^{c}$ Richardson et al., 2000; ${ }^{d}$ Li and Brown, 2000; ${ }^{\mathrm{e}}$ Pearson, 2002 
Table 2-2 Population level patterns of extra-pair paternity summarized by year.

Numbers in parentheses exclude nests that contained only one nestling.

\begin{tabular}{lllllll} 
Year & Nests & Nests with & $\%$ Nests & Nestlings & EPY & $\%$ EPY \\
& & EPY & with EPY & & & \\
\hline 2002 & $25(23)$ & $15(15)$ & $60 \%(65 \%)$ & $74(72)$ & $32(32)$ & $42 \%(43 \%)$ \\
2003 & $25(23)$ & $16(15)$ & $64 \%(65 \%)$ & $74(72)$ & $39(38)$ & $53 \%(51 \%)$ \\
2004 & $39(36)$ & $23(22)$ & $59 \%(61 \%)$ & $116(113)$ & $53(51)$ & $46 \%(45 \%)$ \\
total & $89(82)$ & $54(52)$ & $61 \%(63 \%)$ & $264(257)$ & $124(121)$ & $47 \%(47 \%)$ \\
\hline
\end{tabular}


Table 2-3 Reproductive success of male paternity groups. Paternity groups were determined by a combination of WP (all, some or none) and EP (some or none) success. Paternity groups that share letters (under Total success) did not differ statistically.

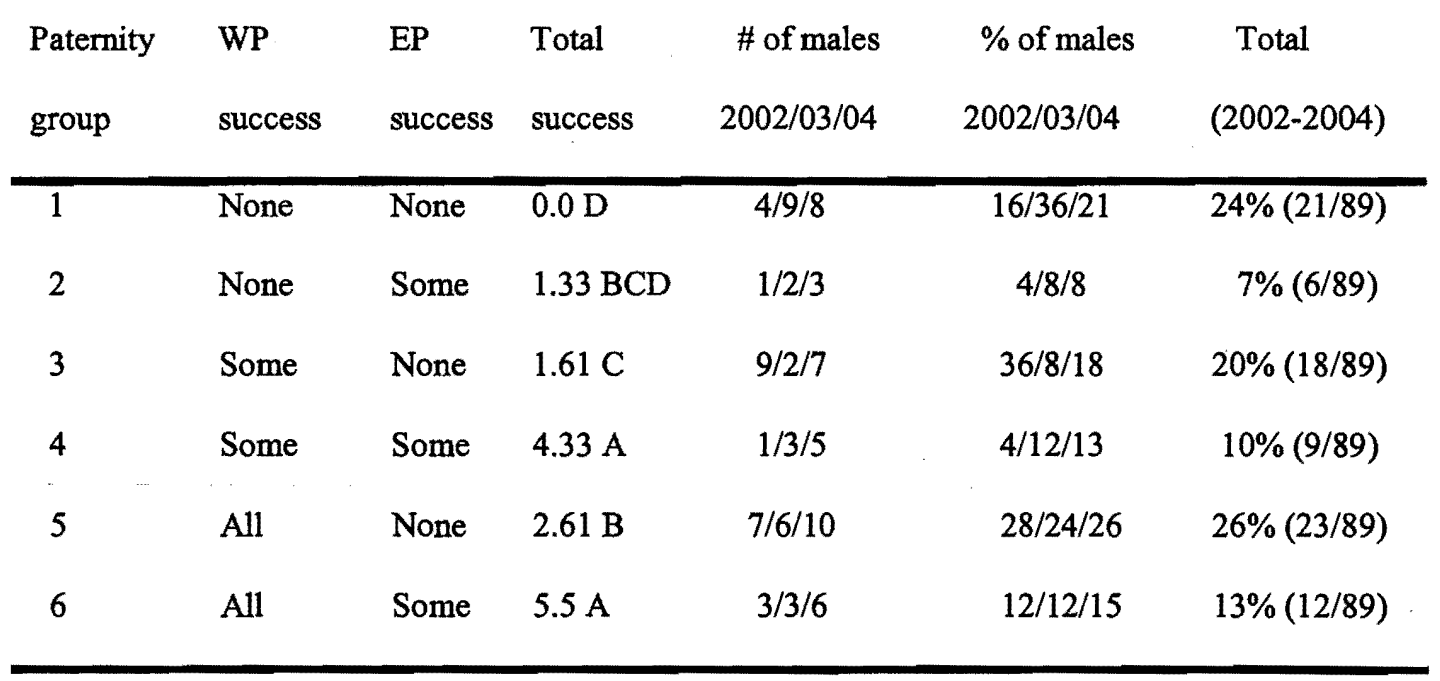


Table 2-4 Apparent and realized male reproductive success. Apparent reproductive success was recorded as the number of young within a nest that were genetically sampled, and realized reproductive success was the total number of young a male sired. Variance (Var) in reproductive success was divided into its component parts as per Webster (1995), and standardized values (Stand var) were calculated as mean/variance ${ }^{2}$ according to Arnold and Wade (1984).

\begin{tabular}{|c|c|c|c|c|c|c|}
\hline & $n$ & range & mean & Var & Covar & Stand var \\
\hline \multicolumn{7}{|l|}{ Apparent reproductive success } \\
\hline & 89 & $1-5$ & 2.97 & 0.83 & - & 0.09 \\
\hline \multicolumn{7}{|l|}{ Realized reproductive success } \\
\hline & 89 & $0-9$ & 2.27 & 4.36 & 0.26 & 0.85 \\
\hline Within-pair & & $0-4$ & 1.57 & 1.82 & - & $0.35(42 \%)$ \\
\hline \# of WP $q$ & & - & - & 0 & - & - \\
\hline WP $q$ quality & & - & - & 0.005 & - & - \\
\hline Prop. WP clutch sired & & - & - & 2.23 & - & - \\
\hline Cov. \# \& quality WP 9 & & - & - & - & 0 & - \\
\hline Cov. \# WP $q q$ and prop. sired & & - & - & - & 0 & - \\
\hline Cov. WP $q$ quality and prop. sired & & - & - & - & 0.02 & - \\
\hline Remainder ${ }^{\mathrm{a}}$ & & - & - & -0.435 & - & - \\
\hline Extra-pair & & $0-7$ & 0.71 & 1.99 & - & $0.38(46 \%)$ \\
\hline \# of EP $q$ & & - & - & 0.24 & - & - \\
\hline $\mathrm{EP} q$ quality & & - & - & 0.02 & - & - \\
\hline Prop. EP clutch sired & & - & - & 0.61 & - & - \\
\hline Cov. \# and quality EP $q$ & & - & - & - & 0.08 & - \\
\hline Cov. \# EP $q$ and prop. sired & & - & - & - & 0.55 & - \\
\hline Cov. EP $q$ quality and prop. sired & & - & - & - & 0.02 & - \\
\hline Remainder & & - & - & 0.47 & - & - \\
\hline
\end{tabular}

The remainder terms result from higher order interactions between variance and covariance terms and multivariante skewness. As a result of these terms, variance is not the simple sum of its component parts. 
Table 2-5 Comparison of nest defense (during incubation and the nestling period) and song behaviors among males in the six paternity groups (P Group).

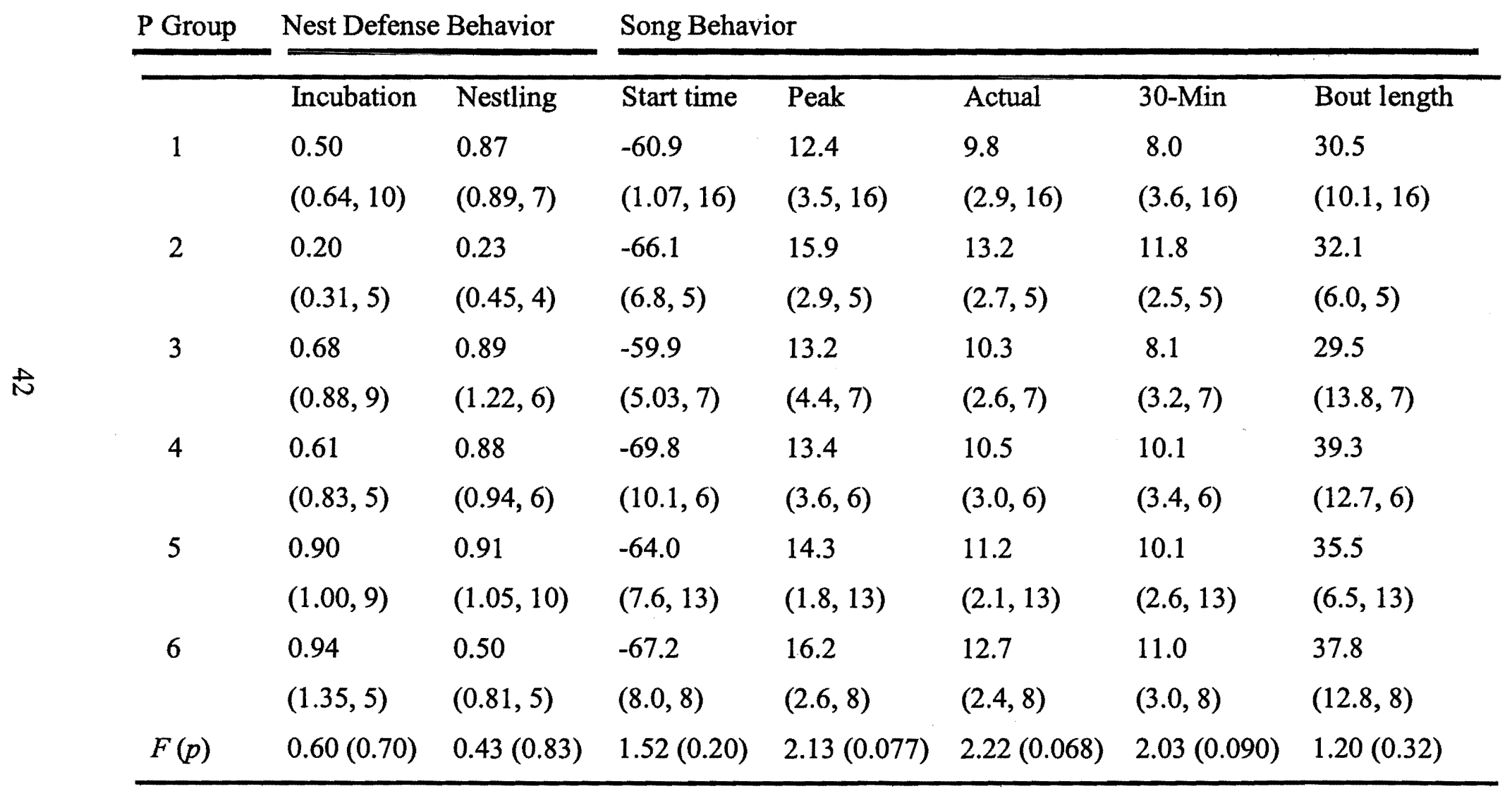


Table 2-6 Pair wise comparisons between successful EP males and WP males who lost paternity. Means, standard deviations and sample sizes of WP and EP males are reported as well as results from paired $t$-tests. Morphological characters are all measured in mm. Significant differences are indicated in bold-faced type.

\begin{tabular}{llll} 
Trait & EP male $\bar{x}(\mathrm{SD}, n)$ & WP male $\bar{x}(\mathrm{SD}, n)$ & $t(p)$ \\
\hline Tarsus & $20.9(1.4,40)$ & $20.4(0.86,40)$ & $\mathbf{2 . 2 ( 0 . 0 3 )}$ \\
Tail $^{1}$ & $89.9(3.1,40)$ & $88.7(3.2,40)$ & $1.76(0.09)$ \\
Wing chord $^{1}$ & $122.4(2.4,40)$ & $122.1(2.6,40)$ & $0.59(0.56)$ \\
Bill $^{1}$ & $14.7(7.7,41)$ & $14.9(0.71,40)$ & $-0.81(0.42)$ \\
Start time $^{2}$ & $-69.4(8.8,21)$ & $-63.2(9.8,21)$ & $-\mathbf{- 3 . 1 4}(\mathbf{0 . 0 0 5})$ \\
PeakRate & $15.2(3.1,21)$ & $13.5(3.4,21)$ & $\mathbf{2 . 2 5 ( 0 . 0 4 )}$ \\
AcutalRate & $12.2(2.7,21)$ & $10.8(2.5,21)$ & $\mathbf{2 . 3 5 ( 0 . 0 3 )}$ \\
30-MinRate & $11.1(2.9,21)$ & $9.2(3.3,21)$ & $\mathbf{2 . 4 5 ( 0 . 0 2 )}$ \\
End time & $-30.8(10.0,21)$ & $-30.0(10.7,21)$ & $-0.2(0.85)$ \\
Drift & $0.42(0.20,21)$ & $0.62(0.43,21)$ & $-1.85(0.08)$ \\
NDI Incubation & $0.44(0.81,16)$ & $0.53(0.81,16)$ & $-0.37(0.72)$ \\
NDI Nestling & $0.54(0.84,15)$ & $1.0(0.82,15)$ & $-1.22(0.24)$ \\
\hline
\end{tabular}

All linear dimensions in millimeters

${ }^{2}$ Start time was recorded in minutes before dawn. 
Figure 2-1

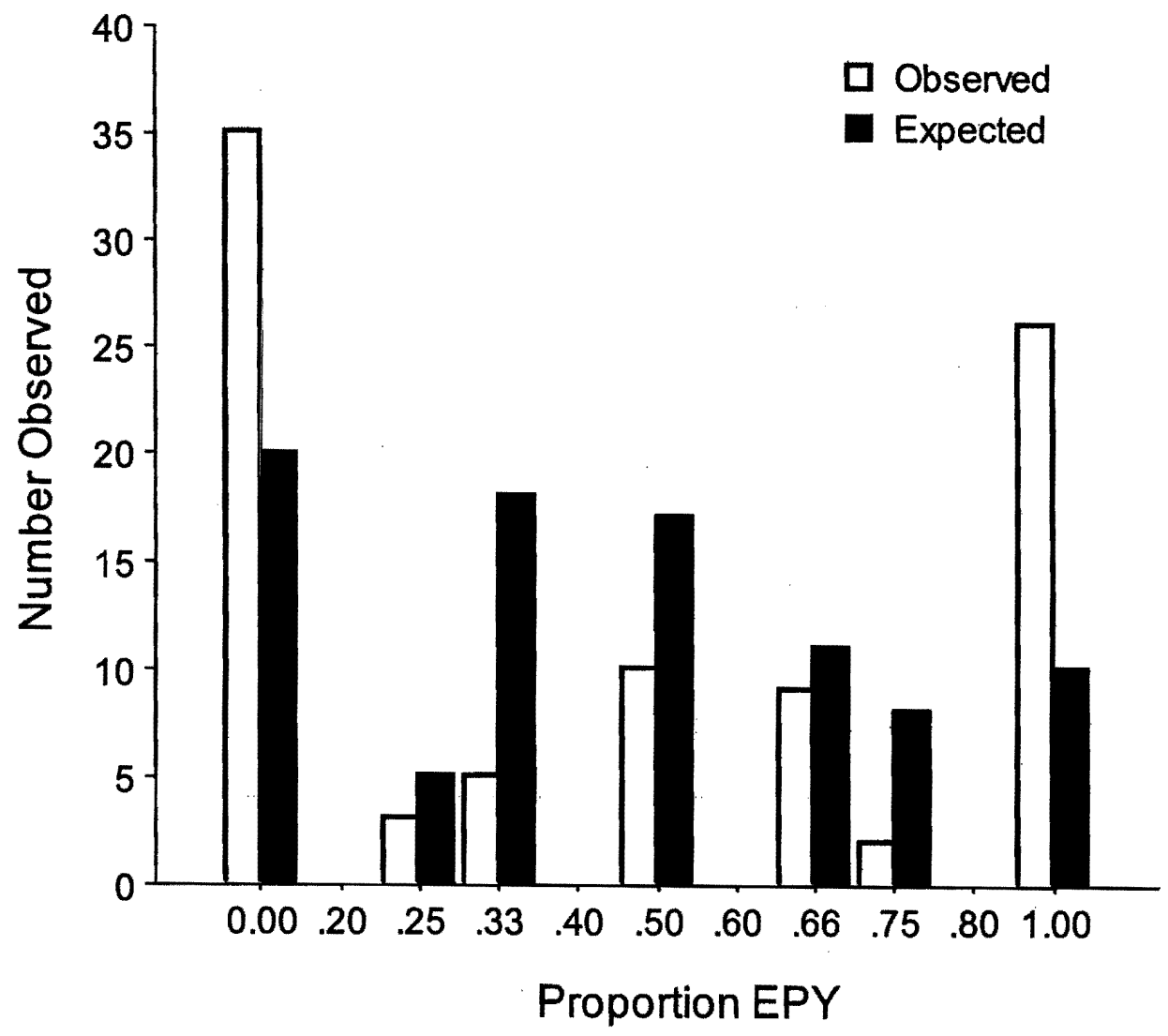


Figure 2-2

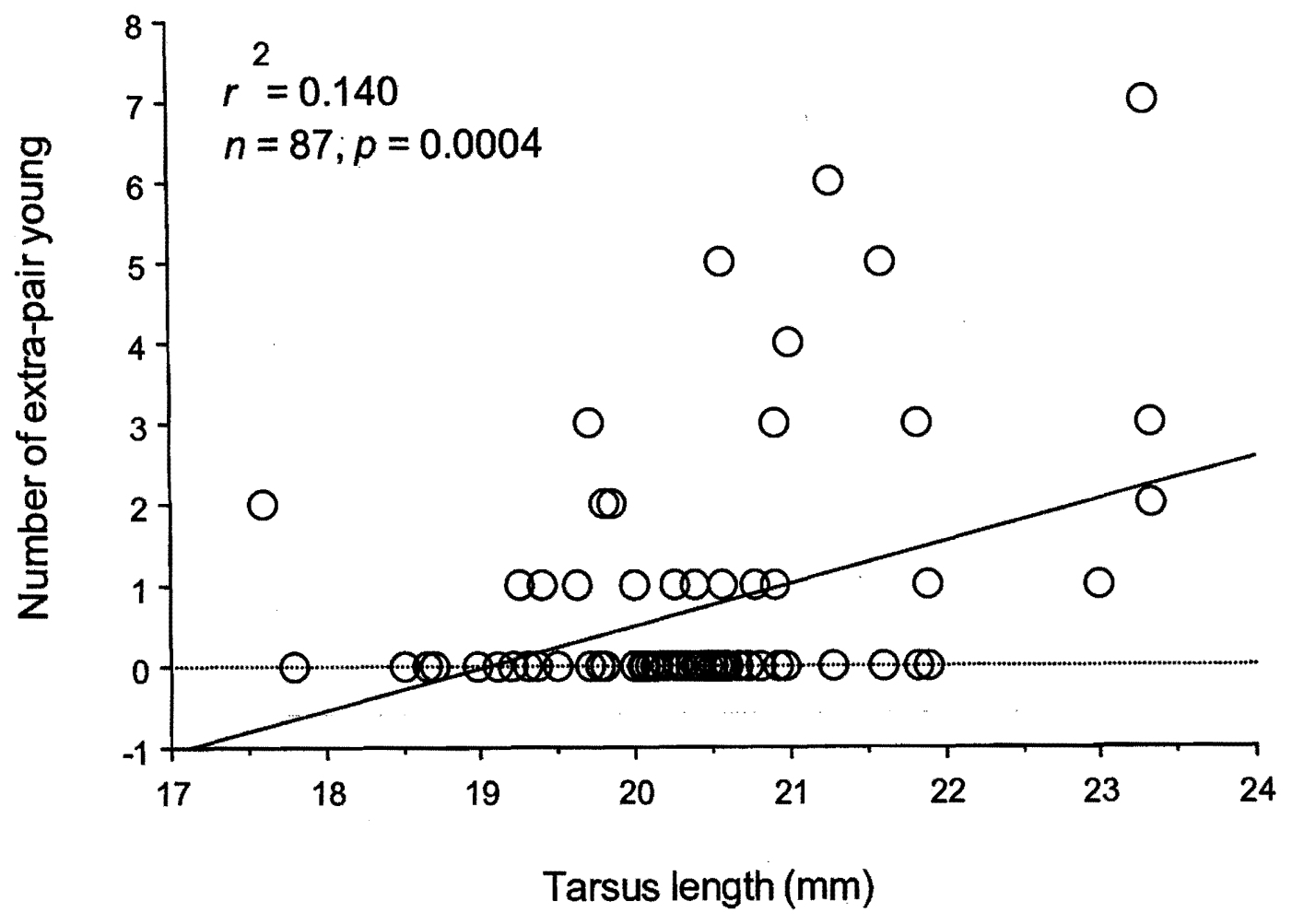


Figure 2-3

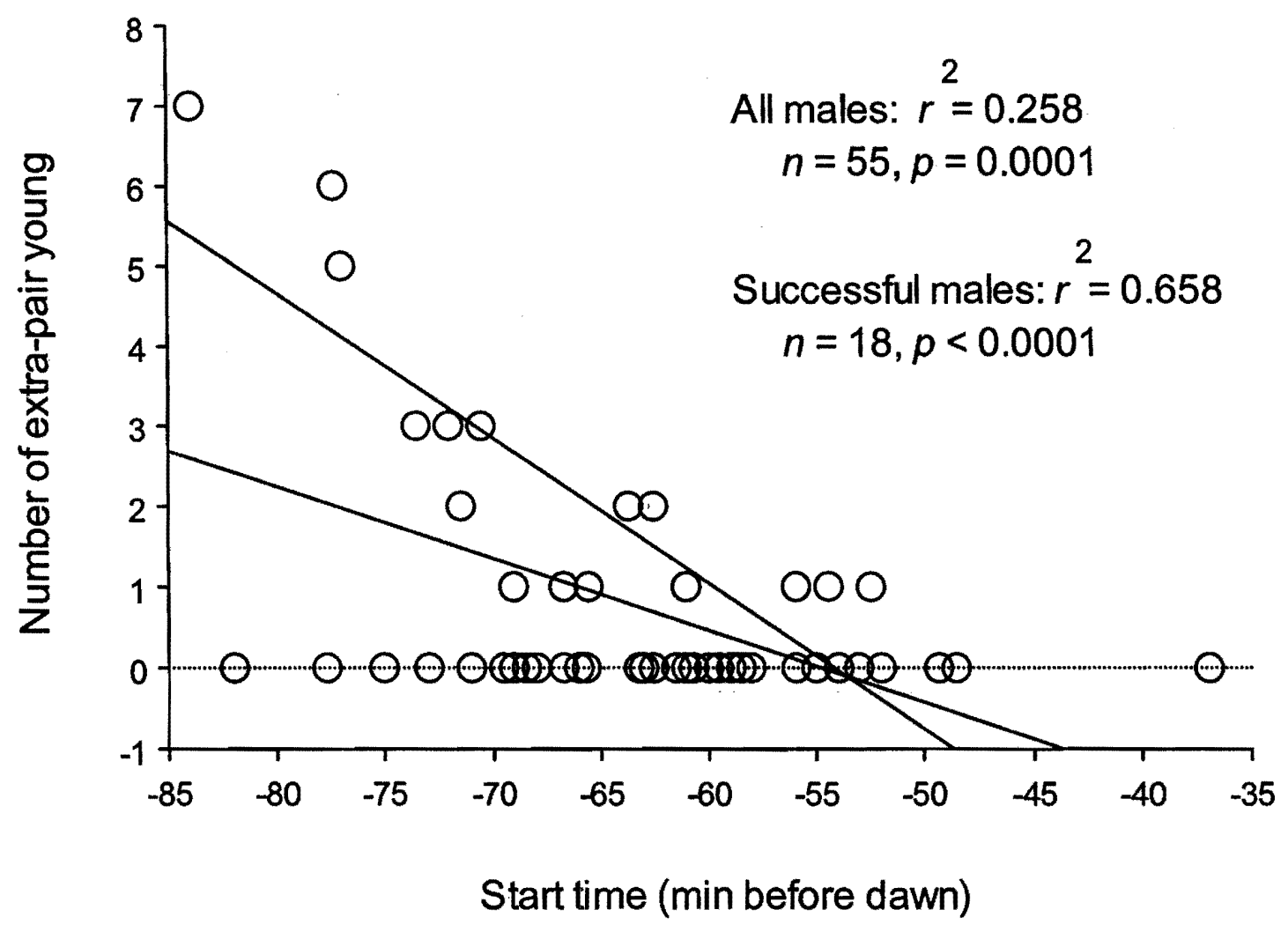




\section{CHAPTER 3 - TESTING THE INDIRECT GENETIC BENEFITS OF EXTRA- PAIR COPULATIONS FOR FEMALE EASTERN KINGBIRDS}

\section{INTRODUCTION}

Extra-pair paternity (EPP) is a widespread reproductive strategy among socially monogamous bird species (Birkhead and Moller, 1992; Griffith, 2000; Hassequist and Sherman, 2001). The benefits of extra-pair fertilizations (EPFs) to males are obvious, and numerous studies have identified factors associated with variable male reproductive success (Forstmeier et al., 2002; Poesel et al., 2001; Yezerinac and Wheatherhead, 1997), but far less is known as to why females engage in extra-pair (EP) mating behavior. EPP does not lead to increased clutch size, and potential costs to females that engage in extra-pair copulations (EPCs) include withdrawal of male parental care (Xia, 1992), retaliatory male aggression (Valera et al., 2003), or the acquisition of sexually transmitted diseases (Poiani and Wilks, 2000). Despite the potential costs, and lack of an increase in fecundity, females are generally thought to actively seek EPFs (Double and Cockburn, 2000; Kempenaers et al., 1992; Smith, 1988), possibly (1) as insurance against mate infertility, or for indirect genetic benefits that include (2) the acquisition of good genes for young, (3) production of a genetically diverse brood of young, or (4) improvement of genetic compatibility between parents.

Testing the fertility insurance hypothesis is difficult, but it assumes that 
females cannot assess the fertility status of males, that females paired to infertile males will produce all extra-pair young (EPY), and that EPY will be randomly distributed throughout the rest of the population (Krokene et al., 1998; Wetton and Parkin, 1991). Because few males are infertile, and under this scenario, fertile males should on average sire EPY as often as they lose within-pair paternity (WPP); the fertility insurance hypothesis predicts that (1) variance of male and female reproductive success should be roughly equivalent, and that no differences should exist in the (2) qualities of EP and within-pair (WP) males, or (3) in the performance of WP and EP offspring (Table 3-1).

In unpredictable environments some genotypes may survive better than others, and the most successful females may be those that hedge their bets by producing genetically diverse young. The genetic diversity hypothesis thus postulates that females seek EPCs to produce a genetically diverse brood (Kempenaers and Dohndt, 1993; Petrie et al., 1998; Westneat et al., 1990), and predicts that (1) EPP should be common and randomly distributed among nests (Kempenaers and Dohndt, 1993), (2) EP sires and WP mates should not differ in measurable qualities (e.g., size or behavior), (3) variance of male and female reproductive success should be equal, and that (4) brood survival rates should increase with number of sires/brood (Table 3-1).

The genetic compatibility hypothesis also predicts that females seek EPCs to increase the genetic diversity of each offspring within the brood (Kempenaers et al., 1999; Tregenza and Wedell, 2000), but the primary difference from the genetic diversity hypothesis is that individual females differ in their propensity to engage in 
EPCs and that (1) the propensity to engage in EP mating behavior increases with relatedness (i.e. genetic similarity) of the pair (Tregenza and Wedell, 2000). The hypothesis further predicts that (2) EPY will not be distributed randomly among broods, and that (3) the offspring most likely to survive will be those produced by the most genetically dissimilar parents. However, (4) no morphological or behavioral differences are expected between successful EP sires and the males they cuckold (Table 3-1).

The good genes hypothesis argues that, at a population level, males differ in inherent quality and that certain traits serve as indicators of male quality. Females assess males through the use of phenotypic cues but they may be prevented from pairing with the highest quality males for various reasons. Females therefore seek EPFs with quality males to produce high quality young (Birkhead and Moller, 1992; Hamilton, 1990; Kempenaers and Dohndt, 1993; Moller, 1988; Westneat et al., 1990), and they use phenotypic cues to identify sires for their young. This hypothesis' primary predictions are that (1) male traits correlate with EP and WP reproductive success (Kempenaers et al., 1992; Kempenaers et al., 1997; Sheldon et al. 1997; Yezerinac and Wheatherhead, 1997), (2) males possessing preferred traits should be most successful, and as a result, (3) variance of male reproductive success will exceed female variance in reproductive success. In addition, (4) nestlings sired by preferred males should exhibit traits associated with survival and be the most likely to survive (Table 3-1; Birkhead and Moller, 1992; Hamilton, 1990; Kempenaers and Dohndt, 1993; Moller, 1988; Westneat et al., 1990). 
Most analyses of the good genes hypothesis have been conducted at a population level and assumed that EP young are of inherently higher quality than WP young. Failure to find a difference in performance of WP and EP young has been taken as evidence against the good genes hypothesis, but this ignores the possibility that females socially paired to high quality males are unlikely to seek EPFs and that some WP young will be sired by high quality males (Kempenaers et al., 1997). The solution is to examine performance of maternal half sibs within broods of mixed paternity to account for maternal and environmental effects (e.g. local food availability, parental proficiency). Alternatively, the performance of individual nestlings sired by specific males can be examined if the identity of EP sires be known. Without the latter comparisons, it is impossible to rigorously test the good genes hypothesis

The eastern kingbird (Tyrannus tyrannus) is a socially monogamous, but genetically promiscuous, species. Rates of EPP in kingbirds are among the highest recorded for passerines ( $\sim 60 \%$ of nests and $\sim 47 \%$ of all nestlings; compare to Griffith et al., 2002; Spottiswoode and Möller, 2004) and my purpose here is to test the four primary hypotheses for the occurrence of EP mating behavior to determine why female kingbirds exhibit such high levels of EPP (Table 3-1). I was able to sample the majority of the breeding population that I studied and determined paternity of appproximately $80 \%$ of offspring. I was thus able to directly compare characteristics of successful EP males and the WP males whom they cuckolded, and to document growth and survival of nestlings sired by known WP and EP males. 


\section{METHODS}

\section{Field methods}

Eastern kingbirds were studied in Malheur National Wildlife Refuge (MNWR) in Harney County, Oregon $\left(43^{\circ} \mathrm{N}, 119^{\circ} \mathrm{W}\right)$ during the $2002-2004$ breeding seasons. General field methods are described in detail in Chapter 2, and thus only briefly summarized here. After breeding pairs were identified, I visited territories at least every third day throughout the breeding season to document laying date, clutch size, hatching date, hatching success and fledging success. I captured adults during the nestling period by placing mist nests near nests, banded them with a unique combination of a numbered aluminum United States Fish and Wildlife band and three color bands, recorded morphological measures (mass, tarsometatarsus [ = tarsus], bill, tail and wing lengths) and collected a small $(\sim 50 \mu \mathrm{L})$ blood sample from the brachial vein. I took blood samples from nestlings 5-13 days after hatching, and measured mass, bill, tarsus and $9^{\text {th }}$ primary feather lengths. I then created nestling condition index by dividing mass by tarsus (both corrected for age). The exact age of the nestlings was determined by either direct knowledge of hatching date or by using $9^{\text {th }}$ primary measures (Murphy, 1981). I corrected mass and tarsus length for differences in nestling age by using the residuals of a linear regression of both against age. Hence, a nestling with a large corrected score was heavy or had a long tarsus for its age. I calculated within-nest averages for tarsus length and mass and subtracted averages from individual nestling's measures to assess nestling size and mass in relation to their nest mates. 
Dawn song performance has been implemented in mate choice (Smith, 1966; Chapter 1). Songs are delivered for approximately one hour in the predawn period, and kingbird males continue to sing after their social female has laid eggs (Smith, 1966). One observer per bird per day continuously documented the following characteristics: start time, end time and song length (actual time and relative to civil daylight). I calculated song rate (SR; songs/min), using the average number of songs delivered in the first 30 minutes because this was highly representative of the entire song bout. Most males were observed several times throughout the breeding cycle and song measures were highly repeatable for individuals both within and between breeding seasons (Sexton 2006)

\section{Genetic Analysis}

I used seven microsatellite loci to determine paternity and heterozygosity of nestlings and measure relatedness among social pairs. A full accounting of genetic methods is provided in chapter 1 . Briefly, I optimized and applied markers that were originally developed for other species ( $\mathrm{Li}$ et al., 1997; Pearson, 2002; Richardson et al., 2000; Tarof et al., 2001; Watson et al., 2002). I used the software program CERVUS 2.0 (Marshall et al., 1998) and determined that all loci were in Hardy-Weinberg equilibrium and that the combined probability of exclusion for all 7 loci was 0.998 . Every mother's genotype matched her nestlings at every locus in all three years, indicating that mutations and null alleles were uncommon at these loci. As a result, a nestling was deemed "extra-pair" if it mismatched its social father at one or more 
locus. EP sires were assigned when they matched an extra-pair nestling at all seven non-maternal alleles. I calculated standardized average heterozygosity as the proportion of heterozygous loci/mean heterozygosity of typed loci (Coulson et al., 1999). I calculated pairwise genetic relatedness between females, her social mate and with EP males if they were known using the software package Relatedness 5.0.8 (http://www.gsoftnet.us/GSoft.html).

\section{Statistical analyses}

The distribution of EPY among broods was analyzed based on the use of a multivariate hypergeometric distribution according to the methods outlined in Neuhauser et al. (2001), using a SAS macro (http::www.bioninf.unihannover.de/ neuhaus/macro.sas). This method calculates the expected frequency of EPY in different sized broods given the total number of EPY and the frequency of broods of each size (Charmantier et al., 2004; Neuhauser et al., 2001). Expected versus observed numbers of EPY were then compared using a $\chi^{2}$ analysis. I calculated standardized variance in male and female reproductive success (variance/mean reproductive success ${ }^{2}$; Arnold and Wade, 1984) and tested for a difference between them using an F-Max test, and analyzed the number of EPY, within-pair young (WPY) and total young a male produced using stepwise linear regression with dawn song start time, song rate, NDI and morphological characters as independent variables. Differences between cuckolded WP males and the EP males who successfully sired young in their nest were evaluated using paired $t$-tests with each morphological and 
behavioral character and pair-wise relatedness scores as response variables. I analyzed the influence of the number of sires on brood performance (hatching and fledging success and over-winter survival) using GLM with binomial errors and logit link using the number of young to hatch, fledge and survive to subsequent breeding seasons as response variables, and clutch size as the binomial denominator. I compared tarsus length and body mass (both corrected for age differences of nestlings), relatedness of parents and average heterozygosity of EPY and WPY using $t$-tests. To control for differences among parental and territory quality, I also restricted the latter analyses to mixed paternity nests. Nestling survival was analyzed using stepwise logistic regression in relation to nestling morphology, hatching date and heterozygosity scores.

\section{RESULTS}

\section{Distribution of EPY}

EPP was extremely common and at least $59 \%$ of nests contained one or more EPY in every year (Table 3-2). The proportion of nests containing EPY did not differ significantly among years $(2 \times 3$ contingency table; $P=0.958, d f=2, N=89)$. When data from all three years were pooled, $61 \%$ of nests contained at least one EP nestling representing $47 \%$ of all nestlings (Table 3-2). EPY were not evenly distributed among broods $\left(\chi^{2}\right.$ test, $\mathrm{P}<0.001, \mathrm{df}=13 ;$ Fig. $\left.3-1\right)$. The exclusion of nests with only a single nestling caused no qualitative and almost no quantitative change in the results. Nonrandomness was due to an excess of nests that contained no or all EPY. 


\section{Variance in male reproductive success}

Within a breeding season, a male averaged 2.3 young $(\mathrm{SD}=2.09)$, but success ranged between 0 and 9 young. Surprisingly, 21 males sired no offspring at all, while 12 males sired all the young in their nest and sired at least one EPY as well. Females showed less variability in the number of young they produced. On average, females produce $3.0(\mathrm{SD}=0.91)$ nestlings, ranging between 1 and 5 . As a result, the standardized variance in male reproductive success (the number of young a male sired; 0.85) was 9.4 times greater than for female reproductive success $(0.09)$, a highly significant difference $\left(F_{\mathrm{MAX}}\right.$ test, $\left.\mathrm{P}<0.001\right)$.

\section{Male quality}

I compared (paired t-test) the morphological measurements of 41 pairs of males in which one male gained paternity ("winner") at the expense of the other ("loser"). Song and nest defense index data were also available for 21 of the 41 pairs. Winners sang faster $(t=2.35, \mathrm{n}=21, P=0.03)$ and started singing earlier $(t=-3.14, \mathrm{n}$ $=21, P=0.005)$ than losers. Winners also had longer $\operatorname{tarsi}(t=2.2, \mathrm{n}=40, P=0.03)$ and tended to have longer tails $(t=1.76, \mathrm{n}=40, P=0.09)$ than losers. The stepwise linear regressions showed that dawn song start time was the only variable to ender the model as a predictor of number of EPY sired $(r=0.401, t=-2.66, \mathrm{n}=39, P=0.014)$ and total number of young $\operatorname{sired}(r=0.318, t=-2.37, \mathrm{n}=39, P=0.023)$. The number of WPY a male sired was related to NDI during the incubation period $(r=0.285, t=$ $2.09, \mathrm{n}=39, P=0.043)$. However, the probability that a male survived to the 
following breeding season was not associated with the number of young he sired, his morphology or song characters (Table 3-3). The proportion of nestlings that returned in the following breeding season was also independent of male characters (bill, tarsus and wing-chord lengths, song start time and song rate; Table 3-4).

\section{Brood performance}

Hatching failure was uncommon. Only 19 out of 308 eggs did not hatch (6\%), and 9 of the 19failed due to either environmental conditions (e.g. wind; $n=4$ ) or human intervention $(n=5)$. Six of the remaining eggs showed no evidence of development, and thus no DNA, and could not be used for genetic analysis. Of the four remaining eggs, two were in an abandoned nest, one was in a mixed paternity nest and one was in a nest sired only by the WP male. Due to the low numbers of unhatched eggs, I carried out the brood performance analysis on the fledging and over winter survival of nestlings. In nests with complete genetic data and parental morphology data, 210 nestling fledged and 45 of those nestlings survived and were resighted in subsequent breeding seasons. The number of males who fertilized a female's brood had no relationship to fledging success or the over-winter survival of her nestlings (GLM, fledging: $\chi^{2}=0.347 ; \mathrm{df}=85, P=0.845 ;$ Over-winter survival: $\chi^{2}=0.596, \mathrm{df}=85, P$ $=0.742)$.

\section{Nestling comparisons}

Comparisons of all WPY to all EPY failed to demonstrate any differences in body 
mass, tarsus length, average heterozygosity or parental relatedness. (Table 3-5). The same results emerged from the comparisons of EP and WP young in mixed paternity nests except that EPY had significantly longer tarsi than their WP siblings (Table 3-6). The probability that a nestling survived to fledge was influenced by mass and tarsus lengths and hatch date such that heavy, early hatched nestlings with long tarsi were the most likely to survive (Table 3-7). Heavy female nestlings with long tarsi were more likely to return in the following breeding season whereas the probability that a male nestling returned was dependent upon hatch date (Table 3-8). However, the relatedness of parents and average heterozygosity did not predict nestling survival (Table 3-8).

\section{DISCUSSION}

Griffith et al. (2002) suggested that to distinguish among the four genetic hypotheses proposed to explain female EP behavior it was necessary to have information to describe the distribution of EPY (1) among broods (2) among males and to be able to (3) compare characteristics and outcome of EPY and WPY. I was able to address all three, and in addition was able to examine survivorship of adults and nestlings. Few studies have simultaneously investigated all four hypotheses simultaneously (but see Charmantier et al., 2004)

EPY were not randomly distributed among nests because a paucity of nests contained an intermediate number of EPY. Some males were highly successful at the expense of other males, and accordingly the variance in male reproductive success was 
9.4 times greater than the variance in female reproductive success. My other work on this population demonstrated a positive relationship between male EP success and both tarsus length and dawn song start time (Chapter 2). Direct comparisons of successful EP sires and cuckolded WP males augmented this relationship and indicated that EP males were larger in linear measurements (tarsus length) and showed greater song performance (faster song rate and earlier dawn song start times). Thus, EP sires were not chosen randomly, and instead were larger and gave a stronger song performance than a female's WP mate.

The fertility insurance hypothesis (Freidel and Klump, 2005; Krokene et al., 1998; Wetton and Parkin, 1991) was very difficult to assess due to low numbers and the distribution of unhatched eggs. Most unhatched eggs were either in nests that failed due to stochastic events (e.g. wind) or were in nests in which there was no genetic information and therefore insufficient data to determine the number of males a female mated with. In addition, I did not examine the perivitelline membranes for evidence of fertilization. As such, the unhatched eggs represent both unfertilized eggs and cases of early nestling mortality (Kempenaers et al., 1996; 1999). However, the primary predictions of the fertility insurance hypothesis, that EPY are distributed randomly among (1) nests and (2) males and that (3) variance of male and female reproductive success are roughly equal, were all rejected.

The genetic diversity hypothesis made similar predictions regarding the distribution of EPY and variance in reproductive success. Charmantier et al.'s 2004, study of three populations of blue tits (Parus caeruleus), also found a non-random 
distribution of EPY and rejected the genetic diversity hypothesis as an explanation as to why blue tit females seek EPCs. However the later study did not test this hypothesis' prediction that brood performance (e.g. survival) should be greatest for broods sired by multiple males. I performed these analyses and found no relationship between the proportion of a brood that fledged or survived to the following breeding season and the number of sires that fertilized a brood. Most support for this hypothesis has come from comparisons of populations with large differences in EPP rates and genetic diversity (Kempanaers and Dohndt, 1993; Petrie et al., 1998; Wesneat et al., 1990). As such, Griffiths et al. (2002) suggest this hypothesis may be most properly applied on the population level, although evidence contradicting this hypothesis on a larger scale exists as well (Charmantier and Blondel, 2003; Griffith et al., 1999; Puurtinen et al., 2005).

Several results were likewise inconsistent with the genetic compatibility hypothesis and lead to its rejection. There was no difference in the relatedness of females to successful EP sires compared to the female and her social WP male. Females therefore did not appear to choose EP sires based on genetic dissimilarity, a requirement of the compatibility hypothesis. EPY did not possess more heterozygous alleles than their WP half siblings, which was the expectation if less related males were chosen as EP sires. Perhaps most damaging, the relatedness of parents did not predict the probability of a nestling's over-winter survival. My results stand in contrast with recent studies in which relatedness predicted EP mate choice (e.g. Freeman-Gallant 2003; Krokene and Lijfield, 2000; Tarvin et al, 2005). Although 
Johnsen et al. (2000) demonstrated a relationship between parental compatibility and immunocompetence (a presumed indicator of nestling fitness), none of these studies directly examined the relationship between nestling survival and relatedness of parents nor did they establish the long-term fitness outcome of mate choice based on that criterion.

My data did support the good genes hypothesis. I found that (1) EPY were distributed non-randomly among broods and males, (2) much higher variance in male reproductive success compared to that of females, (3) specific male traits predicted EP success and that (4) the relatedness of genetic pairs did not differ from that of social pairs. Male quality (measured by preferred characters and total number of young sired) did not predict nestling survival. However, male nestlings that hatched earlier in the season and heavy female nestlings that had long tarsi were more likely to survive to the following breeding season. Previous work in this population has shown that EP males breed significantly earlier (5.5 days) than males who do not sire EPY and this study showed that in mixed nests, EPY had longer tarsi than their WP siblings. Nestlings with long tarsi were more likely to survive until fledging. In addition, early hatched males and heavy female nestlings with long tarsi were more likely to survive into the following breeding season. Thus, nestling survivorship indirectly indicates that females may benefit from EPCs.

Numerous studies have also reported a relationship between male characters and reproductive success (e.g. Forstmeier et al., 2002; Johnsen et al., 2001; Moller and Tegelstrom, 1997; Sheldon and Ellegren, 1999), however few of these have sufficient 
recruitment data to examine survival of nestlings in relation to parental characters and the results are mixed. In the most comprehensive study, Schmoll et al. (2002) found no relationship between nestling recruitment and paternity (WP versus EP) or nestling recruitment and seven aspects of future reproductive success of coal tit (Parus ater) nestlings. Moller (1994) found that barn swallow (Hirundo rustica) nestling longevity was positively related to the social father's tail length, but did not assess paternity. Charmantier et al. (2004) showed higher survival of EPY in one of the three blue tit populations that they studied. My results are consistent with the good genes model of EPP and indicate that female eastern kingbirds procure benefits in the form of more viable young. However, further research into both the survival and long-term reproductive success of nestlings are necessary to further examine tangible benefits to females. 


\section{FIGURE LEGEND}

\section{Figure 3-1}

Comparison of observed and expected number of nests with different levels of extra-pair paternity. The expected number was calculated using a hypergeometric distribution with statistics describing population-level variation in clutch size, and number of extra-pair and within-pair young. 
Table 3-1 Predictions of the four "indirect genetic benefits" hypotheses of female extra pair behavior.

\begin{tabular}{|c|c|c|c|c|c|c|c|}
\hline Theory & \begin{tabular}{|l}
$\begin{array}{l}\text { Distribution of } \\
\text { EPY within } \\
\text { nests }\end{array}$ \\
\end{tabular} & $\begin{array}{l}\text { Successful } \\
\text { males of high } \\
\text { genetic quality? }\end{array}$ & $\begin{array}{l}\text { R between } \\
\text { WP different } \\
\text { than EP sires? }\end{array}$ & $\begin{array}{l}\text { Higher performance } \\
\text { of broods with } \\
\text { mixed paternity? }\end{array}$ & $\begin{array}{l}\text { Mixed nests: } \\
\text { EPY fitter } \\
\text { than WPY }\end{array}$ & $\begin{array}{l}\text { Fittest } \\
\text { offspring }\end{array}$ & Variance in RS \\
\hline $\begin{array}{l}\text { Fertility } \\
\text { insurance }\end{array}$ & Random & No & No & Yes, higher hatching & No & $\begin{array}{l}\text { No predictable } \\
\text { difference } \\
\text { between WPY } \\
\text { and EPY } \\
\end{array}$ & Male $=$ Female \\
\hline $\begin{array}{l}\text { Genetic } \\
\text { diversity }\end{array}$ & Random & No & No & $\begin{array}{l}\text { Yes, number of EP } \\
\text { fathers correlates } \\
\text { with survival }\end{array}$ & No & $\begin{array}{l}\text { No predictable } \\
\text { difference } \\
\text { between WPY } \\
\text { and EPY }\end{array}$ & Male $=$ Female \\
\hline $\begin{array}{l}\text { Genetic } \\
\text { compatibility }\end{array}$ & $\begin{array}{l}\text { No-High } \\
\text { levels when } \\
\text { high within } \\
\text { pair R } \\
\end{array}$ & No & Yes & $\begin{array}{l}\text { No-depends on } \mathrm{R} \text { of } \\
\text { parents }\end{array}$ & $\begin{array}{l}\text { Yes-EPY } \\
\text { more } \\
\text { heterozygous } \\
\text { than WPY }\end{array}$ & $\begin{array}{l}\text { Offspring of } \\
\text { pairs with } \\
\text { lowest R }\end{array}$ & Male $=$ Female \\
\hline Good genes & $\begin{array}{l}\text { No-Bimodal } \\
\text { (many or few } \\
\text { in a nest) }\end{array}$ & Yes & No & $\begin{array}{l}\text { No-depends on } \\
\text { quality of male }\end{array}$ & Yes & $\begin{array}{l}\text { offspring of } \\
\text { most } \\
\text { successful } \\
\text { males } \\
\end{array}$ & Male $\gg$ Female \\
\hline Our results & $\begin{array}{l}\text { No-Bimodal } \\
\text { (many or few } \\
\text { in a nest) }\end{array}$ & $\begin{array}{l}\text { Yes-successful } \\
\text { males larger, } \\
\text { start singing } \\
\text { earlier }\end{array}$ & No & No & Yes & $\begin{array}{l}\text { Largest } \\
\text { females, } \\
\text { earliest born } \\
\text { males }\end{array}$ & Male $\gg>$ Female \\
\hline
\end{tabular}


Table 3-2 Population level patterns of extra-pair paternity divided by year. Numbers in parentheses exclude nests that contained only one nestling.

\begin{tabular}{lllllll} 
Year & Nests & Nests & \% Nests with & Nestlings & EPY & $\%$ EPY \\
& \multicolumn{7}{c}{ with EPY EPY } & & \\
\hline 2002 & $25(23)$ & $15(15)$ & $60 \%(65 \%)$ & $74(72)$ & $32(32)$ & $42 \%(43 \%)$ \\
2003 & $25(23)$ & $16(15)$ & $64 \%(65 \%)$ & $74(72)$ & $39(38)$ & $53 \%(51 \%)$ \\
2004 & $39(36)$ & $23(22)$ & $59 \%(61 \%)$ & $116(113)$ & $53(51)$ & $46 \%(45 \%)$ \\
total & $89(82)$ & $54(52)$ & $61 \%(63 \%)$ & $264(257)$ & $124(121)$ & $47 \%(47 \%)$ \\
\hline
\end{tabular}


Table 3-3 Logistic regression of male over-winter survival by morphological characters. Morphological characters were measured in mm. Number sired includes both WP and EP young sired by a male.

\begin{tabular}{lllll} 
Character & df & $b$ & SE & $P$ \\
\hline Bill & 87 & -0.54 & 0.35 & 0.12 \\
Tarsus & 87 & 0.07 & 0.23 & 0.74 \\
Wing-chord & 87 & -0.11 & 0.09 & 0.21 \\
Song start $^{1}$ & 55 & -0.02 & 0.03 & 0.52 \\
Song rate & 55 & 0.02 & 0.10 & 0.82 \\
Number sired & 87 & 0.12 & 0.11 & 0.25 \\
\hline
\end{tabular}

${ }^{\top}$ Measured in minutes before dawn. 
Table 3-4 GLM of the proportion of a male's offspring that survive into the following breeding season as predicted by male morphological and behavioral characters.

\begin{tabular}{llll} 
Father's characters & df & $\chi^{2}$ & $\mathrm{P}$ \\
\hline Bill & 65 & 2.12 & 0.15 \\
Tarsus & 65 & $>0.001$ & 0.98 \\
Wing-chord & 65 & 0.27 & 0.60 \\
Song start & 37 & 0.10 & 0.75 \\
Song Rate & 37 & 2.32 & 0.13 \\
\hline
\end{tabular}


Table 3-5 Comparisons of nestling parental relatedness, average heterozygosity, mass and tarsus lengths. Mean values, standard deviations and the results of $t$-tests are reported. These analyses included all nestlings for which data were available.

\begin{tabular}{lllll} 
Trait & $\mathrm{N}$ & $\mathrm{WP} \bar{x} \pm \mathrm{SD}$ & $\mathrm{EP} \bar{x} \pm \mathrm{SD}$ & $t(\mathrm{P})$ \\
\hline Relatedness & 180 & $-0.32 \pm 0.15$ & $0.02 \pm 0.26$ & $1.45(0.15)$ \\
Avg. Het & 252 & $0.65 \pm 0.16$ & $0.64 \pm 0.16$ & $-0.61(0.54)$ \\
Mass & 241 & $0.34 \pm 1.37$ & $0.25 \pm 1.45$ & $-0.47(0.64)$ \\
Tarsus & 225 & $-0.14 \pm 1.29$ & $0.08 \pm 1.33$ & $1.22(0.22)$ \\
\hline
\end{tabular}


Table 3-6 Comparisons of nestling parental relatedness, average heterozygosity, mass and tarsus lengths and differences from nest averages. Mean values, standard deviations and the results of $t$-tests are reported. These analyses included only nestlings from mixed paternity nests.

Significant differences are indicated by bold faced type.

\begin{tabular}{lcccl} 
Trait & N & WP $\bar{x} \pm \mathrm{SD}$ & EP $\bar{x} \pm \mathrm{SD}$ & $t(\mathrm{P})$ \\
\hline Relatedness & 60 & $0.003 \pm 0.19$ & $0.062 \pm 1.78$ & $1.20(0.235)$ \\
Avg. Het & 77 & $0.64 \pm 0.17$ & $0.66 \pm 0.15$ & $-0.72(0.475)$ \\
Mass & 68 & $0.16 \pm 1.33$ & $0.23 \pm 1.623$ & $-0.18(0.855)$ \\
Tarsus & 62 & $0.06 \pm 1.16$ & $0.23 \pm 1.53$ & $-0.48(0.634)$ \\
Difference nest mass & 68 & $0.01 \pm 0.67$ & $-0.016 \pm 0.86$ & $0.13(0.9)$ \\
Difference mean tarsus & 62 & $-0.17 \pm 0.55$ & $0.17 \pm 0.60$ & $\mathbf{- 2 . 2 5 ( 0 . 0 2 8 )}$ \\
\hline
\end{tabular}


Table 3-7 Stepwise logistic regression of nestling survival to fledging as predicted by hatch date, tarus length, mass and average heterozygosity. All nestlings are considered together and separated by sex. Significant interactions are indicated by boldfaced type.

\begin{tabular}{llllll} 
& $\mathrm{N}$ & Model & $\boldsymbol{b}$ & $\mathrm{SE}$ & $\mathrm{P}$ \\
\hline All nestlings & 220 & Hatch date & -0.13 & 0.04 & $\mathbf{0 . 0 0 4}$ \\
& & Tarsus & 0.77 & 0.23 & $\mathbf{0 . 0 0 9}$ \\
& & Mass & 0.73 & 0.22 & $\mathbf{0 . 0 0 9}$ \\
Male nestlings & \multirow{2}{*}{115} & Tarsus & 0.83 & 0.33 & $\mathbf{0 . 0 1 1}$ \\
& & Mass & 1.19 & 0.37 & $\mathbf{0 . 0 0 1}$ \\
Female nestlings & \multirow{2}{*}{105} & Hatch date & -0.22 & 0.07 & $\mathbf{0 . 0 0 1 5}$ \\
& & Tarsus & 0.85 & 0.33 & $\mathbf{0 . 0 1}$ \\
& & Mass & 0.75 & 0.35 & $\mathbf{0 . 0 3 4 2}$ \\
\hline
\end{tabular}


Table 3-8 Stepwise logistic regression of nestling over-winter survival as predicted by hatch date, tarsus length, mass and average heterozygosity. All nestlings are considered together and separated by sex. Significant interactions are indicated by boldfaced type.

\begin{tabular}{lcllll} 
& $\mathrm{N}$ & Model & $b$ & $\mathrm{SE}$ & $\mathrm{P}$ \\
\hline All nestlings & 220 & Mass & 0.25 & 0.2 & $\mathbf{0 . 0 2 8}$ \\
Male nestlings & 115 & Hatch date & -0.06 & 0.03 & $\mathbf{0 . 0 5}$ \\
Female nestlings & 105 & Mass & 0.82 & 0.28 & $\mathbf{0 . 0 0 4}$ \\
& & Tarsus & 0.8 & 0.29 & $\mathbf{0 . 0 0 8}$ \\
\hline
\end{tabular}


Figure 3-1

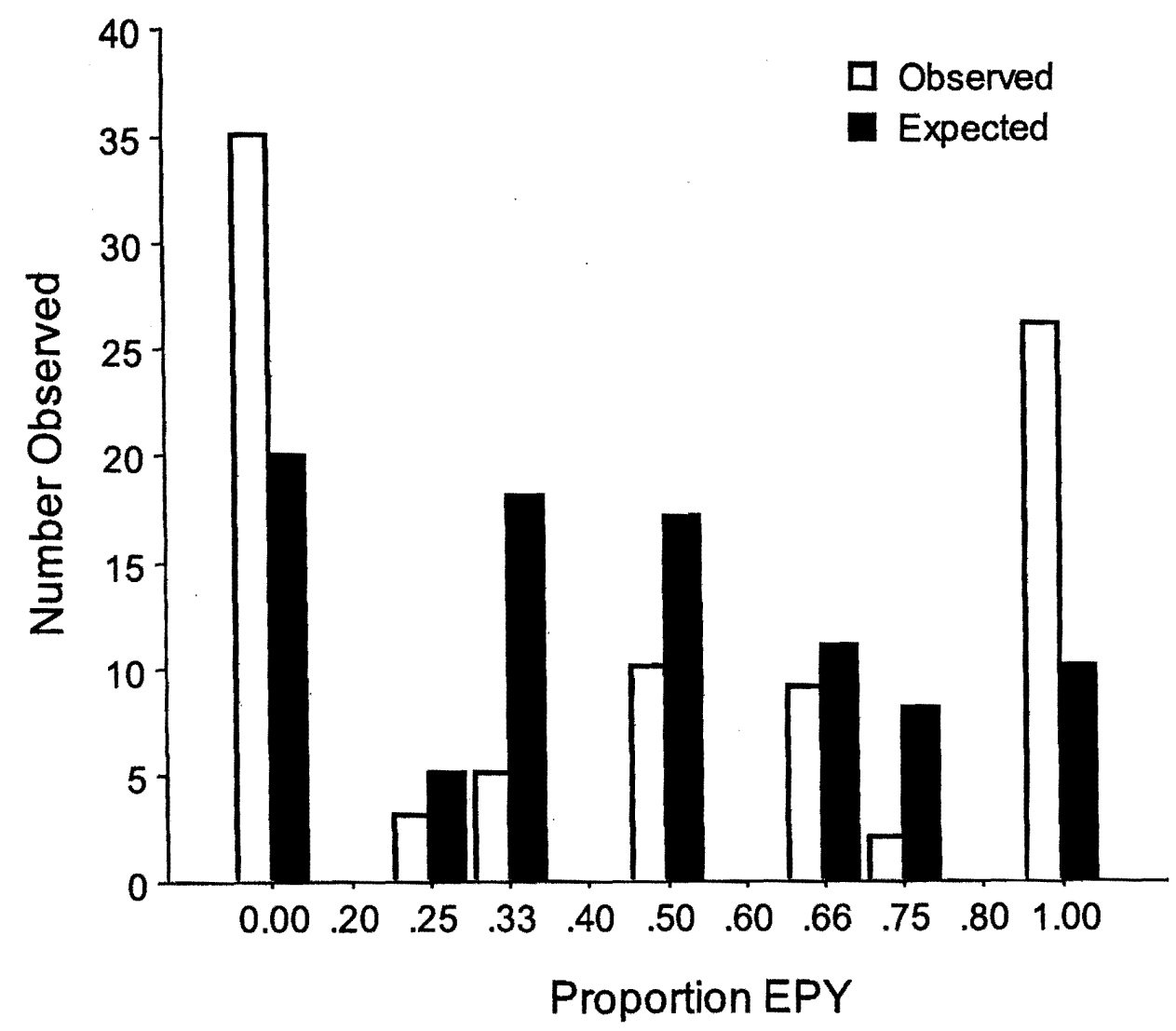




\section{CHAPTER 4- EASTERN KINGBIRD BROOD SEX RATIO DEPENDENT UPON FEMALE CONDITION AND CLUTCH INITIATION DATE, NOT MALE EXTRA-PAIR SUCCESS}

\section{INTRODUCTION}

Trivers and Willard (1973) predicted that parental manipulation of offspring sex ratio should occur when there are sex specific differences in the reproductive value of offspring. Although the mechanism remains largely unelucidated, female birds are the heterogametic sex and empirical evidence suggests that they are capable of brood sex ratio (BSR) manipulation (reviewed in Pike and Petrie, 2003). Accordingly, a relationship between BSR and the factors that most profoundly affect the offspring's reproductive value is predicted, and a spate of recent studies have demonstrated a relationship between offspring sex ratio and territory quality (Appleby et al., 1997; Dzus et al., 1996; Hipkiss and Hornfeldt, 2004; Komdeur et al., 2002), breeding date (Cordero et al., 2001; Daan et al., 1996; Dijkstra et al., 1990; Genovart et al., 2003; Janota et al., 2002; Velando et al. 2002; Zijlstra and Bruinenberg-Rinsma, 1992), parental condition (Nager et al., 2000; Parker, 2002; Rathburn and Montgomerie, 2004; Svensson and Nilsson, 1996; Whittingham and Dunn, 2000; Whittingham et al., 2005) and secondary sexual characters (Ellegren et al., 1996; Sheldon et al., 1999; Pike and Petrie, 2005).

The existence of polygynous mating systems and the widespread occurrence of extra-pair paternity (EPP) in socially monogamous species (Griffiths et al., 2002; 
Westneat and Sherman, 1997) often generates greater variance in reproductive success of males than females and correspondingly, the potential for larger fitness returns for male offspring (Anderson et al., 1994; Whittingham et al., 2002). Assuming that parental characters and condition are at least partially heritable, parental attributes that most influence the future reproductive success of offspring are predicted to lead to adaptive adjustments to offspring sex ratio. For instance when nestling condition is at least partially determined by maternal condition or natal environment females in good condition are predicted to produce a higher proportion of sons in species in which male reproductive success is dependent upon size and or condition (Hipkiss and Hornfeldt, 2004; Parker, 2002). Furthermore, females in poor condition should also bias clutches towards the less expensive sex to produce and provision. Thus, if male eggs and nestlings are typically larger, females in poor condition should produce female-biased clutches (Nager et al., 1999).

If secondary sexual characters influence male reproductive success and sons inherit characteristics that determine attractiveness from their fathers, male characters may play a larger role in determining the fitness of sons than daughters. Females who mate with attractive males should therefore bias BSR toward male offspring because their sons are more likely to inherit attractive secondary sexual characters and subsequently enjoy higher reproductive success. Male secondary sexual characters correlate with BSR in some (Ellegren et al., 1996; Pike and Petrie, 2005; Sheldon et al., 1999) species, but more importantly, manipulation of these characters has been shown to alter sex ratios in the predicted direction (Ellegren et al., 1996; Pike and 
Petrie, 2005; Sheldon et al., 1999). Because secondary sexual characters have been shown to correlate with EP success, one would therefore expect that successful EP males would sire more sons. However, this has generally not been shown to be the case (Sheldon and Ellegren, 1996) possibly due to inaccurate BSRs when complete paternity information is not available. For instance, when the identity of EP sires is not known, most studies analyze BSR of the within-pair young (WPY) in relation to male characters. However, this ignores the possibility that within-pair (WP) males frequently lose paternity and successful EP males sire young in other nests (Kempenaers et al., 1997; Thusius et al., 2001; Webster et al., 2001). Thus, sons of successful males are only examined in light of the WP male's characters rather than those of their genetic sire. Therefore, to have a relatively complete test of the influence of the genetic sire on offspring sex ratio the identity of EP sires should be known.

However, if natal conditions and the quality of care provided by a female's social partner are the primary determinants of a nestling's future prospects of survival and reproductive success, then offspring sex ratio may be related more strongly to the condition of a female's social mate than the condition of her genetic mates (Rathburn and Montgomery, 2005). On the other hand, a male's condition may reflect his ability to provide parental care (Badayev et al., 2002), and in species with biparental care, this could significantly influence the condition, survival prospects and future reproductive success of nestlings. For instance, the size of male house sparrow's forehead patch size (a trait associated with both within-pair and extra-pair success) was positively correlated to the size of their foster father's forehead patch size, but not 
that of their genetic father (Griffith et al., 1999). Because male offspring are often larger, grow faster and, as adults, exhibit greater variance in reproductive success, a female could gain by biasing her clutches toward the more expensive sex when paired socially to a high quality parent. Females likely spend more time with social mates than EP males before laying eggs, which would allow ample time to assess social pair male quality.

Extrinsic factors, such as territory quality and temporal characteristics such as laying date, have also been shown to correlate with BSR. For instance, both correlative (Appleby et al., 1997; Dzus et al., 1996; Hipkiss and Hornfeldt, 2004; Komdeur, 1996; 2002) and experimental studies (Hornfeldt et al., 2000; Komdeur, 1996) support predictions of greater production of the more expensive sex on high quality territories (measured as food abundance). Laying date may influence BSR when there is a sex specific difference in the relationship between hatch date and age at first breeding or survival (Daan et al., 1996). Accordingly, seasonal variation of sex ratio has also been demonstrated in many species such that early broods are biased toward the sex whose survival or chance of reproducing in the following breeding season is most profoundly affected by hatching early in the season (Cordero et al., 2001; Daan et al., 1996; Dijkstra et al., 1990; Genovart et al., 2003; Janota et al., 2002; Velando et al., 2002; Zijlstra and Bruinenberg-Rinsma, 1992).

In this paper I describe sex ratio variation in eastern kingbird (Tyrannus tyrannus) and evaluate the role of (1) maternal condition, (2) paternal quality, (3) social male quality, (4) territory quality and (5) timing of breeding as sources of 
variation of BSR. When EPP is common, brood sex ratio does not necessarily accurately represent the sex ratio of a male's offspring because extra-pair young (EPY) are not included. Therefore, to tease apart the influences of environmental, maternal and social mate's characteristics on the sex ratio, I examined sex ratio from both female and male perspectives. For females and social males, I calculated BSR as the proportion of the brood comprised of males. But, in an attempt to account for EPY of successful sires, I examined progeny sex ratio (PSR) where PSR is the proportion of offspring sired (both WP and EP young) that were male. To assess the costs of producing males versus females I examined differences between male and female nestling morphology, and evaluated the benefits of sex ratio manipulation, by examining the relationship between male and female nestling survival in relation to breeding date and both and territory and parental characters.

Although eastern kingbirds are strictly socially monogamous they demonstrate very high levels of extra-pair paternity and three studies have shown that $60 \%$ of nests contain at least one extra-pair young, and that $45 \%$ of nestlings are of extra-pair origin (McKittrick, 1989; Rowe et al., 2001; Chapter 2). Male reproductive success is highly skewed and variance in male reproductive success is over nine times greater than that of females. Females could thus benefit by biasing BSR toward males if they mate with attractive males and sons inherit their father's attractive characters. I therefore predicted that offspring sex ratio would be dependent upon the characters of genetic sires (defined in Table 4-1) in that characters that positively correlated with male reproductive success (Chapter 2; song start time, nest defense response [NDI] and 
tarsus length) would also positively correlate with PSR. I further predicted females benefited from sex ratio manipulation in that over-winter survival of sons should be positively related to genetic sires' characters and success (Table 4-1; song start time, NDI, tarsus length and total number of young sired).

\section{METHODS}

\section{General field methods}

As part of an ongoing investigation of the reproductive biology of eastern kingbirds, I studied a banded population that bred at Malheur National Wildlife Refuge (MNWR), Harney County, OR between May and July, 2002-2004. The birds nested in trees along a narrow riparian corridor of the Donner und Blitzen River that cuts through the Great Basin Desert. Water flows year-round and creates extensive marshes and wet meadows that are surrounded by high elevation $(\sim 1400 \mathrm{~m})$ desert scrub in which kingbirds do not nest. MNWR is thus an ecological island and kingbirds nest as a linear arrangement of dense breeding territories. An unimproved road runs parallel to the river, which gave ready access to nests. Population size averaged $\sim 55$ pairs (5259) over the study period.

Eastern kingbirds are socially monogamous, long-distance migrants with relatively high annual survival (65-70\%; Murphy, 1996; Murphy 2000). They defend small, all-purpose territories (Smith,1966) and at MNWR average distance to the nearest nest is $\sim 250 \mathrm{~m}$. Females raise a single brood and alone build nests, incubate 2- 
5 egg clutches and brood young. Males perform the majority of nest vigilance and defense, and contribute to the feeding of nestlings, but at only half the rate of females (Woodward and Murphy, 1999). Nest success is generally below $50 \%$, but failed nests are replaced and clutches are therefore laid over a 6 to 7 week period. Details of nest searching and monitoring are provided elsewhere (Chapter 2), but it suffices to say that my monitoring of nests (at least every $2-3$ days) permitted accurate determination of laying dates, clutch size, hatching success and fledgling production.

Adults were captured using mist nets placed near nests and were banded with a unique combination of one numbered aluminum Unite States Fish and Wildlife band and three color plastic leg bands. I took a small blood sample (approximately $50 \mu \mathrm{l}$ ) from the brachial vein and measured body mass to the nearest $0.1 \mathrm{~g}$ with a $50 \mathrm{~g}$ or 100 $\mathrm{g}$ Pesola scale. I also measured unflattened wing-chord to the nearest $0.5 \mathrm{~mm}$ with a stopped wing ruler and the lengths of the tarsometatarsus (henceforth tarsus), bill and tail to the nearest $0.1 \mathrm{~mm}$ with dial calipers. Sex was determined by examining a combination of traits including primary feather structure, morphology (Pyle, 1987) and presence/absence of cloacal protuberance (males only) and brood patch (female only). I identified individuals who returned to the study site in the years following banding by either recapture or resightings of their band combination. I did not always recapture individuals and in such cases, I used tarsus and bill measures from the previous breeding season as those measures are highly repeatable (Murphy, 2004). All other morphological characters were only used in analyses if they were taken in 
the same year for which sex ratio information were available. Sample sizes thus vary among analyses. I measured nestlings (mass and tarsus, bill and $9^{\text {th }}$ primary lengths) and took blood samples of young at 5-13 days of age. Adult and nestling blood samples were immediately mixed with $1 \mathrm{ml}$ of Longmire's Buffer (Longmire et al., 1988) then stored at $4^{\circ} \mathrm{C}$. I obtained samples from 89 complete nests (i.e. mother, social father and nestlings; 25 nests in both 2002 and 2003 and 39 nests in 2004), including 267 nestlings (74; in both 2002 and 2003 and 119 in 2004).

\section{Sex determination and paternity analysis}

I extracted DNA from $100 \mu$ l of buffered blood using a Qiagen Dneasy extraction kit (Qiagen, Valencia, CA 91355; \#69504) using the protocol for whole-nucleated blood. I used the $2550 \mathrm{~F} / 2718 \mathrm{R}$ primers to amplify the $\mathrm{CHD} 1 \mathrm{~W}$ and $\mathrm{CHD} 1 \mathrm{Z}$ introns that are found in different lengths on the $\mathrm{Z}$ and $\mathrm{W}$ chromosomes. Females, the heterogametic sex, exhibited two amplified bands whereas males exhibited a single band (Fridolfsson and Ellegren, 1999). PCR reactions were amplified in $25 \mu 1$ reactions according to the conditions in Fridolfsson and Ellegren (1999). Amplified fragments were run on 2\% agarose gels and stained using ethidium bromide. Twenty adults of known sex were tested to confirm the primer's accuracy, and male nestlings (homozygotes) were retested to double check for errors in amplification.

Parentage of nestlings was described in detail elsewhere (Chapter 2). Briefly, I compared nestling and adult genotypes at seven microsatellite loci (Li et al., 2001; 
Pearson, 2002; Richardson et al., 2000; Tarof et al., 2000; Watson et al., 2002) that amplified a total of 80 alleles and the combined probability of exclusion was 0.998 . I confirmed maternity assignment by direct comparison of mother and offspring genotypes. Every nestling genotype matched the putative mother at every locus, indicating mutation events and nonamplifying alleles were rare or absent. I determined paternity by direct exclusionary analysis using the nestling's non-maternal genotype. The social male was deemed to be the genetic father if he shared all seven non-maternal alleles with the offspring. When mismatches occurred, I compared the nestling's genotype to all other males in the population for which data were available o identify probable sires.

\section{Parental characteristics}

I used morphology, body condition and behavior to evaluate parental quality. Body mass increased over the course of the day and declined seasonally. My analyses therefore used residual mass that I obtained from a multiple linear regression of body mass against time and date. I then measured condition as residual mass divided by tarsus. I used this measure of condition because in studies of other species it has been shown to be positively related to lipid reserves and survival probability (e.g. Bachman and Widemo, 1999; Linden et al., 1992).

I also used nest defense and song behavior as measures of parental quality because they correlated with male WP and EP success, respectively (Chapter 2). To assess parental investment, I measured kingbird response to the presentation of a 
taxidermic mount of an american crow (Corvus brachyghynchos), a common nest predator. I chose nest defense behavior to assess parental investment because the vast majority of nest failures are the result of predation and therefore nest defense should have a strong influence on nestling production (Blancher and Robertson, 1982). Highly defensive males may therefore be "attractive" to females and preferred as mates or sires. I quantified behaviors according to Blancher and Robertson's (1982) methods. Briefly, one person held a mount of a perched crow that was attached to a 3 $\mathrm{m}$ pole within $\sim 1 \mathrm{~m}$ of the nest. During a five minute trial, two observers (one for each parent $)$ recorded responses on a scale of 1 to $5(1=$ calling, $2=$ approaching the mount, 3 = hovering near the mount, $4=$ diving at the mount, $5=$ striking the mount). Observations were carried out between 0900 and 1200, once during incubation and once during the nestling period when the nestlings were 6 to 8 days old. Behaviors 1 and 2 were uninformative because they were performed by all birds and therefore, I used the number of times behaviors 3,4 , and 5 were performed to generate a nest defense index (NDI) using the following equation:

$$
\mathrm{NDI}=\log \left((\Sigma \text { hover }+1)^{*}(\Sigma \text { dive }+1)^{*}(\Sigma \text { strike }+1)\right)
$$

I added 1.0 to all behaviors to account for zeros. NDI was repeatable both between and within years (Redmond 2005).

Song represents a form of reproductive investment that may or may not conflict with parental investment, but regardless, song likely yields information on male quality (Forstmeier, et al., 2002; Hasselquist et al., 1996). Male kingbirds deliver a ritualized dawn song for approximately one hour in the predawn period 
darkness, preventing a person from recording data from more than a single bird/day. I therefore worked with a team of 2 to 4 people to record the following song variables for 3 to 5 territory holding males/day: start time, end time (actual time and relative to civil daylight), song length (absolute difference between start and end time) and three measures of song rate. Average song rate (30MinRate) was the average number of songs/minute over the first 30 minutes of song. Actual song rate (ActualRate) was measured as the average number songs per minute omitting minutes of silence, and maximum song rate (PeakRate) was the average song rate for the five continuous minutes of highest song production Males continue to sing well into their social mates' nestling period (Sexton, 2006), and as a result, most males were observed several times throughout the breeding cycle. Song measures were highly repeatable for individuals both within and between breeding seasons (Sexton, 2006), therefore I used average values for all song variables for each male.

I also evaluated male and female quality using reproductive performance. I evaluated female reproductive success using the total number of young produced, as well as by whether they included extra-pair young in their clutch. I divided males into six reproductive success groups based on their within-pair success (all, some or none) and whether they sired extra-pair young (yes or no). I also assessed male reproductive success using the total number of young sired (WP + EP), and tested the hypothesis that a female's social mate choice rather than genetic mate choice influenced sex allocation by analyzing female BSR by her social mate's characteristics (condition, size, NDI, dawn song start time, song rates, reproductive success). 


\section{Territory quality}

Insect abundance on kingbird territories was estimated in 2003 and 2004 using a modification of Blancher and Robertson's (1987) visual estimation approach. Weekly (2003) or biweekly (2004) counts of flying insects ( $\geq 5 \mathrm{~mm}$ in length) were conducted in four replicates of each habitat type present in the study area (willow, wet meadow, marsh and open water/pond) during 3 minute visual observations. Insects that passed between the observer and a $1 \mathrm{~m}^{2}$ white background were counted. Date, air temperature, wind speed and relative humidity were recorded prior to each count and their effects removed (multiple regression analysis) before I averaged within habitat types to establish mean insect abundance for each habitat. Insect abundance for a kingbird territory was calculated as the sum of the proportion of each habitat type within a $100 \times 100 \mathrm{~m}$ square centered on a nest, multiplied by mean insect abundance for that habitat type (for a complete description see Redmond, 2005).

\section{Nestling characteristics}

I evaluated nestling quality using nestling mass, tarsus length characters and observations of recruitment into the adult population in subsequent breeding seasons. I determined the age of the nestlings during the nestling periods through direct knowledge of hatching date or comparison of $9^{\text {th }}$ primary length to standard growth curves (Murphy 1981). 


\section{Statistical analyses}

I tested whether sex ratio differed from parity using a Wilcoxon signed-rank test, which used each brood as a data point, and thereby accounted for nonindependence of nestlings within the same brood. I tested for differences in population BSR among years using a $2 \times 2$ contingency table. Within a brood, BSR was recorded as the number of males divided by the total number of offspring sexed (arcsine square root transformed). I compared BSR among male paternity groups (for description see Chapter 2) using a Kruskall-Wallace analysis of variance, and examined sex ratio by female EP behavior by comparing the BSR between females who did or did not acquire EP fertilizations with analysis of variance (ANOVA). I also generated sex ratio groups (SRGs) by dividing adults according to whether they produced all sons (SRG 1), a mix of sons and daughters (SRG 2) or all daughters (SRG 3) and analyzed adult characters amongst SRGs using ANOVA.

I recorded calendar date (May $\left.1^{\text {st }}=1\right)$, and because the average clutch initiation date occurred significantly later ( 8 days) in 2004 than in 2002-2003. I also standardized dates relative to the average date clutches were initiated each year. I examined BSR/PSR in relation to temporal, ecological and parental characteristics in two ways. First, I examined sex ratio in relation to male and female characteristics using stepwise linear regression with insect abundance, standardized date, condition, size, NDI, dawn song start time, song rates and reproductive success as predictor variables. Secondly, I used generalized linear models (GLM) with binomial errors and 
logit links, where the number of male offspring was the response variable, and total number of offspring sampled in a brood was the binomial denominator. This analysis avoided the problems associated with nonnormal variances present in proportional data. Significance was determined by the change in model deviance including and excluding predictor variables, which is distributed approximately as a $\chi^{2}$ (McCullagh and Nelder 1983).

Nestling mass and size increased with age, and to correct for this effect I used the residuals that I obtained from a linear regression of nestling characters against age. I analyzed whether nestling survival and morphological characters differed according to sex using logistic regression, with the binomial variable "sex" as the dependent variable, and within nests compared male and female siblings to directly assess sex effects without parental/natal environmental effects using $t$-tests to determine if males or females were heavier or larger than average within their nest. This removed the differential effects of parental quality at a particular nest. I carried out GLM analysis using the statistical package GLMstat@ 6.0.0 Software (Ken Beath; www.ozemail.com.au/kjbeath/glmstat.html, Belmont, NSW, Australia). All other analyses were performed using the statistical package STATISTIX, v. 8.0 (Analytical. Software, Tallahassee, FL, USA).

\section{RESULTS}

\section{Paternity results}

The microsatellite analysis provided high power to assign parentage as the total 
exclusion probability of all loci combined was $>0.998$ and all loci were in HardyWeinberg equilibrium. Extra-pair paternity was frequent in all years, and accounted for $47 \%$ of all young (Chapter 2). Mother and offspring genotypes always matched, indicating an absence of intraspecific brood parasitism and mutation. In each season, females produced between 1 and 5 nestlings (mean $=3$ ), but males sired between 0 and 9 nestlings. I determined the identity of the genetic fathers of 211 of 267 (79\%) nestlings (2002 through 2004 combined). Due to the high incidence of extra-pair paternity, the offspring of male and female individuals represent different subsets of nestlings. Henceforth, I refer to the offspring sex ratio of (1) a female's brood as BSR (proportion of male offspring produced by a female), (2) a social male's BSR (proportion of male offspring within a male's nest) and (3) the progeny sex ratio (PSR) of a male's progeny (proportion of males of total offspring sired [WP + WP]). This makes it possible to separately examine the influence of WP males on the sex of the offspring in their nest (BSR) and the influence of genetic sires on the sex of all their progeny (PSR), both WP and EP.

\section{General sex ratio patterns}

Broods tended to contain more males than females 2002 and 2003, although the difference from parity was not significant $(P=0.16)$. Likewise, the number of males and females produced did not differ among years (Table 4-2). Female's offspring sex ratio ranged from $0-1$, with fourteen broods being comprised completely of males and eleven comprised completely of females (Table 4-2). Thirteen males sired only male 
offspring, whereas 10 males sired only female offspring (Table 4-2).

\section{Food abundance, female condition, date and BSR}

Insect abundance on territories did not differ between females who did $(\bar{x}=6.96 \pm$ $1.99, \mathrm{n}=40)$ or did not $(\bar{x}=7.42 \pm 2.49, \mathrm{n}=24)$ have EPY in their brood $(t=0.77, d f$ $=62, P=0.442)$, or among female SRGs (Table 4-3). Food supply was significantly greater in 2003 than in 2004 (Redmond, 2005), and average BSR tended to be more male-biased in 2003 (Table 4-2), but not significantly so. Thus, on an annual level there was a weak tendency (Table 4-2; $P=0.07$ ) for a higher proportion of females to be produced under conditions of lower food abundance, but local food supply and BSR were independent of one another.

There was no difference in BSR between females who did $(\bar{x}=0.547 \pm 0.300$, $\mathrm{n}=55)$ or $\operatorname{did} \operatorname{not}(\bar{x}=0.525 \pm 0.291, \mathrm{n}=34)$ produce EPY $(t=0.77, d f=87, P=$ 0.790 ), or condition of females between either group (EPY in nest: $\bar{x}=-0.018 \pm 0.14$, $\mathrm{n}=38$; no EPY in nest: $\bar{x}=-0.067 \pm 0.163, \mathrm{n}=21 ; t=-1.23, d f=57, P=0.226)$. Females in SRG 1 (male only broods) were in better condition than females who produced mixed sex or female only broods (Table 4-3). However, female condition did not differ among years $(F=0.21, \mathrm{n}=60, d f=2, P=0.809)$ and was independent of insect abundance $(r=0.05, \mathrm{n}=40, P=0.751)$.

Comparisons of SRGs revealed that females who produced only male offspring bred five days earlier than females who produced mixed sex broods and 10 days earlier than females who produced all female broods (Table 4-3). Based on analysis of 
variance, the difference only approached significance, but a least squares linear regression established that BSR declined with calendar date of clutch initiation ( $r=-$ $0.290, \mathrm{n}=73, \mathrm{P}=0.013)$, but not with standardized date $(r=-0.184, \mathrm{n}=73, P=$ $0.101)$.

Females in better condition also tended to produce male-biased clutches $(r=$ $0.235, \mathrm{n}=60, P=0.07)$. Female condition accounted for $8.4 \%$ of the variation in BSR ( $\mathrm{n}=60 ; P=0.013)$. The GLM analysis showed that BSR declined with date $\left(\chi^{2}=\right.$ $62.95, d f=71, P=0.013)$ and failed to detect a significant effect of condition on BSR $\left(\chi^{2}=49.51, d f=58, P=0.488\right)$. However, examination of the partial plots identified one point as a statistical outlier (Mahalanobis distance $=4.694, P=0.05$ ). I removed the outlier from the analysis, reran the GLM and performed a multiple regression analysis of BSR with date and condition entered as variables to test for their independent effects. The outlier's removal from the linear regression produced a significant relationship between BSR and both condition $(P=0.015$; Figure 4-1) and clutch initiation date $\left(P=0.004, \mathrm{R}^{2}\right.$ of 2 -variable model $=17.7 \%$; Figure $\left.4-2\right)$. Results of the GLM were similar: both condition $(P=0.041)$ and date $(P=0.048)$ contributed significantly to the 2-variable model (model: $\chi^{2}=37.33, d f=51, P=0.05$ ). In summary, BSR was independent of a female's EP mating behavior, and food availability, but male-biased broods were common early in the breeding season, and although less conclusive, appeared to be produced more commonly by females of above average body condition. 


\section{BSR and social and genetic pair characteristics}

Condition did not differ between males who did $(\bar{x}=-0.02 \pm 0.095)$ or $\operatorname{did} \operatorname{not}(\bar{x}=$ $0.02 \pm 0.098)$ lose paternity $(t=1.15, d f=61, P=0.13)$, and BSR was independent of social male condition (Table 4-3). PSR also failed to differ between male paternity groups (Table 4-4; Kruskall-Wallace test $\mathrm{H}=6.11, \mathrm{n}=67, P=0.296$ ), but somewhat surprisingly, genetic males that sired only male offspring (SRG 1) were in poorer condition than males in other SRGs (Table 4-3). Neither song behaviors nor nest defense behavior differed among SRGs for either social fathers or genetic fathers (Table 4-3). Analysis of PSR against male characters using least squares linear regression yielded similar results. Males in poor condition sired a higher proportion of male offspring, but all other characters, including tarsus length, NDI, song performance and total number of young sired were independent of PSR (Table 4-5).

However, given my previous demonstration of the effect of calendar date and female condition on BSR, it seemed unlikely that I would be able to detect an influence of either social or genetic male characters on sex ratio without first controlling for date and female effects. I therefore conducted separate stepwise regression analyses of BSR for females according to the characters of EP and WP males. In both analyses I forced date and female condition into the model, and for females without EPY, I included the social male's condition, NDI score and dawn song start time and song rates (Table 4-6). I conducted identical analyses for females 
with EPY, except that the EP sire's condition and behavioral scores were included as predictor variables. Neither WP male or EP male characters significantly predicted brood sex ratio (Table 4-6).

\section{Nestlings}

Male and female offspring less than 10 days old did not differ in tarsus length or condition, but female nestlings tended to be heavier (Table 4-7). Analysis of only nestlings between 11 and 13 days of age indicated that females were heavier, but again, tarsus length and condition did not differ between the sexes (Table 4-7). A high proportion $(45 / 210=21.4 \%$, for comparisons see Weatherhead and Forbes, 1994) of nestlings that fledged recruited into the potulation. The probability that a male nestling returned declined with the date of hatch (logistic regression, $b=-0.623, \mathrm{n}=$ $126, P=0.043$ ) but was independent of mass (logistic regression, $b=-0.094, \mathrm{n}=125$, $P=0.602$ ) and tarsus length (logistic regression, $b=-0.04, \mathrm{n}=122, P=0.816$ ). On the other hand, the probability of female recruitment was dependent upon mass $(P=$ 0.034 , logistic regression, $\mathrm{n}=115, b=0.295$ ) but was independent of both hatch date ( $P=0.757$, logistic regression, $\mathrm{n}=112, b=0.01$ ) and tarsus (logistic regression, $b=$ $0.249, \mathrm{n}=113, P=0.198)$. The latter analyses included mortality both in the nest and after fledging, and when I restricted the analysis to nestlings that actually fledged the pattern was similar, but no longer significant (male recruitment versus hatch date: logistic regression, $b=-0.047, \mathrm{n}=106, P=0.10$; female recruitment versus mass: logistic regression, $b=0.233, \mathrm{n}=99, P=0.059$ ). 


\section{DISCUSSION}

I predicted that male reproductive success (within-pair or extra-pair components) and attractive male qualities (dawn song start time and NDI, factors previously associated with male reproductive success) would influence the probability that nestlings would be male. This prediction was based on the premise that mothers of male offspring inheriting these characteristics would benefit via the increased reproductive success of their sons in a system where variance in male reproductive success is very large. Contrary to my predictions, male reproductive success (the ultimate measure of male attractiveness), start time for dawn song and NDI did not influence the sex of nestlings within nests or the sex of all the young sired by a male. Like Grindstaff et al. (2001) and Leech et al. (2001), I also failed to detect a relationship between BSR and either paternal attractiveness or male reproductive success.

However, contrary to expectations, I found that males in poor condition sired more male offspring. Although I cannot fully explain latter relationship, all these assumptions rest on the assumption that the behavioral and morphological male characters that I measured are heritable. Attractive male characters may instead be dependent upon the conditions experienced during development. (e.g. Haywood and Perrins, 1992; Lindstrom, 1999; Nagub and Gil, 2005; Visser and Verboven, 1998; 1999). In such a case, one would predict a positive relationship between rearing environmental conditions and offspring BSR and there would be no adaptive value in biasing BSR toward males based upon the characters of genetic sires. However, I also 
detected no relationship between insect abundance and social male characters.

In kingbirds, condition is inversely related to parental effort (Maigret and Murphy, 1997), as observed in other species (e.g. Weimerskirch, 1998; Wright and Cuthill, 1990). Thus, females may bias BSR based upon expected parental effort. However, this is unlikely because EP males were never observed provisioning nestlings at nests other than those in their social mate's nest. If BSR is biased based upon parental effort I would have predicted a relationship between BSR and the social male rather than (or in addition to) the EP sires. However, I did not find any relationship between WP male characteristics and BSR. This stands in contrast with recent findings by Rathburn and Montgomerie (2005) who found a strong relationship between nestling sex ratio and their social (not genetic) father's condition. I suspect this reflects the fact that eastern kingbird nestling condition is more dependent upon the condition of their mother rather than their social father because females feed nestlings at twice the rate of males (Woodward and Murphy, 1999).

Although territory quality did not explain any variation in BSR in kingbirds, it has been demonstrated to influence BSR in many species (Appleby et al., 1997; Dzus et al., 1996; Hipkiss and Hornfeldt, 2004; Komdeur et al., 2002). Eastern kingbirds are aerial insectivores (Murphy, 1996), and the nonpasserine examples sited above typically consume larger vertebrate prey. Food is perhaps a limiting factor for most predators of vertebrates, but insects appeared to be abundant (i.e. very few nestlings starved) so as to have no impact on kingbird BSR. Hornfeldt et al. (2000) drew a similar conclusion when supplementary feeding failed to influence sex ratio in 
tengmalm's owls (Aegolius furerus, Hornfeldt; et al., 2000).

Female condition did affect BSR as females in good condition produced more male offspring. Similar results have been found in a variety of species including peafowl (Pavo cristatus, Pike and Petrie et al., 2004), tree swallows (Tachycineta bicolor; Whittingham and Dunn, 2000; Whittingham et al., 2005); red jungle fowl (Gallus gallus; Parker et al., 2002), house wrens (Troglodytes aedo; Whittingham et al., 2002) and zebra finches (Poephila guttata; Bradbury and Blakey, 1998). If maternal condition affects offspring condition (Whittingham and Dunn, 2000), when a female is in good condition, biasing BSR toward the sex with the larger variance in reproductive success may positively influence female reproductive success in terms of the number of grand-offspring produced.

Hatch date also affected BSR, and nestlings born early in the season were more likely to be male. The adaptive significance of sex ratio variation by date could be explained by sex specific differences in the relationship between birth/hatch date and age at first reproduction (reviewed in Daan et al., 1996). Spotless starlings (Sturnus unicolor), for instance, showed female biased early broods and male biased late broods. In this species, the probability that a female will breed as a second-year bird is dependent upon hatch date, whereas males never breed until the following breeding season (Cordero et al., 2001). Hence it is most productive for a female to produce female offspring early in the season. In other species, survival of male fledglings may be more dependent upon hatch date than females because they are more expensive to provision. Resources may be more abundant early in the breeding season or males 
fledged early in the season may need more time to complete growth and prepare for the fall migration. Territory holding male eastern kingbirds show a large variance in reproductive success, and during the period of this study, nearly a quarter of socially paired birds failed to sire any offspring at all (Chapter 2). To the best of my knowledge, virtually all females breed and maintain maternity of all young in their nests. Thus, male success is likely to be more sensitive to body condition and therefore more sensitive to date. The relationship between date and BSR was not evident when standardized hatch date was included in the model, but only emerged when calendar date was used. This finding establishes that BSR varies with real seasonal phenomena, most likely migration, rather than being a function of individual position in the sequence at which individuals begin to breed.

Together, date and female condition accounted for nearly a fifth of the variation in BSR. It is generally accepted that individuals in good condition begin breeding earlier in the season (Lack, 1966; reviewed in Price et al., 1988), and the date an individual hatches influences both juvenile survival and adult parameters of reproductive success (Stauss et al., 2005; Verboven and Vissner, 1998; Vissner and Verboven, 1999). These facts alone do not establish the benefit of BSR manipulation, and few studies have done so (but see Appleby et al., 1997; Komdeur, 2002). Due to high recruitment ( $20 \%$ of nestlings) I was able to track nestling survival and found a sex specific difference in the interaction between hatch date, mass and probability of survival. In males, but not females, offspring survival to the following breeding season was dependent on date. On the other hand, female nestling survival was 
positively influenced by mass, and among older nestlings ( $>10$ days of age) females were heavier than males. This differential survival may reflect sex specific differences in migration strategies (Mabey, 2002) or sex specific reactions to nutritional stress (Clutton-Brock et al., 1985; Nager et al., 1999). Vissner and Verboven (1999) found a sex specific relationship between hatch date and lifetime reproductive success among male great tits (Parus major). I have shown female kingbirds benefit directly by biasing BSR early in the season as males who fledge early showed an increased probability of survival. Continued research is needed to investigate whether females benefit doubly by biasing BSR by determining whether males born early in the season or heavy female nestlings also exhibit increased lifetime reproductive success. 


\section{FIGURE LEGEND}

\section{Figure 4-1}

Scatter plot of the proportion of male offspring by clutch initiation date. Proportion of male offspring was calculated as number of male nestlings divided by total offspring in each female's nest and 1 corresponds to May $1^{\text {st }}$.

\section{Figure 4-2}

Scatter plot of the proportion of male offspring by female condition. Proportion of male offspring was calculated as number of male nestlings divided by total offspring in each female's nest and female condition was measured such that a negative score represents a female in poor condition and a positive score indicates a female in good condition. 
Table 4-1 Theoretical predictors of BSR adjustment by territory quality, date and parental characters.

\begin{tabular}{lll}
\hline Predictor & Broods male biased & Broods female biased \\
Territory quality & High quality territories & Low quality territories \\
Timing & Early in the season & Late in the season \\
Female condition & Females in good condition & Females in poor condition \\
WP and EP male quality & & \\
song & Start singing early & Start singing late \\
nest defense & Aggressively defend nest & Less aggressively defend nest \\
condition & Males in good condition & Males in poor condition \\
\# of young sired & Males who sire many offspring & Males who sire few offspring \\
\hline
\end{tabular}


Table 4-2 Number of male and females nestlings produced among years. $2 \times 2$ contingency tables were used to test for differences in population wide BSR among years and the $P$ values reported.

\begin{tabular}{rcccccccc} 
& & & & & $\begin{array}{l}\text { \# Fem. } \\
\text { producing } \\
\text { all male } \\
\text { broods }\end{array}$ & $\begin{array}{l}\text { \# Fem. } \\
\text { producing } \\
\text { all fem. } \\
\text { Broods }\end{array}$ & $\begin{array}{l}\text { \# Males } \\
\text { producing } \\
\text { all male } \\
\text { offspring }\end{array}$ & $\begin{array}{l}\text { \# Males } \\
\text { all female } \\
\text { offspring }\end{array}$ \\
\hline 2002 & 25 & 44 & 30 & 0.54 & 9 & 2 & 6 & 3 \\
2003 & 25 & 42 & 32 & 0.76 & 1 & 2 & 2 & 2 \\
2004 & 40 & 58 & 61 & 0.40 & 4 & 7 & 5 & 5 \\
Combined & 90 & 144 & 123 & - & 14 & 11 & 13 & 10 \\
\hline
\end{tabular}


Table 4-3 Comparisons among sex ratio groups (SRGs) of date, condition, insect abundance and dawn song start time and nest defense index (NDI). Means, standard deviateions and number of individuals per group are all reported. Individuals in SRG1 produced all male offspring; SRG 2 produced mixed sex offspring and SRG 3 produced all female offspring.

$\begin{array}{lllll}\text { Date }^{1} & \text { Condition } & \text { Insect } & \text { Song start }^{2} & \text { NDI } \\ \bar{x}(\mathrm{SD}, \mathrm{N}) & \bar{x}(\mathrm{SD}, \mathrm{N}) & \bar{x}(\mathrm{SD}, \mathrm{N}) & \bar{x}(\mathrm{SD}, \mathrm{N}) & \bar{x}(\mathrm{SD}, \mathrm{N})\end{array}$

\begin{tabular}{cccc}
\hline Females & & & \\
SRG 1 & $46.5(10.8,10)$ & $0.086(0.21,11)$ & $6.84(2.44,5)$ \\
SRG 2 & $51.7(9.0,54)$ & $-0.072(0.12,44)$ & $7.42(2.35,50)$ \\
SRG 3 & $56.7(9.3,9)$ & $-0.003(0.12,5)$ & $6.42(2.14,9)$ \\
F(P) & $2.91(0.061)$ & $\mathbf{3 . 2 8 ( 0 . 0 4 8 )}$ & $0.08(0.46)$
\end{tabular}

Social father

$\begin{array}{lccccc}\text { SRG 1 } & - & 0.019(0.21,11) & - & -60.4(7.6,3) & 0.84(0.92,3) \\ \text { SRG 2 } & - & -0.004(0.085,45) & - & -63.4(9.2,44) & 0.59(0.83,33) \\ \text { SRG 3 } & - & 0.035(0.068,7) & - & -68.2(7.5,7) & 0.27(0.37,4) \\ \text { F(P) } & & 0.64(0.53) & & 1.10(0.34) & 0.46(0.64)\end{array}$

Genetic father

\begin{tabular}{lccccc} 
SRG 1 & - & $-0.063(0.06,13)$ & $6.9(2.62,8)$ & $-58.2(11.3,7)$ & $0.32(0.32,7)$ \\
SRG 2 & - & $0.017(0.76,31)$ & $7.13(2.11,31)$ & $-66.0(8.0,28)$ & $0.88(1.05,22)$ \\
SRG 3 & - & $-0.063(0.06,7)$ & $6.75(2.40,7)$ & $-66.4(-8.0,4)$ & $0.27(0.37,4)$ \\
F(P) & & $3.43(0.044)$ & $0.1(0.91)$ & $2.39(0.11)$ & $0.39(0.67)$ \\
\hline
\end{tabular}

Tecorded such that May $1^{\text {st }}=1 ;{ }^{2}$ Measured in minutes before dawn 
Table 4-4 Comparison of reproductive success and PSR among male paternity groups.

Eighty-nine complete nests were sampled.

\begin{tabular}{cccccc}
$\begin{array}{l}\text { Paternity } \\
\text { Group }\end{array}$ & $\begin{array}{l}\text { WP } \\
\text { success }\end{array}$ & $\begin{array}{l}\text { EP } \\
\text { success }\end{array}$ & $\begin{array}{l}\text { Avg. \# } \\
\text { young in } \\
\text { group }\end{array}$ & PSR $^{1}$ & $\begin{array}{l}\text { \# of adult } \\
\text { males in } \\
\text { group }\end{array}$ \\
\hline 1 & None & None & -- & 0 & 21 \\
2 & None & Some & 1.33 & 0.8 & 6 \\
3 & Some & None & 1.61 & 0.53 & 18 \\
4 & Some & Some & 4.33 & 0.46 & 9 \\
5 & All & None & 2.61 & 0.46 & 23 \\
6 & All & Some & 5.5 & 0.47 & 12 \\
\hline
\end{tabular}

${ }^{1}$ PSR measured by number of male nestlings sired divided by total number of EPY and WPY sired. 
Table 4-5 Linear regression analysis of PSR by male morphology and behavioral characters.

\begin{tabular}{|c|c|c|c|}
\hline & $\mathrm{n}$ & $\mathrm{P}$ & $r$ \\
\hline Condition & 51 & 0.01 & 0.351 \\
\hline Tarsus length & 66 & 0.49 & 0.0866 \\
\hline NDI & 33 & 0.699 & 0.0715 \\
\hline Song start ${ }^{1}$ & 39 & 0.11 & 0.262 \\
\hline 30MinRate & 39 & 1.14 & 0.215 \\
\hline PeakRate & 39 & 0.076 & 0.288 \\
\hline ActualRate & 39 & 0.21 & 0.205 \\
\hline Total Young & 67 & 0.24 & 0.146 \\
\hline
\end{tabular}


Table 4-6 Stepwise linear regression of BSR and morphological and behavioral characters or WP and EP males. BSR was measured as the number of males divided by total offspring in each nest. Female condition and clutch initiation date were forced into the model to control for their effects.

\begin{tabular}{|c|c|c|c|c|}
\hline & \multicolumn{2}{|c|}{ WP male } & \multicolumn{2}{|c|}{ EP male } \\
\hline & $\mathrm{n}$ & $r(\mathrm{P})$ & $\mathrm{n}$ & $r(\mathrm{P})$ \\
\hline Condition & 50 & $0.291(0.32)$ & 9 & $0.357(0.15)$ \\
\hline Tarsus & 54 & $0.278(0.79)$ & 16 & $0.314(0.69)$ \\
\hline NDI & 26 & $0.266(0.32)$ & 11 & $0.434(0.49)$ \\
\hline Dawn song start & 32 & $0.155(0.61)$ & 15 & $0.334(0.42)$ \\
\hline 30MinRate & 32 & $0.155(0.70)$ & 14 & $0.334(0.69)$ \\
\hline PeakRate & 32 & $0.155(0.45)$ & 14 & $0.334(0.64)$ \\
\hline Actual Rate & 32 & $0.155(0.68)$ & 14 & $0.334(0.62)$ \\
\hline
\end{tabular}


Table 4-7 Comparisons of nestling mass, tarsus and condition of nestlings of all ages and restricted to nestlings greater than ten days of age. Mean values and standard deviations along with the results of $t$-tests.

\begin{tabular}{lccccc} 
Character & $\mathrm{N}$ & Male $\bar{x} \pm \mathrm{SD}$ & Female $\bar{x} \pm \mathrm{SD}$ & $\mathrm{t}$ & $\mathrm{P}$ \\
\hline $\begin{array}{l}\text { All ages } \\
\text { Mass }\end{array}$ & 261 & $0.17 \pm 1.28$ & $0.18 \pm 0.55$ & -1.92 & 0.056 \\
Tarsus & 244 & $0.02 \pm 1.30$ & $-0.02 \pm 1.32$ & 0.23 & 0.82 \\
Condition & 240 & $0.03 \pm 1.31$ & $0.02 \pm 1.32$ & 0.04 & 0.97 \\
\hline Age $>10$ days & & & & & \\
Mass & 199 & $0.52 \pm 0.98$ & $0.98 \pm 1.60$ & -2.18 & 0.03 \\
Tarsus & 199 & $-0.02 \pm 1.17$ & $0.11 \pm 1.28$ & -0.74 & 0.18 \\
Condition & 198 & $-0.02 \pm 1.169$ & $0.11 \pm 1.28$ & -0.74 & 0.46 \\
\hline
\end{tabular}


Figure 4-1

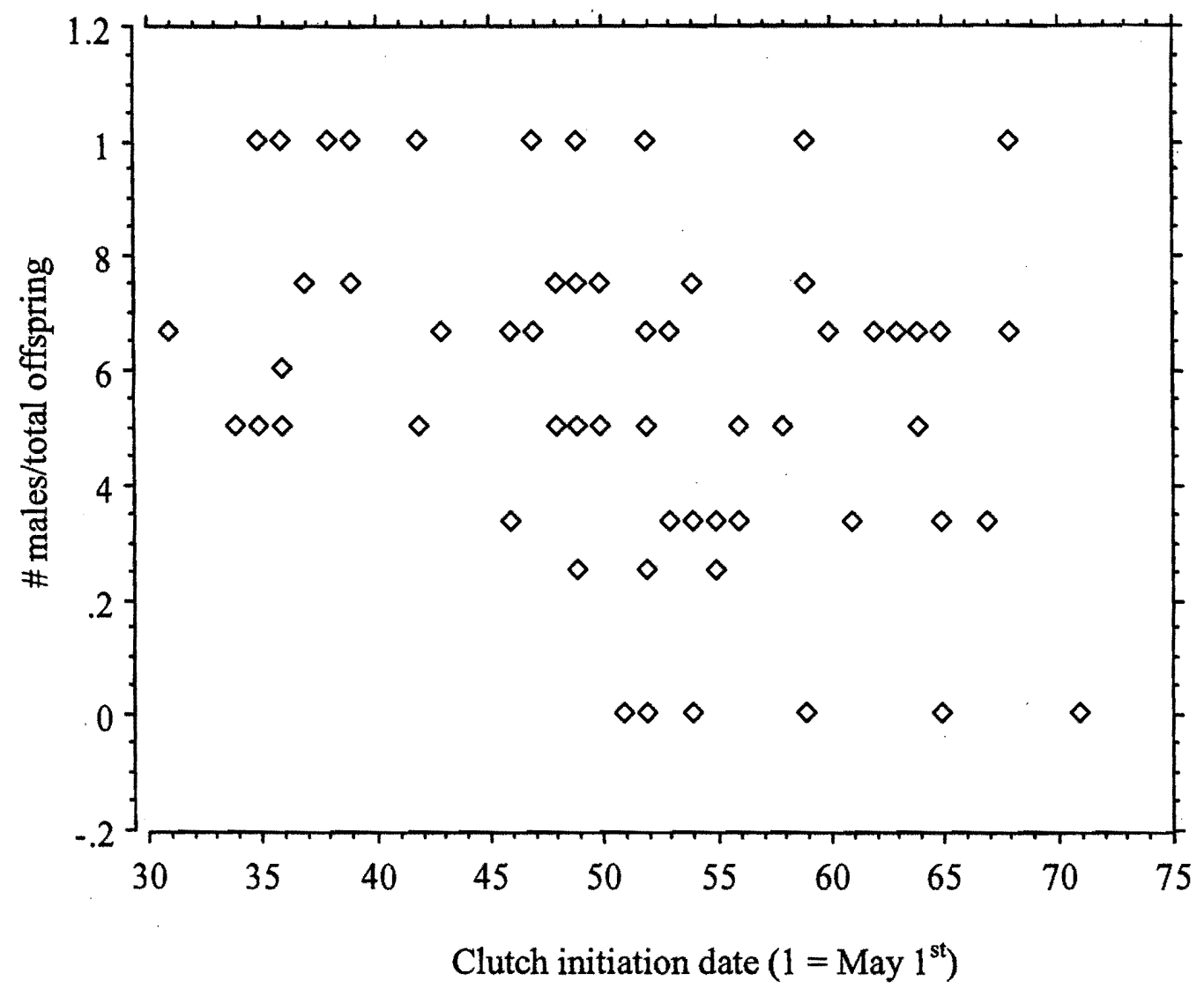


Figure 4-2

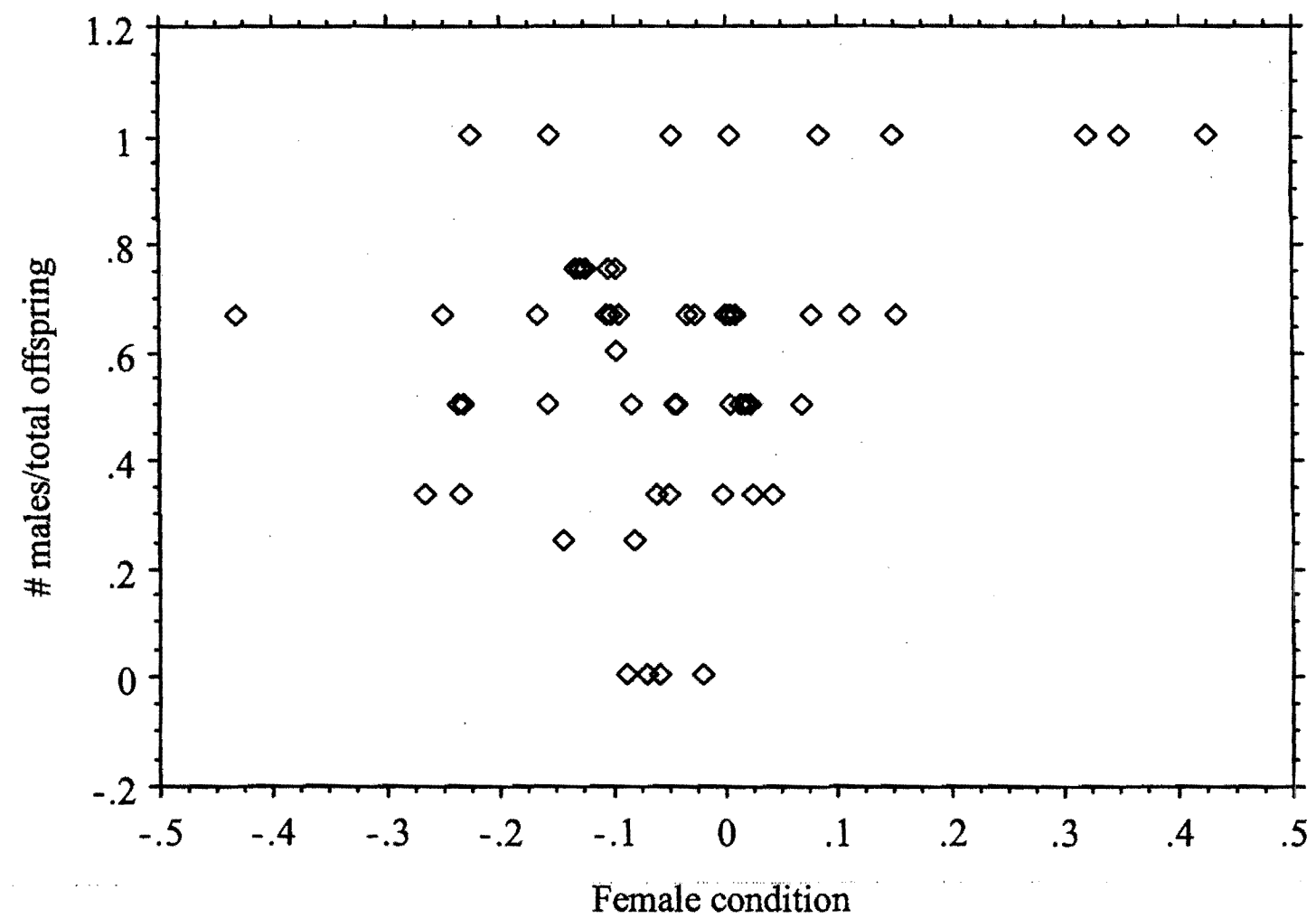




\section{CHAPTER 5-CONCLUSIONS:}

In chapter 2, I showed that extra-pair paternity (EPP) plays a major role in the reproductive biology of eastern kingbirds, and that some males gained substantial numbers of EPFs at the expense of others. In a surprising number of cases $(n=$ 21/89) males sired no offspring at all, while in other cases males sired only EP or WP young. A moderate proportion of males were highly successful and sired all WP and some EP young and in a few cases, success at siring EPY doubled their annual production of young. In studies not identifying EP sires, a major source of reproductive success has been disregarded, and thus accounts of male reproductive success under these circumstances have been incomplete. The observed pattern of EPP in eastern kingbirds created large variance in male reproductive success, more than nine times greater than that of females, indicating that sexual selection is an important selective force in this species. This is particularly significant because classical studies discount this possibility due to the generally sexually monomorphic size and plumage of kingbirds. Furthermore, recent studies claim that the effects of EPP on sexual selection have been overestimated. However, these studies examined facultatively polygynous and double-brooded species, both of which increase the importance of WPP in relation to EPP when examining variance in reproductive success. Because strict social monogamy represents the most common breeding system of passerine species, my research is more representative of the whole. I found two behaviors to be most related to male reproductive success: dawn song start time 
correlated with EP success and nest defense intensity correlated with WP success. Given that EP and WP success represent nearly equal contributions to male success, discrete traits dictating performance in each arena seems logical. Although song characters have long been touted as targets of sexual selection, nest defense intensity has not been examined in this light. This suggests the importance of broadening our view of possible targets of sexual selection.

In chapter 3, I examined the female aspect of mixed reproductive strategies in eastern kingbirds. Four genetic hypotheses have been proposed to explain female cooperation in EPCs based upon the variance of male versus female reproductive success, distribution of young, genetic similarity of females to EP and WP sires, and quality of EP and WP sires. There were no differences in genetic relatedness between females and successful EP sires and WP males, however EP sires were physically larger than and out-performed WP males in several song performance characters. Brood performance (proportion of a clutch to survive) was not affected by the number of sires. These are all consistent with the good genes hypothesis of EPP. Females benefited from mating with successful EP sires in that they tended to breed early and male nestling's over-winter survival was inversely related to hatch date. Mating with EP sires also produced nestlings that were larger (as estimated by tarsus length) than their WP siblings, and nestlings with long tarsi were more likely to survive to fledge, and among female nestlings were more likely to survive to the following breeding season.

As a result of the availability of demographic, genetic parentage and 
environmental quality data, I was able to evaluate all major factors thought to influence sex ratio manipulation (Chapter 4). I also examined the costs and benefits of producing male and female nestlings by assessing size and survival of nestlings. Due to the large skew in male reproductive success, I predicted male characters associated with male reproductive success would also correlate with sex ratio such that successful males would sire more male offspring. Contrary to my predictions, I found that brood sex ratio was independent of WP and EP male traits, but that male-biased clutches were produced early in the season and by females in good condition. Individuals in good condition are often the earliest breeders, and thus it is difficult to separate seasonal and female effects. My results demonstrated independent effects of both variables. I also established that male nestling survival was dependent upon date, whereas female nestling survival was related to tarsus length and mass. Females that produce males early in the season benefited because male nestlings that hatched early were more likely to survive than males that hatch later in the season. On the other hand, females that produce female nestlings late in the season benefited because females nestling survival was unrelated to date, but was instead a function of body mass and tarsus length. Insect abundance increases seasonally at Malheur (Redmond, 2005) and therefore female biased broods are produced when conditions favored high parental provisioning rates.

Further research in this population of eastern kingbirds will no doubt be productive. I feel the following topics are of particular interest:

- Documenting the arrival time of males and females in respect to past 
reproductive success and in relationship to the current breeding season to establish a link between arrival time, condition and reproductive success.

- Documenting individual lifetime reproductive in regards to behavioral and morphological characters. Reproductive success should be examined both by the total number of offspring and the offspring over several generations (F2s, F3s etc.) produced by each individual.

- Determining the heritability of traits focusing on song performance, morphology and the reproductive performance of parents. This could include questions such as: Do early-singing males sire early-singing sons? Are sons of successful EP sires more likely to sire EPY? Are females whose mothers include EPY in their clutch more likely to do the same?

- Food supplementation experiments on the effects of breeding date, female condition/sex ratio of offspring and male condition/song performance. This would assess whether sex ratio is directly affected by female condition or date and whether song characters are honest indicator of male condition.

This research has afforded me the opportunity to examine in detail the sometimes antagonistic reproductive strategies of male and female eastern kingbirds. Female kingbirds are presumably constrained by the number of eggs they can produce or offspring they can provision. Thus, to produce high quality offspring females seek EPCs when not socially paired to a high quality male, while still obtaining parental care for their offspring from the social male. In an attempt to maximize the number of offspring produced, male kingbirds must balance the pursuit of EPCs with the 
maintenance of WP paternity. My data suggests that males who secured complete WP paternity and ignored EP success had lower reproductive performance than those who employed a mixed strategy.

In addition, I would argue these results can be broadly applied. Our view of vertebrate mating systems has changed vastly in the past two decades with the advent of techniques that allow genetic paternity analysis. With these tools, we are able to go beyond appearances and examine not only genetic pairings, but also the implications of mate choice. 


\section{REFERENCES}

Amrhein V, Kunc H, Naguib M. 2004. Non-territorial nightingales prospect territories during the dawn chorus. Proc R Soc Lond B. 271:S167-S169.

Andersson M, 1994. Sexual Selection. Princeton, NJ: Princeton University Press.

Appleby BM, Petty SJ, Blakey JK, Rainey P, MacDonald DW, 1997. Does variation of sex ratio enhance reproductive success of offspring in tawny owls (Strix aluco)? Proc R Soc Lond B. 264:1111-1116.

Arnold KE, Owens IPF. 2002. Extra-pair paternity and egg dumping in birds: Life history, parental care and the risk of retaliation. Proc R Soc Lond B. 269:12631269.

Arnold SJ, Wade MJ, 1984. On the measurement of natural and sexual selection: applications. Evolution. 38:720-734.

Bachman G, Widemo F, 1999. Relationships between body composition, body size and alternative reproductive tactics in a lekking sandpiper, the Ruff (Philomachus pugnax). Funct Ecol. 13:411-416.

Badyaev AV, Hill GE, 2002. Paternal care as a conditional strategy: distinct reproductive tactics associated with elaboration of plumage ornamentation in the house finch. Behav Ecol. 13:591-597.

Ballentine B, Hyman J, Nowicki S. 2004. Vocal performance influences female response to male bird song: an experimental test. Behav Ecol. 15:163-168.

Barash DP. 1976. Male response to apparent female adultery in the mountain bluebird: an evolutionary interpretation. Am Nat. 110:1097-1101. 
Birkhead TR, Moller AP, 1992. Sperm competition in birds. London: Academic Press. Blancher PJ, Robertson RJ, 1982. Kingbird aggression: does it deter predation? Anim Behav. 30:929-930.

Blancher PJ, Robertson RJ, 1987. Effect of food supply on the breeding biology of Western Kingbirds. Ecology. 68:723-732.

Byers BE, Mays HL, Jr., Stewart IRK, Westneat DF. 2004. Extrapair paternity increases variability in male reproductive success in the chestnut-sided warbler (Dendroica pensylvanica), a socially monogamous songbird. Auk. 121:788795.

Charmantier A, Blondel J, 2003. A contrast in extra-pair paternity levels on mainland and island populations of Mediterranean blue tits. Ethology. 109:351-363.

Charmantier A, Blondel J, 2003. What prompts birds to engage in extra-pair paternity? Vogelwarte. 42:60.

Charmantier A, Blondel J, Perret P, Lambrechts MM, 2004. Do extra-pair paternities provide genetic benefits for female blue tits Parus Caeruleus? J Avian Biol. $35: 524-534$.

Charmantier A, Perret P, 2004. Manipulation of nest-box density affects extra-pair paternity in a population of blue tits (Parus caeruleus). Behav Ecol Sociobiol. $56: 360-365$.

Clutton-Brock T, S. A, Guiness FE, 1985. Parental investment and sex differences in juvenile mortality in birds and mammals. Nature. 313:131-133.

Conrad KF, Clarke MF, Robertson RJ, Boag PT, 1998. Paternity and the relatedness 
of helpers in the cooperatively breeding bell miner. Condor. 100:343-349.

Cordero J, Wetton JH, Parkin DT, 1999. Extra-pair paternity and male badge size in the House Sparrow. JAvian Biol. 30:97-102.

Cordero PJ, Vinuela J, Aparicio JM, Veiga JP, 2001. Seasonal variation in sex ratio and sexual egg dimorphism favouring daughters in first clutches of the spotless starling. J Evolution Biol. 14:829-834.

Coulson JC, Pemberton JM, Albon SD, Beaumont M, Marshall TC, Slate J, Guiness FE, Clutton-Brock T, 1999. Microsatellites reveal heterosis in red deer. Proc $\mathrm{R}$ Soc Lond B. 265:489-495.

Daan S, Dijkstra C, Weissing FJ, 1996. An evolutionary explanation for seasonal trends in avian sex ratios. Behav Ecol. 7:426-430.

Dale S, Gustavsen R, Slagsvold T. 1996. Risk taking during parental care: A test of three hypotheses applied to the pied flycatcher. Behav Ecol Sociobiol. 39:3142.

Darwin C, 1871. The descent of man and selection in relation to sex. New York, New York: D. Appleton and Company.

Davis DE. 1941. The belligerency of the kingbird. Wilson Bull. 53:157-168.

Dijkstra C, Daan S, Buker JB, 1990. Adaptive Seasonal Variation in the Sex Ratio of Kestrel Broods. Funct Ecol. 4:143-148.

Double M, Cockburn A, 2000. Pre-dawn infidelity: Females control extra-pair mating in superb fairy-wrens. Proc R Soc Lond B. 267:465-470.

Dunn PO, Whittingham LA, Pitcher TE. 2001. Mating systems, sperm competition, 
and the evolution of sexual dimorphism in birds. Evolution. 55:161-175.

Dzus EH, Bortolotti GR, Gerrard JM, 1996. Does sex-biased hatching order in bald eagles vary with food resources? Ecoscience. 3:252-258.

Eberhardt LS. 1994. Oxygen-Consumption During Singing by Male Carolina Wrens (Thryothorus ludovicianus). Auk. 111:124-130.

Ellegren H, Gustafsson L, Sheldon BC, 1996. Sex ratio adjustment in relation to paternal attractiveness in a wild bird population. P Natl A Sci USA.93:1172311728.

ESRI Inc. 2000ArcView v. 3.29. Redlands, CA.

Forstmeier W, 2003. Extra-pair paternity in the dusky warbler, Phylloscopus fuscatus: A test of the 'constrained female hypothesis'. Behaviour. 140:1117-1134.

Forstmeier W, Balsby TJS. 2002. Why mated dusky warblers sing so much: Territory guarding and male quality announcement. Behaviour. 139:89-111.

Forstmeier W, Kempenaers B, Meyer A, Leisler B, 2002. A novel song parameter correlates with extra-pair paternity and reflects male longevity. Proc R Soc Lond B. 269:1479-1485.

Freeman-Gallant CR. 1996. DNA fingerprinting reveals female preference for male parental care in Savannah sparrows. Proc R Soc Lond B. 263:157-160.

Freeman-Gallant CR. 1997. Parentage and paternal care: Consequences of intersexual selection in savannah sparrows? Behav Ecol Sociobiol. 40:395-400.

Freeman-Gallant CR, Meguerdichian M, Wheelwright NT, Sollecito SV, 2003. Social pairing and female mating fidelity predicted by restriction fragment length 
polymorphism similarity at the major histocompatibility complex in a songbird. Mol Ecol. 12:3077-3083.

Freeman-Gallant CR, Wheelwright NT, Meiklejohn KE, States SL, Sollecito SV. 2005. Little effect of extrapair paternity on the opportunity for sexual selection in savannah sparrows (Passerculus sandwichensis). Evolution. 59:422-430.

Fridolfsson AK, Ellegren H, 1999. A simple and universal method for molecular sexing of non-ratite birds. J Avian Biol. 30:116-121.

Friedl TWP, Klump GM, 2005. Extrapair fertilizations in the Red Bishop (Euplectes orix). Auk. 122:57-70.

Genovart M, Jover L, Ruiz X, Oro D, 2003. Offspring sex ratios in subcolonies of Audouin's gull, Larus audouinii, with differential breeding performance. Can J Zoolog. 81:905-910.

Gowaty PA, Buschhaus N. 1998. Ultimate causation of aggressive and forced copulation in birds: Female resistance, the CODE hypothesis, and social monogamy. Am Zool. 38:207-225.

Griffith SC, 2000. High fidelity on islands: A comparative study of extrapair paternity in passerine birds. Behav Ecol. 11:265-273.

Griffith SC, Owens IPF, Thuman KA. 2002. Extra pair paternity in birds: A review of interspecific variation and adaptive function. Mol Ecol. 11:2195-2212.

Griffith SC, Stewart IRK, Dawson DA, Owens IPF, Burke T, 1999. Contrasting levels of extra-pair paternity in mainland and island populations of the house sparrow (Passer domesticus): Is there an 'island effect'? Biol J Linn Soc. 68:303-316. 
Griffith SCO, Ian P. F.; Bruke, Terry, 1999. Environmental determination of a sexually selected trait. Nature. 400:358-360.

Grindstaff JL, Buerkle CA, Casto JM, Nolan V, Jr., Ketterson ED, 2001. Offspring sex ratio is unrelated to male attractiveness in dark-eyed juncos (Junco hyemalis). Behav Ecol Sociobiol. 50:312-316.

Hamilton WD, 1990. Mate choice near or far. American Zoologist 30:341-352.

Hasselquist D, Bensch S, 1991. Trade-off between mate guarding and mate attraction in the polygynous great reed warbler. Behav Ecol. 28:187-193.

Hasselquist D, Bensch S, Von Schantz T, 1996. Correlation between male song repertoire, extra-pair paternity and offspring survival in the great reed warbler. Nature. 381:229-232.

Hasselquist D, Bensch S, Von Schantz T, 1996. Correlation between male song repertoire, extra-pair paternity and offspring survival in the great reed warbler. Nature. 381:229-232.

Hasselquist D, Sherman PW, 2001. Social mating system and extrapair fertilizations in passerine birds. Behav Ecol. 12:457-466.

Haywood S, Perrins CM, 1992. Is Clutch Size in Birds Affected by EnvironmentalConditions During Growth. Proc R Soc Lond B. 249:195-197.

Hipkiss T, Hornfeldt B, 2004. High interannual variation in the hatching sex ratio of Tengmalm's owl broods during a vole cycle. Popul Ecol. 46:263-268.

Hoi-Leitner M, Hoi H, Romero-Pujante M, Valera F, 1999. Female extra-pair Behaviour. and environmental quality in the serin (Serinus serinus): A test of 
the 'constrained female hypothesis'. Proc R Soc Lond B. 266:1021-1026.

Hornfeldt B, Hipkiss T, Fridolfsson AK, Eklund U, Ellegren H, 2000. Sex ratio and fledging success of supplementary-fed Tengmalm's owl broods. Mol Ecol. 9:187-192.

Houtman AM, 1992. Female Zebra Finches Choose Extra-Pair Copulations with Genetically Attractive Males. Proc R Soc Lond B. 249:3-6.

Janota SM, Soukup SS, Thompson CF, 2002. Male-biased offspring sex ratio in the House Wren. Condor. 104:881-885.

Jenness, J. 2004. nearest features (nearfeat.avx) extension for Arcview 3.x, v. 3.80 . Jeness Entrprises. Available at http://www.jennessnt.com/arcview/nearestfeatures.htm.

Johnsen A, Anderson V, Sunding C, Lifjeld JT, 2000. Female bluethroats enhance offspring immunocompetence through extra-pair copulations. Nature. 406:296299.

Johnson K, Burley N, 1997. Mating tactics and mating systems of birds. Ornithol Monog. 1997:21-60.

Kempenaers B. 1993. The Use of a Breeding Synchrony Index. Ornis Scand. 24:8484.

Kempenaers B, Adriaensen F, Van Noordwijk AJ, Dhondt AA, 1996. Genetic similarity, inbreeding and hatching failure in blue tits: Are unhatched eggs infertile? Proc R Soc Lond B. 263:179-185.

Kempenaers B, Congdon B, Boag P, Robertson RJ, 1999. Extrapair paternity and egg 
hatchability in tree swallows: Evidence for the genetic compatibility hypothesis? Behav Ecol. 10:304-311.

Kempenaers B, Dhondt AA, 1993. Why do females engage in extra-pair copulations?

A review of hypotheses and their predictions. Belg J Zool. 123:93-103.

Kempenaers B, Verheyen GH, Van Der Broeck M, Burke T, Van Broeckhoven C, Dhondt AA, 1992, Extra-pair paternity results from female preference for high-quality males in the Blue Tit. Nature. 357:494-496.

Kempenaers B, Verheyen GR, Dhondt AA, 1997. Extrapair paternity in the blue tit (Parus caeruleus: Female choice, male characteristics, and offspring quality. Behav Ecol. 8:481-492.

Kempenaers B, Verheyen GR, Van Der Broeck M, Burke T, Van Broeckhoven C, Dhondt AA, 1992. Extra-Pair Paternity Results from Female Preference for High-Quality Males in the Blue Tit. Nature. 357:494-496.

Knight RL, Temple SA. 1988. Nest-defense behavior in the red-winged blackbird. Condor. 90:193-200.

Komdeur J, 1996. Facultative sex ratio bias in the offspring of Seychelles warblers. Proc R Soc Lond B. 263:661-666.

Komdeur J, Magrath MJL, Krackow S, 2002. Pre-ovulation control of hatchling sex ratio in the Seychelles warbler. Proc R Soc Lond B. 269:1067-1072.

Krokene C, Lifjeld JT, 2000. Variation in the frequency of extra-pair paternity in birds: A comparison of an island and a mainland population of blue tits. Behaviour. 137:1317-1330. 
Krokene C, Rigstad K, Dale M, Lifjeld JT, 1998. The function of extrapair paternity in blue tits and great tits: Good genes or fertility insurance? Behav Ecol. 9:649656.

Kroodsma DE, Konishi M. 1991. A suboscine bird (eastern phoebe Sayornis phoebe) develops normal song without auditory feedback. Anim Behav. 42:477-488.

Kroodsma DE. 1984. Songs of the alder flycatcher (Empidonax alnorum) and willow flycatcher (Empidonax trailii) are innate. Auk. 101:13-24.

Lack, D, 1968. Ecological adaptations for breeding in birds. London: Chapman and Hall.

Leech DI, Hartley IR, Stewart IRK, Griffith SC, Burke T, 2001. No effect of parental quality or extrapair paternity on brood sex ratio in the blue tit (Parus caeruleus). Behav Ecol. 12:674-680.

Lessells CM, Boag PT. 1987. Unrepeatable repeatabilities: a common mistake. Auk. 104:116-121.

Li SH, Brown JL. 2000. High frequency of extrapair fertilization in a plural breeding bird, the Mexican jay, revealed by DNA microsatellites. Anim Behav. 60:867877.

Lifjeld JT, Dunn PO, Robertson RJ, Boag PT, 1993. Extra-pair paternity in monogamous tree swallows. Anim Behav. 45:213-229.

Linden M, Gustafsson L, Part T, 1992. Selection on Fledging Mass in the Collared Flycatcher and the Great Tit. Ecology. 73:336-343.

Lindstrom J, 1999. Early development and fitness in birds and mammals. Trends Ecol 
Evol. 14:343-348.

Longmire JL, Lewis AK, Brown NC, Buckingham JM, Clark LM, Jones MD, Meincke LJ, Meyne L, Ratliff RL, Ray FA. 1988. Isolation and molecular characterization of a highly polymorphic centromeric tandem repeat in the family Falconidae. Genomics. 2:14-24.

Lozano GA, Pereault S, Lemon, RE. 1996. Age, Arrival date and reproductive success of male American redstarts Setophaga ruticilla. J Avian Biol. 27(2): $164-170$.

Mabey SE, 2002.Sex-based differential migration: An examiniation of proximate causes and ecological consequences. Hattiesburg, Mississippi: University of Southern Mississippi.

Mace R, 1987. Why do birds sing at dawn? Ardea. 75:123-132.

Maigret JL, Murphy MT. 1997. Costs and Benefits of Parental Care in eastern kingbirds. Behav Ecol. 8:250-259.

Marshall TC, Slate J, Kruuk LEB, Pemberton JM. 1998. Statistical confidence for likelihood-based paternity inference in natural populations. Mol Ecol. 7:639655.

Mauk RA, Marschall EA, Parker PG, 1999. Adult survival and imperfect assessment of parentage: Effects on male parenting decisions. Am Nat. 154:99-109.

McCullagh P, 1983. Generalized Linear Models. New York, New York: Chapman and Hall.

McKitrick MC. 1990. Genetic evidence for multiple parentage in eastern kingbirds 
Tyrannus tyrannus. Behav Ecol Sociobiol. 26:149-156.

Minnesota DNR. 2001. DNRGarmin 4.2.1, Minnesota.

Moller AP, 1988. Female choice slects for male sexual ornaments in the monogamous swallow. Nature. 332:640-642.

Moller AP, 1994. Male ornament size as a reliable cue to enhanced offspring viability in the barn swallow. P Natl A Sci USA. 91:6929-6932.

Moller AP, 2000. Male parental care, female reproductive success, and extrapair paternity. Behav Ecol. 11:161-168.

Moller AP, Alatalo RV, 1999. Good-genes effects in sexual selection. Proc R Soc Lond B. 266:85-91.

Moller AP, Birkhead TR, 1993. Certainty of paternity covaries with paternal care in birds. Behav Ecol Sociobiol. 33:261-268.

Moller AP, Birkhead TR, 1994. The Evolution of plumage brightness in birds is related to extrapair paternity. Evolution. 48:1089-1100.

Moller AP, Brohede J, Curevo JJ, deLope F, Primmer C. 2003. Extrapair paternity in relation to sexual ornamentation, arrival date, and condition in a migratory bird. Behav Ecol. 14(5): 707-712.

Moller AP, Cuervo JJ, 2000. The evolution of paternity and paternal care in birds. Behav Ecol. 11:472-485.

Moller AP, Ninni P, 1998. Sperm competition and sexual selection: A meta-analysis of paternity studies of birds. Behav Ecol Sociobiol. 43:345-358.

Moller AP, Ninni P. 1998. Sperm competition and sexual selection: A meta-analysis 
of paternity studies of birds. Behav Ecol Sociobiol. 43:345-358.

Moller AP, Tegelstrom H, 1997. Extra-pair paternity and tail ornamentation in the barn swallow Hirundo rustica. Behav Ecol Sociobiol. 41:353-360.

Montgomerie R, Weatherhead PJ. 1988. Risks and rewards of nest defense by parent birds. Q Rev Biol. 63:167-187.

Murphy M, 1981. Growth and aging of nestling Eastern Kingbirds and Eastern Phoebes. J Field Ornithol. 52:309-316.

Murphy MT, 1996. Eastern Kingbird: Tyrannus tyrannus. Birds of North America 123.

Murphy MT. 2000. Evolution of clutch size in the Eastern Kingbird: Tests of alternative hypotheses. Ecol Monogr. 70:1-20.

Murphy MT. 2004. Intrapopulation variation in reproduction by female eastern kingbirds Tyrannus tyrannus: the impacts of age, individual performance, and breeding site. J Avian Biol. 35:252-261.

Nabguib M, Gil D, 2005. Transgenerational effects on body size caused by early developmental stress in zebra finches. Biol Lett-UK. 1:95-97.

Nager RG, Managhan P, Griffiths R, Houston DC, Dawson R, 1999. Experimental demonstration that offspring sex ratio varies with maternal condition. P Natl A Sci USA.96:570-573.

Nager RG, Monaghan P, Houston DC, Genovart M, 2000. Parental condition, brood sex ratio and differential young survival: An experimental study in gulls (Larus fuscus). Behav Ecol Sociobiol. 48:452-457. 
Neuhauser M, Forstmeier W, Bretz F. 2001. The distribution of extra-pair young within and among broods - a technique to calculate deviations from randomness. J Avian Biol. 32:358-363.

Oberweger K, Goller F. 2001. The metabolic cost of birdsong production. J Exp Biol. 204:3379-3388.

Otter K, Chruszcz B, Ratcliffe LM, 1997. Honest advertisement of song output during the dawn chorus of black-capped chickadees. Behav Ecol. 8:167-173.

Parker TH, 2002. Maternal condition, reproductive investment, and offspring sex ratio in captive Red Junglefowl (Gallus gallus). Auk. 119:840-845.

Part T. 1991. Is dawn sining related to paternity insurance? The case of the collared flycatcher. Anim Behav. 41:451-456.

Pearson T, 2002. Polygyny and extra-pair paternity in a population of southwestern willow flycatchers (Empidonax traillii extimus). Flagstaff, Arizona: Northern Arizona University.

Petrie M, Doums C, Moller AP, 1998. The degree of extra-pair paternity increases with genetic variability. P Natl A Sci USA.95:9390-9395.

Petrie M, Kempenaers B. 1998. Extra-pair paternity in birds: Explaining variation between species and populations. Trends Ecol Evol. 13:52-58.

Pike TW, Petrie M, 2003. Potential mechanisms of avian sex manipulation. Biol Revs $78: 553-574$

Pike TW, Petrie M, 2005. Offspring sex ratio is related to paternal train elaboration and yolk corticosterone in peafowl. Biol Lett-UK. 1:204-207. 
Poesel A, Foerster K, Kempenaers B, 2001. The dawn song of the blue tit Parus caeruleus and its role in sexual selection. Ethology 107:521-531.

Poesel A, Hangsjorerg PK, Foerster K, Johnsen A, Kembenaers B. 2006. Early birds are sexy: male age, dawn song and extrapair paternity in blue tits Cyanistes (formerly Parus) caeruleus. Anim Behav. 72:531-538.

Poiani A, Wilks C, 2000. Sexually transmitted diseases: a possible cost of promiscuity in birds? Auk 117:1061-1065.

Price T, Kirkpatrick M, Arnold SJ, 1988. Directional selection and the evolution of breeding date in birds. Science. 240:798-9.

Puurtinen M, Ketola T, Kotiaho JS, 2005. Genetic compatibility and sexual selection. Trends Ecol Evol. 20:157-158.

Pyle PH, SNG; Yunick, RP and DeSante, DF, 1987. Identification Guide to North American Passerines. Bolinas, California: Slate Creek Press.

Rathburn MK, Montgomerie R, 2005. Offspring sex ratios correlate with pair-male condition in a cooperatively breeding fairy-wren. Behav Ecol. 16:41-47.

Redmond L, 2005. Breeding habitat selection, nest reuse and nest defense of Eastern Kingbirds in SE Oregon. Portland, Oregon: Portland State University.

Richardson DS, Jury FL, Dawson DA, Salgueiro P, Komdeur J, Burke T, 2000. Fifty Seychelles warbler (Acrocephalus sechellensis) microsatellite loci polymorphic in Sylviidae species and their cross-species amplification in other passerine birds. Mol Ecol. 9:2226-2231.

Rodrigues M. 1996. Song activity in the chiffchaff: Territorial defence or mate 
guarding? Anim Behav. 51:709-716.

Rowe DL, Murphy MT, Fleischer RC, Wolf PG, 2001. High frequency of extra-pair paternity in Eastern Kingbirds. Condor. 103:845-851.

Rytkonen S, 2002. Nest defence in great tits Parus major: support for parental investment theory. Behav Ecol Sociobiol. 52:379-384.

Schmoll T, Dietrich V, Winkel W, Epplen JT, Lubjuhn T, 2003. Long-term fitness consequences of female extra-pair matings in a socially monogamous passerine. Proc R Soc Lond B. 270:259-264.

Sexton K, 2006. Eastern kingbird dawn song characterization and a test of the fertility announcement hypothesis. Portland, Oregon: Portland State University.

Sheldon BC, Andersson S, Griffith SC, Ornborg J, Sendecká J, 1999. Ultraviolet colour variation influences blue tit sex ratios. Nature. 402:874-877.

Sheldon BC, Ellegren $\mathrm{H}, 1999$. Sexual selection resulting from extrapair paternity in collared flycatchers. Anim Behav. 57:285-298.

Sheldon BC, Merilä J, Qvarnström A, Gustafsson L, Ellegren H, 1997. Paternal genetic contribution to offspring condition predicted by size of male secondary sexual character. Proc R Soc Lond B. 264:297-302.

Siderieus, JA. 1993. Nest defense in relation to nesting stage and response of parents to repeated model presentations in the eastern kingbird (Tyrannus tyrannus). Auk. 110:921-923.

Slagsvold T, Dale S, Saetre GP. 1994. Dawn singing in the great tit (Parus major): Mate attraction, mate guarding, or territorial defence? Behaviour. 131:115-138. 
Slate J, Visscher PM, MacGregor S, Stevens D, Tate ML, Pemberton J. 2002. A genome scan for quantitative trait loci in a wild population of red deer (Cervus elaphus). Genetics. 162:1863-1873.

Smith SM, 1988. Extra-pair copulations in black-capped chickadees: The role of the female: Behaviour. 107:15-23.

Smith WJ, 1966. Communications in the genus Tyrannus. Cambridge, MA:

Publication of the Nuttall Ornithological Club No. 6.

Soler JJ, Cuervo JJ, Moller AP, De Lope F, 1998. Nest building is a sexually selected Behaviour. in the barn swallow. Anim Behav. 56:1435-1442.

Soler JJ, Cuervo JJ, Moller AP, De Lope F. 1998. Nest building is a sexually selected Behaviour. in the barn swallow. Anim Behav. 56:1435-1442.

Soler M, Martin-Vivaldi M, Martin JM, Moller AP: 1999. Weight lifting and health status in the black wheatear. Behav Ecol. 10:281-286.

Spottiswoode C, Moller AP. 2004. Extrapair paternity, migration, and breeding synchrony in birds. Behav Ecol. 15:41-57.

Stauss M, Segelbacher G, Tomiuk J, Bachamnn L, 2005. Sex ratio of Parus major and P. Caeruleus broods depends on parental condition and habitat qualit. Oikos $367: 367-373$

Strohbach S, Curio E, Bathen A, Epplen JT, Lubjuhn T, 1998. Extrapair paternity in the great tit (Parus major): A test of the "good genes" hypothesis. Behav Ecol. 9:388-396.

Stutchbury BJ, Morton ES 1995. The effect of breeding synchrony on extra-pair 
mating systems in songbirds. Behaviour. 132:675-690.

Stutchbury BJM, 1998. Female male choice of extra-pair males: Breeding synchrony is important. Behav Ecol Sociobiol. 43:213-215.

Stutchbury BJM, Piper WH, Neudorf DL, Tarof SA, Rhymer JM, Fuller G, Fleischer RC, 1997. Correlates of extra-pair fertilization success in hooded warblers. Behav Ecol Sociobiol. 40:119-126.

Svensson E, Nilsson J-A, 1996. Mate quality affects offspring sex ratio in blue tits. Proc R Soc Lond B. 263:357-361.

Szentirmai I, Komdeur J, Szekely T. 2005. What makes a nest-building male successful? Male behavior and female care in peduline tits. Behav Ecol. 16:994-1000.

Tarof SA, Ratcliffe LM, Boag PT. 2001. Polymorphic microsatellite loci for assigning parentage in least flycatchers (Empidonax minimus). Mol Ecol Notes. 1:146148.

Tarvin KA, Webster MS, Tuttle EM, Pruett-Jones SG, 2005. Genetic similarity of social mates predicts the level of extrapair paternity in splendid fairy-wrens. Animal Behaviour. 70:945-955.

Thusius KJ, Dunn PO, Peterson KA, Whittingham LA, 2001. Extrapair paternity is influenced by breeding synchrony and density in the common yellowthroat. Behav Ecol. 12:633-639.

Thusius KJ, Dunn PO, Peterson KA, Whittingham LA, 2001. Extrapair paternity is influenced by breeding synchrony and density in the common yellowthroat. 
Behav Ecol. 12:633-639.

Tregenza T, Wedell N, 2000. Genetic compatibility, mate choice and patterns of parentage: an invited review. Mol Ecol. 9:1013-1027.

Trivers R, Willard D, 1973. Natural selection of parental ability to vary the sex ratio of offspring. Science. 179:90-92.

Turner WC, Barber CA. 2004. Male song sparrows Melospiza melodia do not announce their female's fertility. J Avian Biol. 35:483-486.

Valera F, Hoi H, Kristin A, 2003. Male shrikes punish unfaithful females. Behav Ecol. $14: 403-408$.

Vallet E, Beme I, Kreutzer M. 1998. Two-note syllables in canary songs elicit high levels of sexual display. Anim Behav. 55:291-297.

Velando A, Graves J, Ortega-Ruano JE, 2002. Sex ratio in relation to timing of breeding, and laying sequence in a dimorphic seabird. Ibis. 144:9-16.

Verboven N, Visser ME, 1998. Seasonal variation in local recruitment of great tits: the importance of being early. Oikos. 81:511-524.

Visser ME, Verboven N, 1999. Long-term fitness effects of fledging date in great tits. Oikos 85:445-450.

Watson CJW, Beheler AA, Rhodes OE. 2002. Development of hypervariable microsatellite loci for use in eastern phoebes (Sayornis phoebe) and related Tyrannids. Mol Ecol Notes. 2:117-118.

Weatherhead PJ, Forbes MRL, 1994. Natal Philopatry in Passerine Birds - Genetic or Ecological Influences. Behav Ecol. 5:426-433. 
Webster MS, Chuang-Dobbs HC, Holmes RT. 2001. Microsatellite identification of extrapair sires in a socially monogamous warbler. Behav Ecol. 12:439-446.

Webster MS, Pruett-Jones S, Westneat DF, Arnold SJ. 1995. Measuring the effects of pairing success, extra-pair copulations and mate quality on the opportunity for sexual selections. Evolution. 49:1147-1157.

Weimerskirch H, 1998. How can a pelagic seabird provision its chick when relying on a distant food resource? Cyclic attendance at the colony, foraging decision and body condition in sooty shearwaters. J Anim Ecol. 67:99-109.

Westneat DF, Sherman PW. 1997. Density and extra-pair fertilizations in birds: A comparative analysis. Behav Ecol Sociobiol. 41:205-215.

Westneat DF, Sherman PW, Morton ML, 1990. The ecology and evolution of extrapair copulations in birds. Curr Ornithol. 7:331-369.

Westneat DF, Stewart IRK, 2003. Extra-pair paternity in birds: Causes, correlates, and conflict. Futuyma, DJ. Annu Rev Ecol Evol S. 365-396.

Wetton JH, Parkin DT, 1991. An Association between Fertility and Cuckoldry in the House Sparrow Passer-Domesticus. Proc R Soc Lond B. 245:227-234.

Whittingham LA, Dunn PO, 2000. Offspring sex ratios in tree swallows: Females in better condition produce more sons. Mol Ecol. 9:1123-1129.

Whittingham LA, Dunn PO. 2005. Effects of extra-pair and within-pair reproductive success on the opportunity for selection in birds. Behav Ecol. 16:138-144.

Whittingham LA, Dunn PO, Nooker JK, 2005. Maternal influences on brood sex ratios: an experimental study in tree swallows. Proc R Soc Lond B. 272:1775- 
1780.

Whittingham LA, Valkenaar SM, Poirier NE, Dunn PO, 2002. Maternal condition and nestling sex ratio in House Wrens. Auk. 119:125-131.

Wink M, Dyrcz A, 1999. Mating systems in birds: A review of molecular studies. Acta Ornithologica. 34:91-109.

Woodard JD, Murphy MT. 1999. Sex roles, parental experience and reproductive success of eastern kingbirds, Tyrannus tyrannus. Anim Behav. 57:105-115.

Wright J, Cuthill IC, 1990. Manipulation of sex differences in parental care: the effect of brood size. Animal Behaviour. 40.

Xia X, 1992. Uncertainty of paternity can select against paternal care. Am Nat. 139:1126-1129.

Yezerinac SM, Weatherhead PJ, 1997. Extra-pair mating, male plumage coloration and sexual selection in yellow warblers (Dendroica petechia). Proc R Soc Lond B. $264: 527-532$.

Yezerinac SM, Weatherhead PJ, Boag PT. 1995. Extra-pair paternity and the opportunity for sexual selection in a socially monogamous bird (Dendroica petechia). Behav Ecol Sociobiol. 37:179-188.

Zenone PG, Sims E, Erickson CJ. 1979. Male Ring Dove behavior and the defence of genetic paternity. Am Nat. 114:615-626.

Zijlstra M, Daan S, Bruinenberg-Rinsma J, 1992. Seasonal variation in the sex ratio of marsh harrier Circus aeruginosus broods. Funct Ecol. 6:553-559. 
Zuk M, Popma SL, Johnsen TS, 1995. Male courtship displays, ornaments and female mate choice in captive red jungle fowl. Behaviour. 132:821-836. 